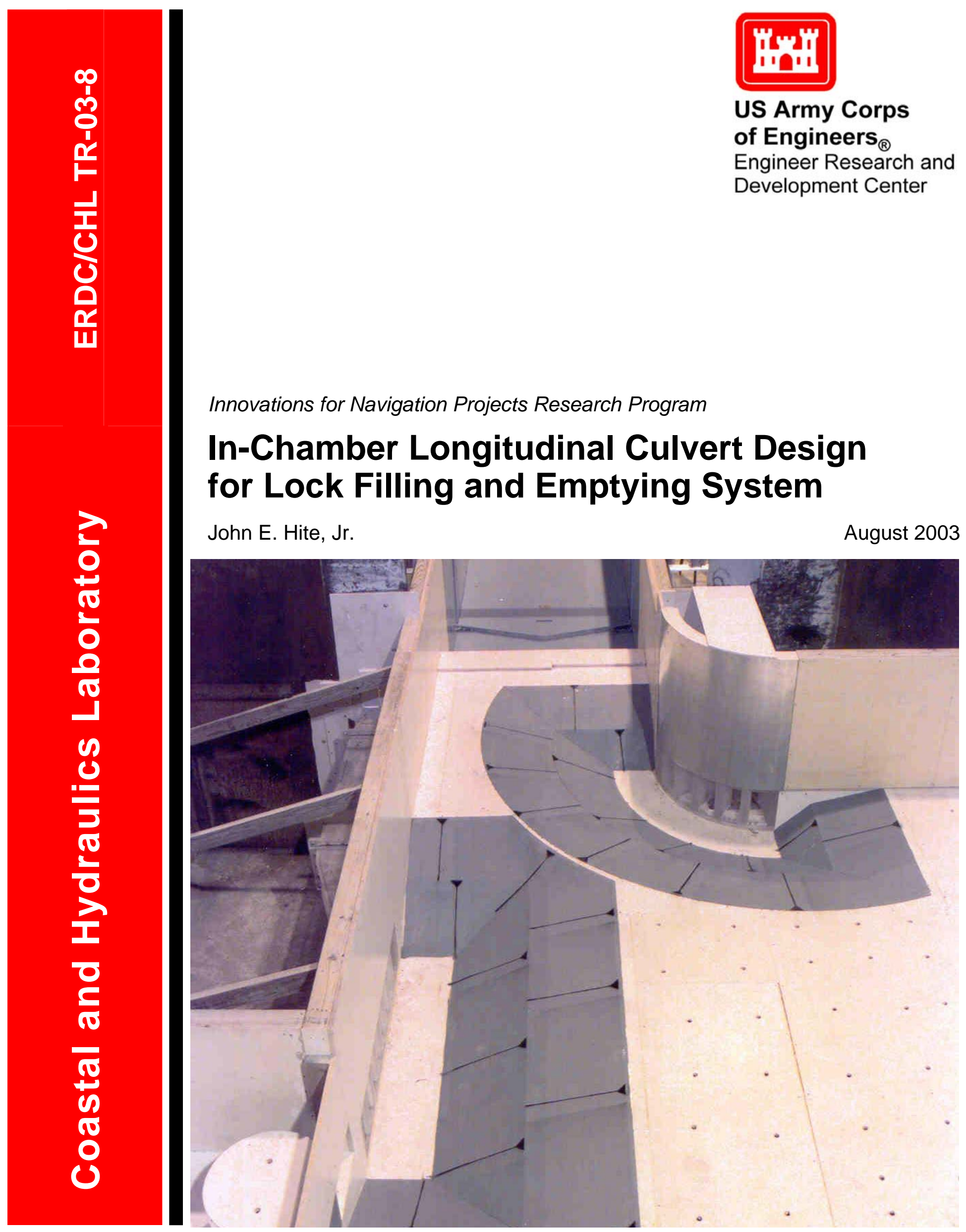

Approved for public release; distribution is unlimited. 


\section{In-Chamber Longitudinal Culvert Design for Lock Filling and Emptying System}

John E. Hite, Jr.

Coastal and Hydraulics Laboratory

U.S. Army Engineer Research and Development Center

3909 Halls Ferry Road

Vicksburg, MS 39180-6199

Final report

Approved for public release; distribution is unlimited

Prepared for U.S. Army Corps of Engineers

Washington, DC 20314-1000

Under INP Work Unit 33140 


\begin{abstract}
The U.S. Army Corps of Engineers is planning navigation improvements for many projects to meet predicted increases in tow traffic. Some of these improvements include the addition or replacement of the navigation lock. Innovative design and construction techniques are being investigated for reducing construction costs, as well as operation and maintenance costs. The Corps identified that a savings in lock construction could be achieved if the conventional concrete gravity lock walls with culverts inside them could be replaced with thin walls and longitudinal culverts located inside the chamber. This culvert design was designated the In-chamber Longitudinal Culvert System (ILCS).

This report provides the results of research conducted under Work Unit 33140, "In-Chamber Longitudinal Culvert Design for Lock Filling and Emptying Systems,” of the Innovations for Navigation Projects Research Program. Design guidance for the ILCS is provided for low- to medium-lift locks. The guidance includes culvert location; port size, location, and spacing; port extensions; roof overhang; and wall baffles. Guidance is also provided for modified ILCS designs and single-culvert designs. Lock chamber performance guidance, based on acceptable filling and emptying operations, is also included. The results show that the ILCS is a feasible design based on the hydraulic performance determined from the investigation.
\end{abstract}

DISCLAIMER: The contents of this report are not to be used for advertising, publication, or promotional purposes. Citation of trade names does not constitute an official endorsement or approval of the use of such commercial products. All product names and trademarks cited are the property of their respective owners. The findings of this report are not to be construed as an official Department of the Army position unless so designated by other authorized documents. 


\section{Contents}

Conversion Factors, Non-SI to SI Units of Measurement.................................. vii

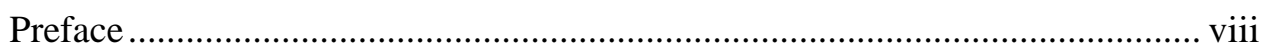

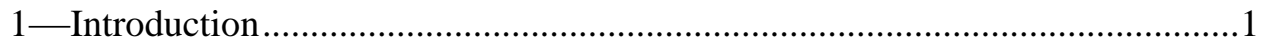

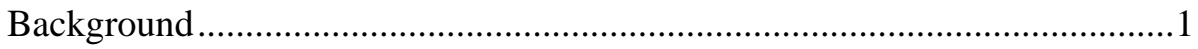

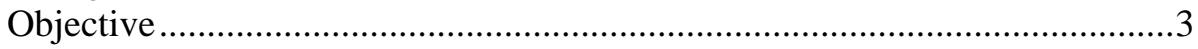

2-Previous Investigations ..............................................................................4

Initial ILCS Design for 1,200-ft-Long........................................................

Lock Addition at McAlpine Project..............................................................

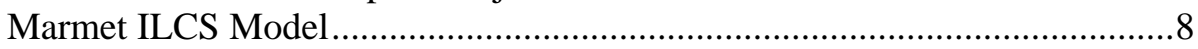

Second McAlpine ILCS Model Study ....................................................11

3-Lock Filling and Emptying Design Considerations .....................................14

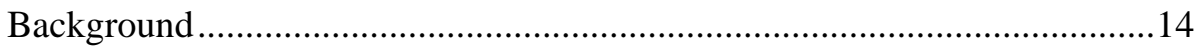

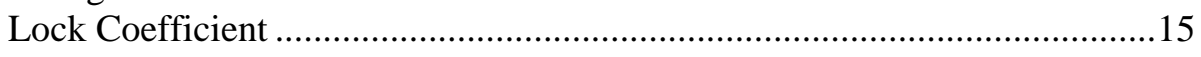

4-Laboratory Model .................................................................................19

Description of Research Model .....................................................................19

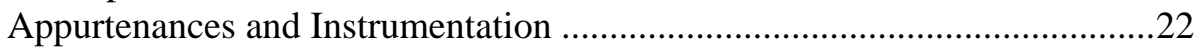

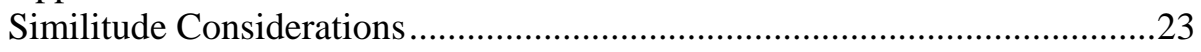

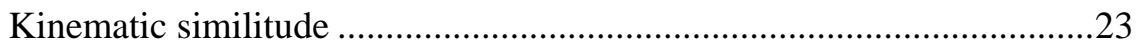

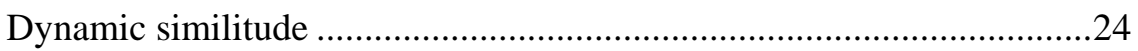

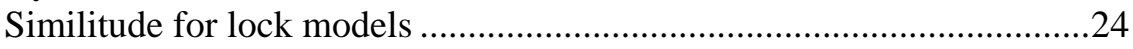

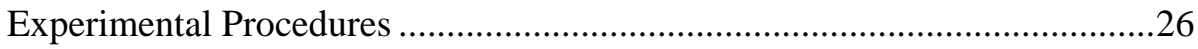

5-Laboratory Model Experiments and Results..............................................27

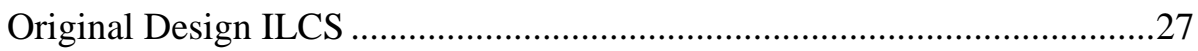

Original design filling experiments ...................................................22

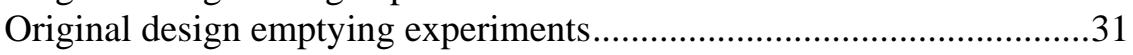

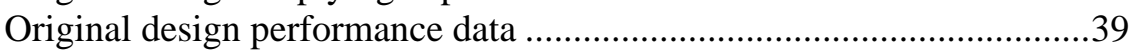

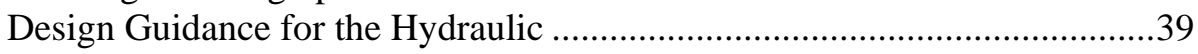

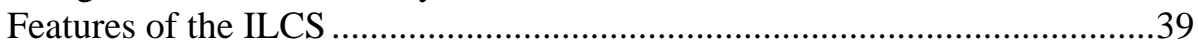

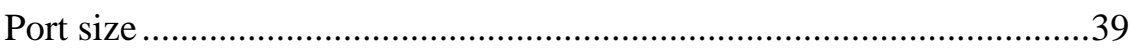

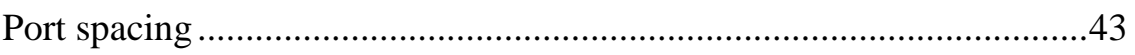

Number and location of ports ...........................................................43

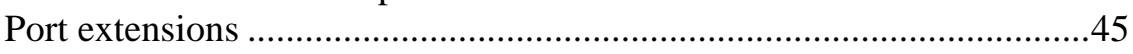

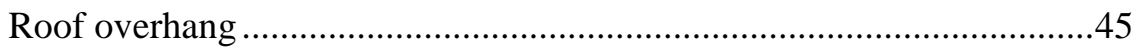




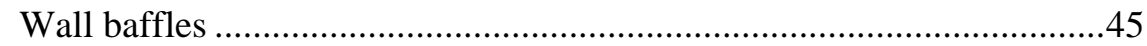

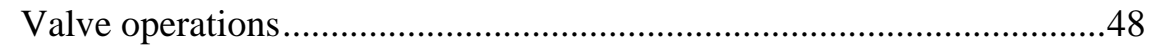

Modified ILCS Operation and Design ........................................................49

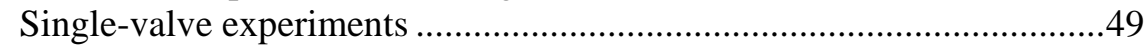

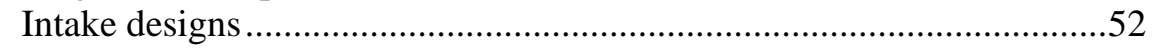

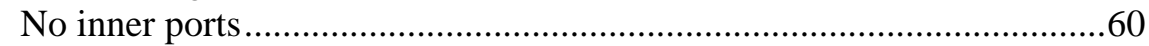

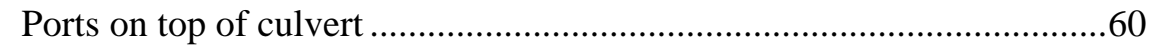

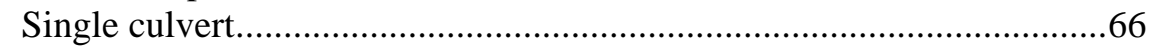

Summary of experimental results with modified ILCS ...........................73

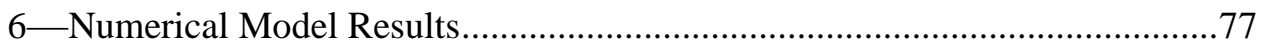

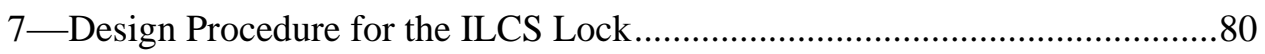

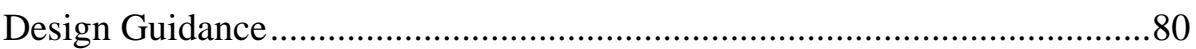

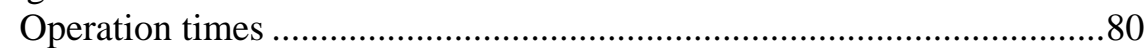

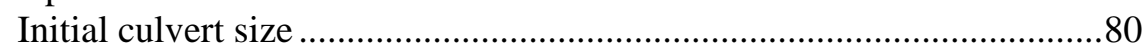

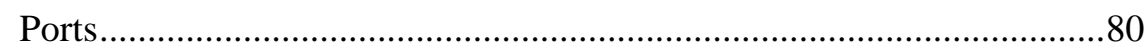

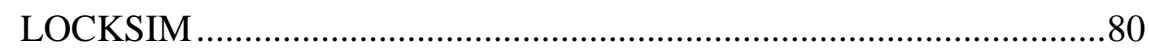

Example ILCS Lock Design ................................................................... 81

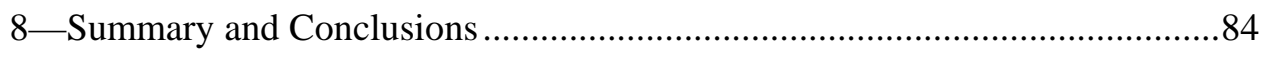

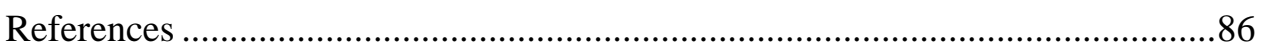

SF 298

\section{List of Figures}

Figure 1. Comparison of lock culvert locations ...........................................2

Figure 2. Initial ILCS lock design from Stockstill (1998) ...............................5

Figure 3. Comparison of longitudinal hawser forces measured during filling in the initial McAlpine ILCS model with higher than design lift ..................................................................................

Figure 4. Initial ILCS design proposed for Marmet Lock from Hite (1999)... 9

Figure 5. Comparison of hawser forces measured during filling with the Marmet ILCS model for a 24-ft lift .................................................10

Figure 6. Initial ILCS design proposed for McAlpine Lock from Hite

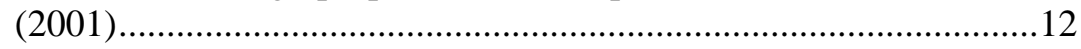

Figure 7. Comparison of hawser forces measured during filling with a 37-ft lift from Hite (2001).................................................................13

Figure 8. Comparison of permissible filling times determined from previous model studies of side port systems and ILCS model studies 
Figure 9. Schematic of laboratory model used in ILCS research....................20

Figure 10. View of ILCS modeling looking downstream ...............................21

Figure 11. Hawser-pull (force links) measuring device ..................................23

Figure 12. Lift and submergence definitions for the ILCS investigation...........28

Figure 13. Valve opening curves for the ILCS model .....................................29

Figure 14. Results from typical experiment with original design ILCS.............30

Figure 15. Hawser forces during filling with Original Design ILCS model, lifts between 20 and $40 \mathrm{ft}$ and $19-\mathrm{ft}$ submergence ...........................32

Figure 16. Hawser forces during filling with Type 2 intake design in ILCS model, lifts of 10 and $15 \mathrm{ft}$ and $19-\mathrm{ft}$ submergence ..........................33

Figure 17. Hawser forces during filling with Original Design ILCS model, lifts between 10 and $30 \mathrm{ft}$ and 24-ft submergence

Figure 18. Hawser forces during filling with Original Design ILCS model, lifts between 10 and $30 \mathrm{ft}$ and 29-ft submergence .. 35

Figure 19. Hawser forces during emptying with ILCS model, lifts between 10 and $40 \mathrm{ft}$ and 19-ft submergence.

Figure 20. Hawser forces during emptying with ILCS model, lifts between 10 and $30 \mathrm{ft}$ and 24-ft submergence.

Figure 21. Hawser forces during emptying with ILCS model, lifts between 10 and $30 \mathrm{ft}$ and 29-ft submergence.

Figure 22. Performance guidance during filling from the ILCS model .............40

Figure 23. Performance guidance during emptying from ILCS model..............41

Figure 24. Comparison of permissible filling times determined from previous model studies and the ILCS model study..........................42

Figure 25. Port location guidance for ILCS .................................................44

Figure 26. Flow patterns with and without port extensions in the upper

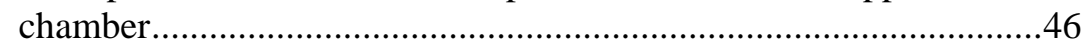

Figure 27. Cross-sectional view of ILCS ports ............................................47

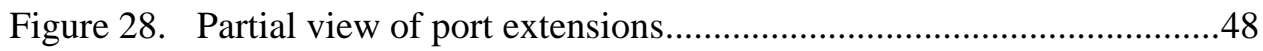

Figure 29. Left 10-min single valve operation with 37-lift..............................50

Figure 30. Hawser forces determined with left single valve operation and 37-ft lift and 19-ft submergence .....................................................51

Figure 31. Views of intake located at upper miter sill ......................................53

Figure 32. Plan view of intakes in upper approach walls.................................54 
Figure 33. Filling characteristics with sill mounted intakes.

Figure 34. Filling characteristics with normal intakes .....................................56

Figure 35. Filling characteristics with Type 2 intakes ...................................57

Figure 36. Valve curves for the reverse tainter and butterfly valves (ILCS)

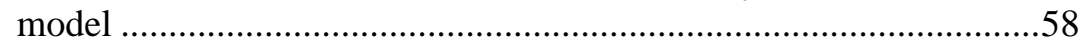

Figure 37. Hawser forces determined with different intake locations................59

Figure 38. Filling characteristics with no inside ports and 5-min normal valve.

Figure 39. Hawser forces determined with no inside ports ..............................62

Figure 40. Hawser forces determined during emptying with no inside ports ....63

Figure 41. Culvert design with ports on top..................................................64

Figure 42. Filling characteristics with ports on top of culvert and 5-min

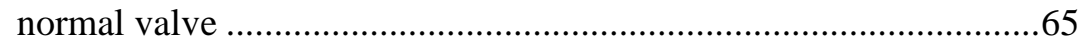

Figure 43. Hawser forces determined with ports on top of culvert ...................67

Figure 44. Comparison of hawser forces with different port configurations .....68

Figure 45. Type 1 single culvert design .......................................................69

Figure 46. Filling characteristics with Type 1 single culvert and 12-min

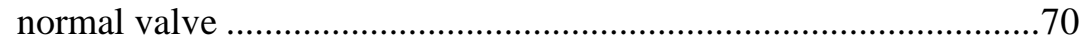

Figure 47. Comparison of hawser forces with different single culvert designs and 35-ft lift .........................................................................71

Figure 48. Type 2 single culvert design .........................................................72

Figure 49. Type 4 single culvert design .......................................................... 74

Figure 50. Hawser forces determined with Type 4 single culvert and 20-ft

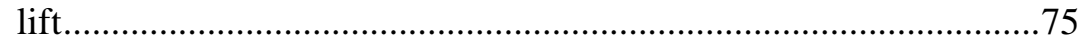

Figure 51. Schematic representation of ILCS model for lock filling .................78

Figure 52. Comparison of filling characteristics for ILCS model and

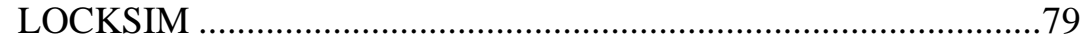

Figure 53. Example ILCS lock design for 15-ft lift with 9-min filling time......83 


\section{Conversion Factors, Non-SI to SI Units of Measurement}

Non-SI units of measurement used in this report can be converted to SI units as follows:

\begin{tabular}{||l|l|l||}
\hline \hline Multiply & By & To Obtain \\
\hline \hline cubic feet & 0.02831685 & cubic meters \\
\hline feet & 0.3048 & meters \\
\hline square feet & 0.09290304 & square meters \\
\hline tons (force) & 8.896444 & kilonewtons \\
\hline
\end{tabular}




\section{Preface}

The investigation reported herein was authorized by the Headquarters, U.S. Army Corps of Engineers (HQUSACE), and was performed during the period September 1998 to September 2002 as part of the Innovations for Navigation Projects (INP) Research Program. The study was conduced under Work Unit (WU) 33140, "In-Chamber Longitudinal Culvert Design for Lock Filling and Emptying System.”

HQUSACE personnel who provided direction for this research included Dr. Tony C. Liu, INP Coordinator, Directorate of Research and Development; Mr. Barry Holliday, Research Area Manager; and Program Monitors Messrs. Don Dressler, Joe Hartman, Bruce Riley, Dave Wingerd, Al Branch, Hari Singh, Dan Casapulla, Brad James, and Mike Kidby and Ms. Anjana Chudgar. Mr. William H. McAnally of the U.S. Army Engineer Research and Development Center (ERDC), Coastal and Hydraulics Laboratory (CHL), was the Lead Technical Director for Navigation Systems. The INP Program Manager was Dr. Stanley C. Woodson of the ERDC Geotechnical and Structures Laboratory.

This research was conducted by personnel of the ERDC/CHL, under the general supervision of Mr. Don Wilson, Chief, Navigation Branch; Mr. Thomas J. Pokrefke, Acting Deputy Director; and Mr. Thomas W. Richardson, Director. The experimental program was led by Mr. J. E. Myrick under the supervision of Dr. John E. Hite, Jr., Leader, Locks Group, CHL. Model construction was completed by Messrs. Mitchell A. Simmons and Joseph A. Lyons, under the supervision of Mr. James Schultz, Chief of the Model Shop, Directorate of Public Works, ERDC. Data acquisition and remote-control equipment were installed and maintained by Messrs. Wallace Guy and Tim Nisley, Instrumentation Systems Development Division (ISDD), Information Technology Laboratory (ITL). Data acquisition software was developed by Dr. Barry W. McCleave, ISDD, ITL.

This report was written by Dr. Hite, CHL. Mr. Mario J. Sanchez, CHL, performed peer review of the report. Ms. Kathy Miller, Navigation Branch, CHL, assisted in preparation of the draft report.

Appreciation is expressed to the members of the Field Advisory Committee, who made valuable suggestions and contributions during the course of this investigation: Messrs. Billy Arthur and Tom Quigley, U.S. Army Engineer (USAE) District, St. Louis; Mr. Byron McClellan, USAE District, Louisville; Messrs. John Clarkson, Coy Miller, and Sean Smith, USAE District, Huntington; 
Mr. Mike Fallon, USAE Division, Mississippi Valley; Mr. Harry Simpson and Mr. Dan Steiner (retired), USAE Division, Great Lakes and Ohio River; and Messrs. Walt Leput and Ray Povirk, USAE District, Pittsburgh.

COL James R. Rowan, EN, was Commander and Executive Director of ERDC. Dr. James R. Houston was Director. 


\section{Introduction}

\section{Background}

Many U.S. Army Corps of Engineers lock projects on the Upper Mississippi River and Ohio River systems are planning additional locks, enlargements to existing locks, or repairs to existing locks. These projects are necessary to meet the predicted increases in tow traffic. Innovative designs are being considered on many of the project components to save construction costs as well as operation and maintenance $(\mathrm{O} \& \mathrm{M})$ costs.

A Regional Navigation Design Team composed of Corps personnel identified that a large savings in lock wall construction costs could be realized if the lock filling and emptying culverts were located inside the lock chamber rather than within the lock walls (Figure 1) and if new and innovative construction techniques were employed.

The filling and emptying system is the primary component of a lock and must be hydraulically efficient and safe. Detailed design guidance is not available for longitudinal culverts placed inside the chamber. The guidance presented herein is needed to help develop these innovative designs for navigation project improvements. This design (longitudinal culverts placed in the chamber) was designated the In-chamber Longitudinal Culvert Filling and Emptying System and is referred to as "the ILCS" throughout this report.

Results from a physical model study performed for the proposed 1,200- $\mathrm{ft}^{1}$ lock addition at the McAlpine Project on the Ohio River (Stockstill 1998) showed that the ILCS design was feasible. However, additional research was needed to further develop the design guidance over a wider range of hydraulic conditions.

Longitudinal culverts located inside the lock chamber are not a new concept. The Davis and Sabin Locks, which are part of the Soo Lock System at the St. Mary's Falls Canal, were constructed in the early 1900s and contain culverts inside the lock chamber. The locks were originally constructed with six culverts underneath the lock floor, but two of the six culverts were blocked off due to “excessive lock filling and emptying currents.” During conversations with field personnel at Davis Lock, it was stated that the two outside culverts were blocked off probably because of turbulence within the lock chamber. Also, field

\footnotetext{
${ }^{1}$ A table of factors for converting non-SI units of measurement to SI units is presented on page vii.
} 


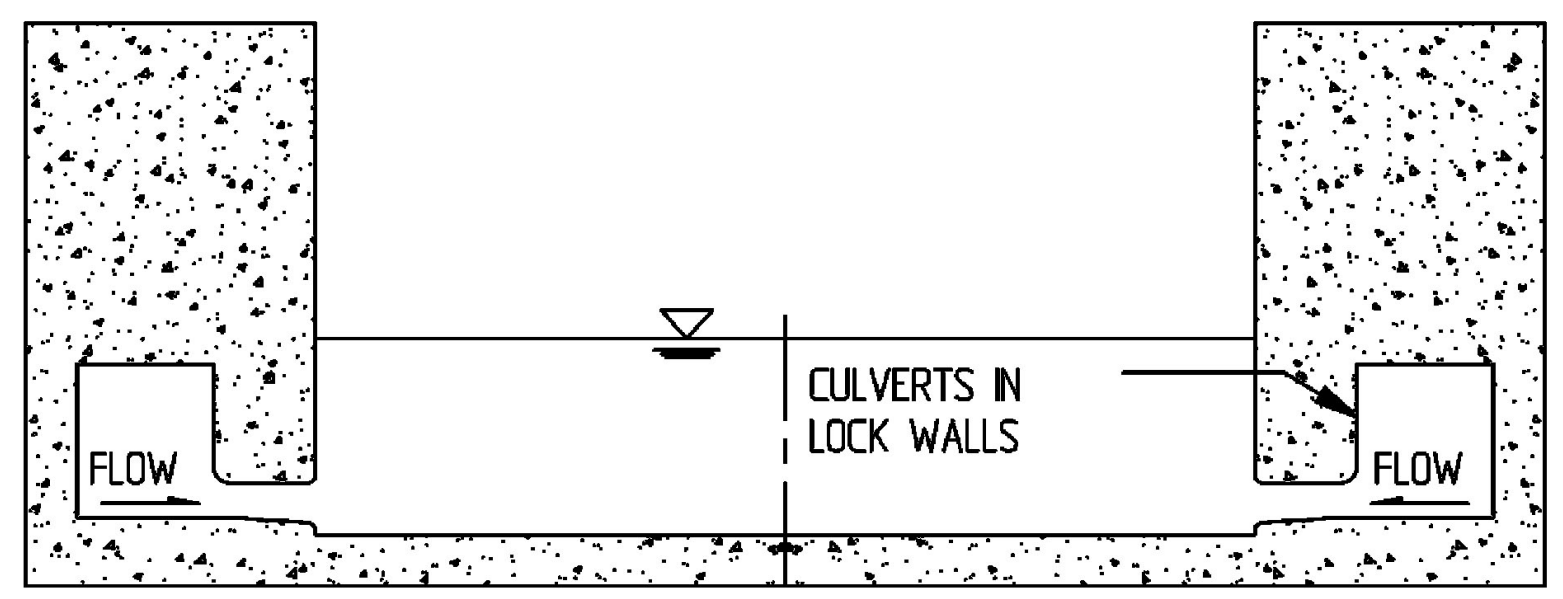

SIDE PORT SYSTEM

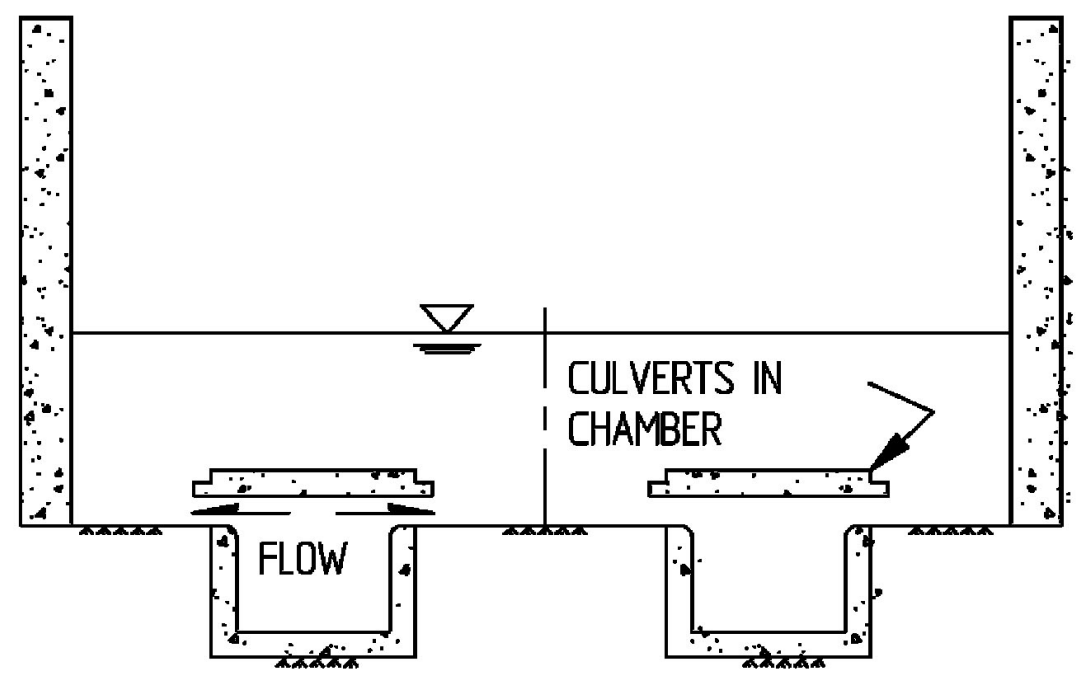

\section{LCS SYSTEM}

Figure 1. Comparison of lock culvert locations 
personnel indicated that, with a 21-ft lift and 3-min valve operation, Davis Lock filled in $13 \mathrm{~min}$ and emptied in $11 \mathrm{~min}$. The intakes for these two locks also contain horizontally mounted butterfly valves, which allowed water into culverts located under the upper miter sill. The discharge outlets are also located in the lower approach at Davis Lock.

\section{Objective}

The objective of this work unit was to provide design information necessary to develop an ILCS for low- and medium-lift locks (10 to $40 \mathrm{ft}$ ). A physical lock model was used to perform a thorough evaluation of the ILCS to cover the range of design conditions typical for Corps of Engineers low- to medium-lift locks. The evaluation provided lock filling times, valve operation times, and performance guidance for the ILCS. This design guidance will be beneficial for Corps Divisions/Districts and for private industries responsible for developing the filling and emptying systems for the innovative locks. Specific guidance needed to help design the ILCS includes culvert location, port spacing, port size, port shape, and chamber baffles.

Through-the-sill filling and emptying systems have the potential for significant savings. The overall savings estimated from the use of innovative construction concepts for the Corps' top 11 high-priority navigation projects (lock replacements) is between $\$ 1.4$ and $\$ 1.8$ billion. 


\section{Previous Investigations}

In 1994, several Corps Districts began to investigate the feasibility of innovative designs for lock intakes and lock filling and emptying systems. Physical model experiments were considered necessary to determine the hydraulic performance of the proposed designs and to make modifications if needed or applicable to achieve an acceptable design. The initial modeling program involved four sites where new locks are proposed for construction: McAlpine Lock and Dam (L\&D), Louisville District; Marmet L\&D, Huntington District; Monongahela River No. 4 L\&D, Pittsburgh District; and a representative lock from the Upper Mississippi Lock Replacement Study, St. Louis District.

Memorandum reports were published for the through-the-sill intake studies for McAlpine, Marmet, and Monongahela River No. 4, and a lock study (Stockstill 1998) was published for the McAlpine Lock. These studies showed that acceptable hydraulic conditions could be achieved in the lock approaches for the through-the-sill intakes and that the longitudinal culverts could produce acceptable chamber performance.

\section{Initial ILCS Design for 1,200-ft-Long Lock Addition at McAlpine Project}

The navigation improvements planned for the McAlpine Project provided a desirable site to investigate this ILCS design. The filling and emptying system originally proposed also included a through-the-sill intake and discharge outlet with the ILCS.

A 1:25-scale laboratory model was used for the study. The model reproduced portions of the upper and lower approaches, the entire filling and emptying system (including portions of the upper and lower guide and guard walls), intakes, valves, culverts, lock chamber, and outlets. Details of the initial ILCS design for the McAlpine Project are shown in Figure 2.

Stockstill (1998) provides details regarding the results of this investigation. Numerous culvert designs with various port arrangements were evaluated. Evaluation of the lock system was based on performance data obtained during typical filling and emptying operations. Performance was based primarily on hawser forces on tows in lockage, movement of unmoored (free) tows in the lock 


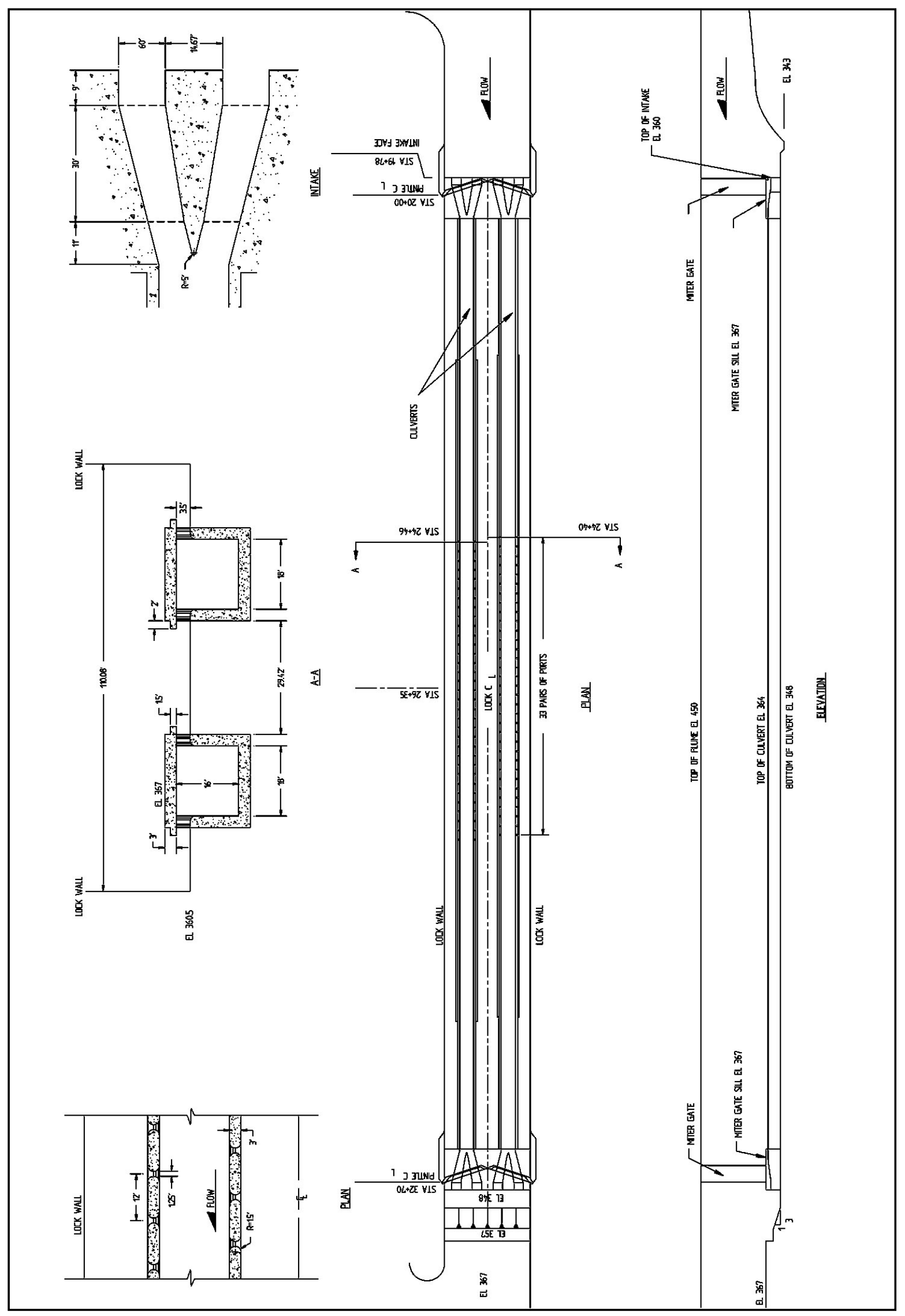

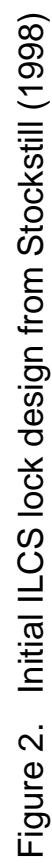


chamber, the roughness of the water surface, pressures, and lock filling and emptying times. The design recommended from the study (Type 17 design) consisted of 16 pairs of ports in each culvert in both halves of the lock chamber. The upstream and downstream ports were centered in the vicinity of the lock third points. Wall baffles were placed on the lock walls adjacent to the ported sections of the manifolds, and port extensions were installed on the upstream ports.

Acceptable and safe performance of a Corps filling and emptying system is considered to be no hawser forces higher than 5 tons, with acceptable valve operations and filling and emptying times for the design lift condition. Stockstill's study showed that a 5-min filling valve resulted in maximum hawser forces of 4.5 tons and a lock filling time of about 10.7 min with a 37-ft lift. Flow conditions in the lock chamber with the recommended design during filling were acceptable, and an unmoored tow rose almost vertically. Unmoored tows during lock filling and emptying should not occur in locks, but this performance provided a good indication of how uniform the flow distribution was in the lock chamber during a filling operation.

A series of experiments not reported in Stockstill (1998) were performed to determine the performance of the recommended design with a $10-\mathrm{ft}$ higher lift than the design lift of $37 \mathrm{ft}$. Hawser force measurements were obtained with a 47-ft lift for filling valve operations of 4 and $10 \mathrm{~min}$. The hawser forces obtained with the Type 17 design and 47-ft lift are shown in Figure 3.

The technique used to determine the hawser forces in model studies will be discussed in a subsequent section. The results with the higher lift indicated that the Type 17 design would need to be modified significantly to achieve the same filling and emptying performance as determined with the 37-ft lift. Corps design guidance given in Engineer Manual (EM) 1110-2-1604 (Headquarters, Department of the Army (HQDA) 1995a) suggests that the side-port filling and emptying system design is best suited for lifts below $30 \mathrm{ft}$, and these results suggest this may also be the case for the ILCS design. This laboratory investigation of the initial McAlpine ILCS lock demonstrated that filling and emptying culverts located on the lock floor between the lock walls could produce acceptable hydraulic conditions in the lock chamber during lock operations.

The following general conclusions drawn from this study served as the basis for the initial design guidance for the ILCS:

a. The port-to-culvert area ratio should be about 0.97 .

$b$. The port spacing in each manifold should be staggered.

c. Two groups of ports should be centered about the one-third points of the lock length.

d. Port extensions on the upstream group improved the longitudinal distribution of flow along the length of the chamber more uniformly. 


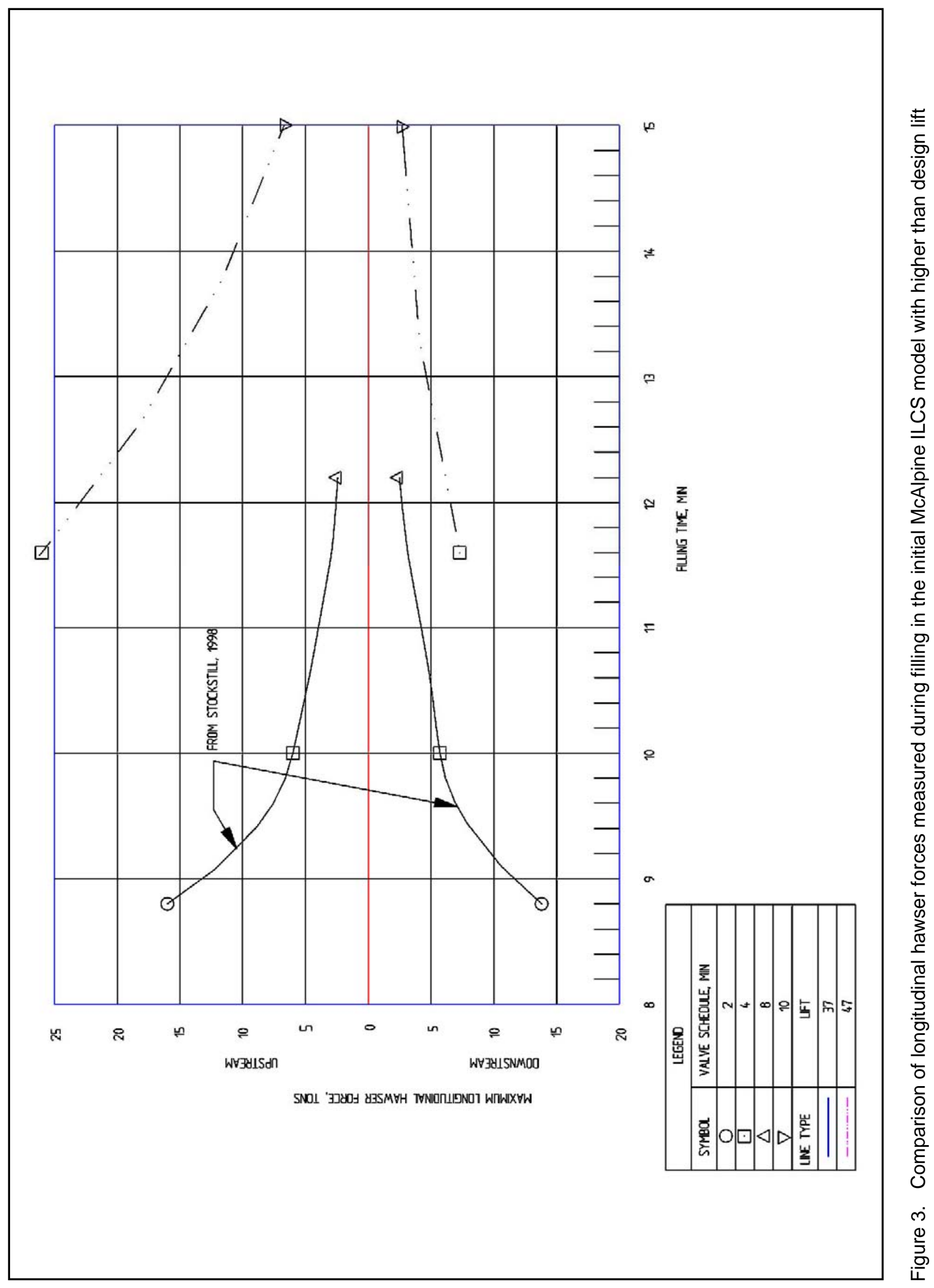


e. Port extensions also train the jets issuing from these ports in a direction normal to the longitudinal culvert.

f. Wall baffles are beneficial because they diffuse the port jets at the lock chamber floor.

\section{Marmet ILCS Model}

A second ILCS model investigation was performed for a new lock proposed for construction at the Marmet Navigation Project in the Corps' Huntington District. Improvements to the project to enhance navigation include construction of an additional lock ( $870 \mathrm{ft}$ from pintle to pintle and $110.08 \mathrm{ft}$ wide) that will be located on the east side of the existing locks. The design lift was $24.0 \mathrm{ft}$, which occurs with the normal upper pool elevation of 590 and a normal lower pool elevation of 566. The new lock design featured a through-the-sill intake, a longitudinal in-chamber filling and emptying system, and a conventional sidewall discharge outlet.

The purpose of the model study was to evaluate and make modifications to the filling and emptying system if necessary to provide a design acceptable to the Huntington District and the towing industry. Since the length of the Marmet ILCS Lock was less than the McAlpine ILCS design, model experiments were necessary to check the adequacy of this design with a shorter length and to determine the operational characteristics. The results from this model investigation are provided in Hite (1999).

A 1:25-scale laboratory model was also used for this investigation. The filling and emptying system for the Marmet replacement lock is shown in Figure 4. Model experiments showed the chamber performance was acceptable for the 4-min valve operation (for which the system was designed) and a 24-ft lift. Minor modifications to the baffling arrangement and the port extensions inside the lock chamber were made in an attempt to reduce longitudinal hawsers during filling operations with the 2-min valve operation. No significant reductions were observed, and since the performance was satisfactory with the 4-min valve, the original design filling and emptying was considered acceptable.

The Huntington District requested that experiments be performed with the floor of the lock chamber raised by $3.27 \mathrm{ft}$ to reduce construction costs. The ports were moved to the top of the culvert to accommodate this modification. This design was designated the Type 5 chamber design, and hawser forces measured with this design were similar to those measured with the Type 1 design. A comparison of the hawser forces measured with the Types 1 and 5 designs is shown in Figure 5. The performance of the Type 5 design chamber was considered acceptable with 4-min normal valve operations and 24-ft lift. 


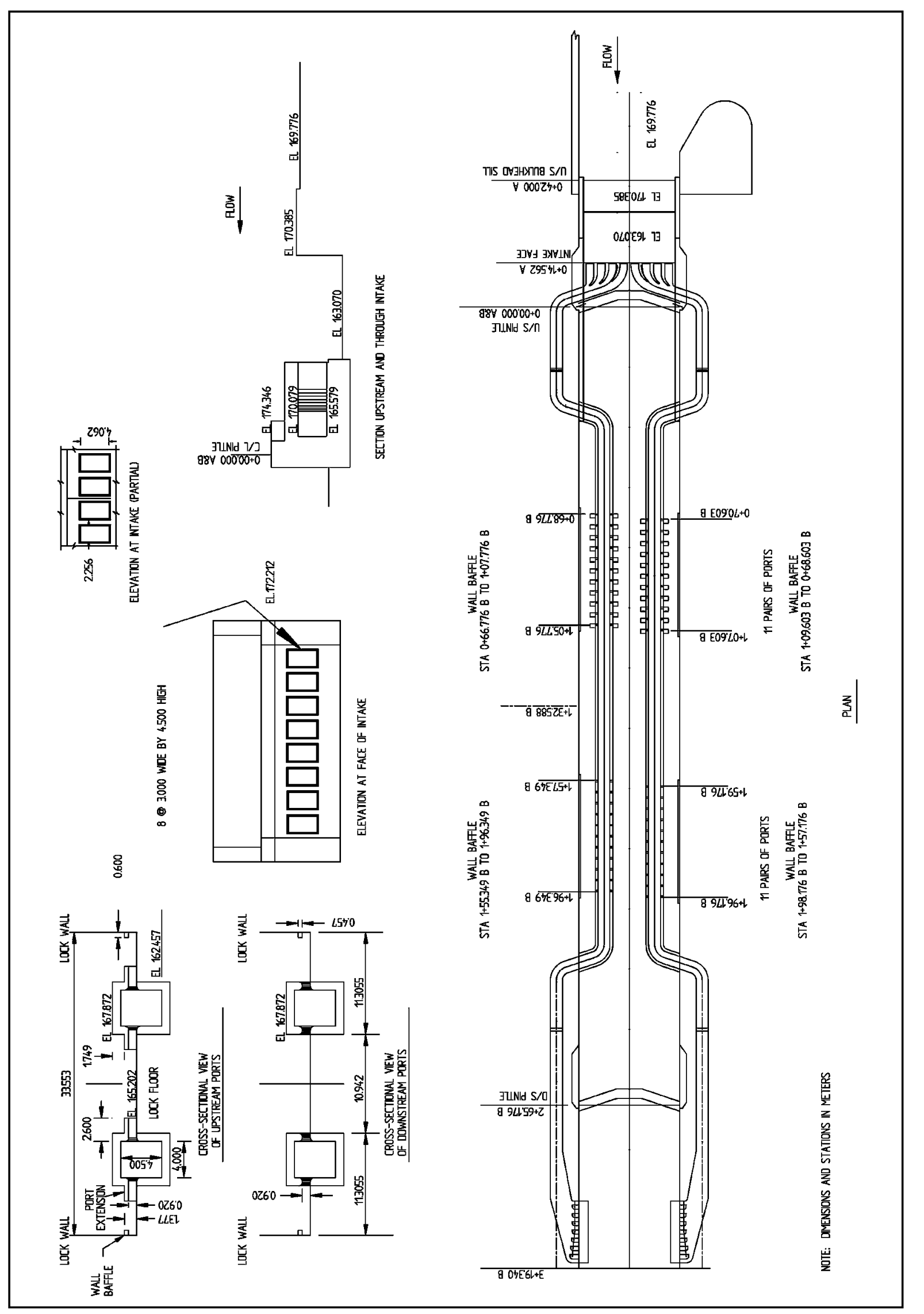

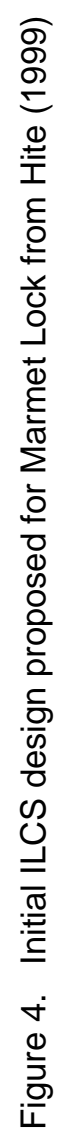




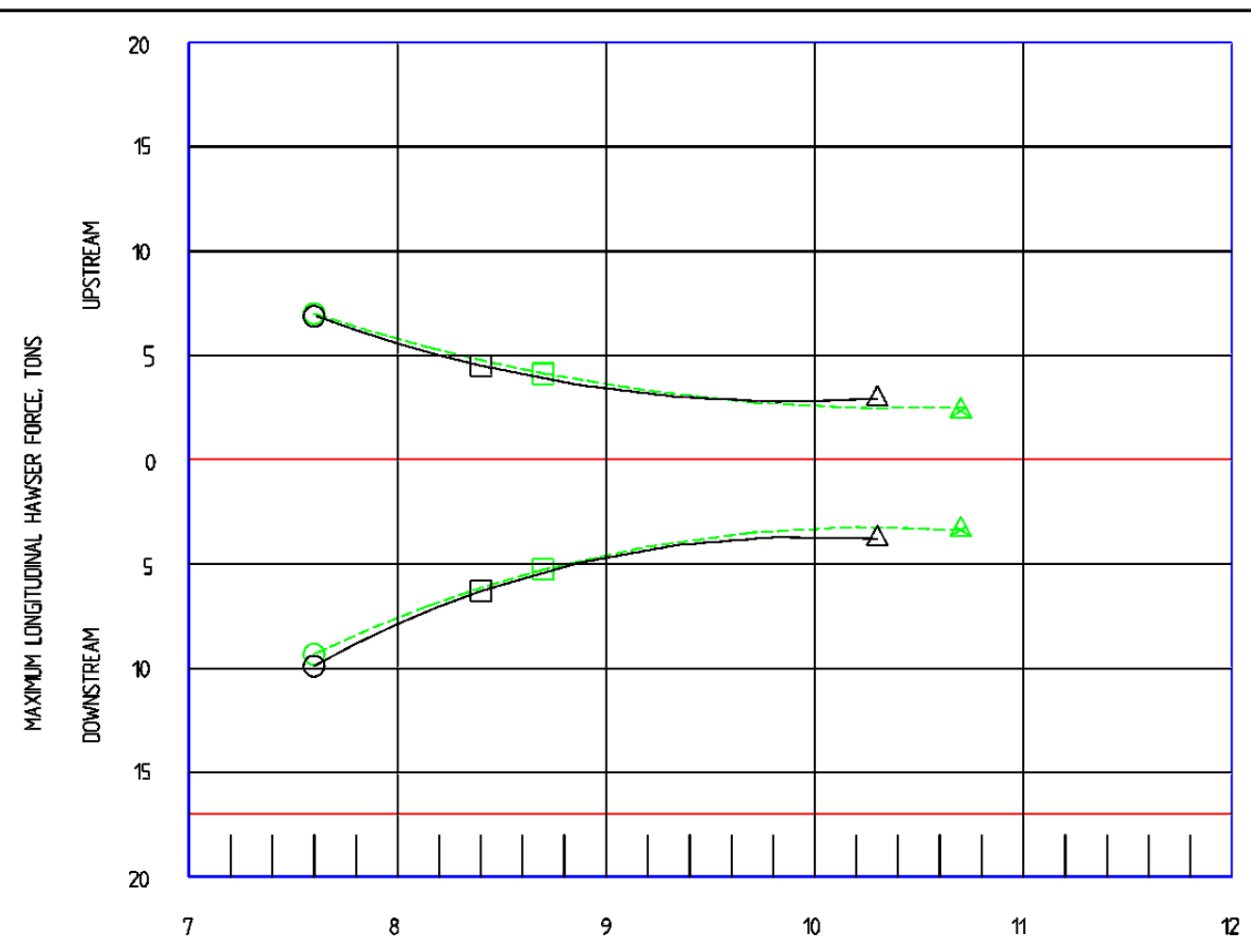

FILLNG TIME, MN

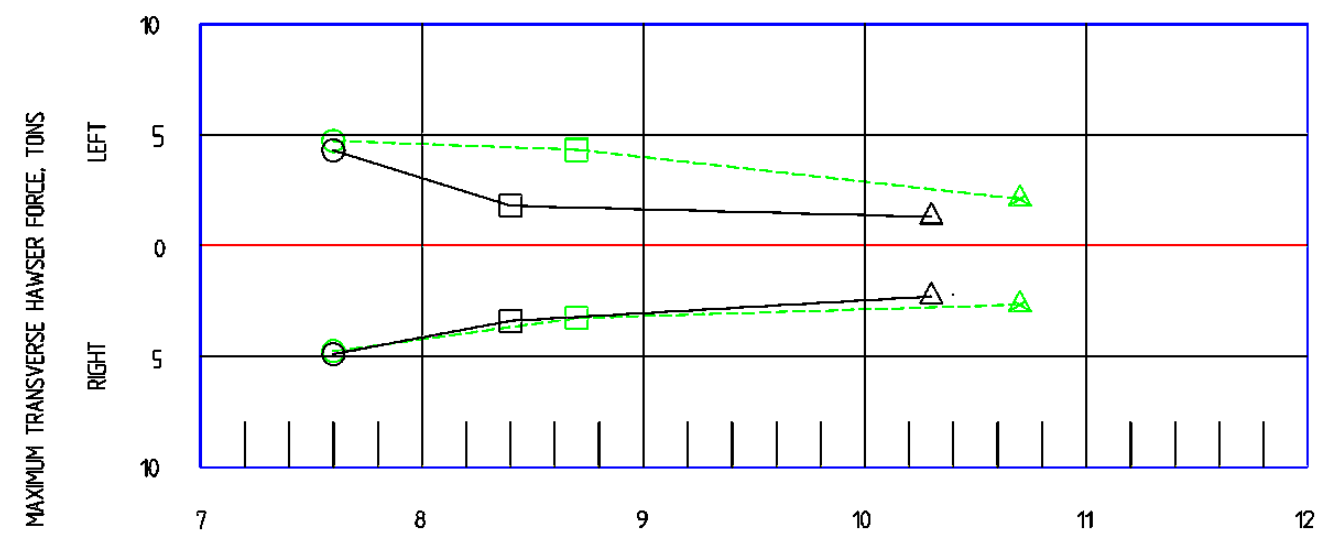

\begin{tabular}{|c|c|}
\hline \multicolumn{2}{|c|}{ LEGEND } \\
\hline SYMBOL & VALVE SCHEDULE, MN \\
\hline$O$ & 2 \\
\hline$\square$ & 4 \\
\hline$\triangle$ & 8 \\
\hline LINE TYPE & DESIGN TYPE \\
\hline & 1 \\
\hline------ & 5 \\
\hline
\end{tabular}

FILLNG TIME, MN

Figure 5. Comparison of hawser forces measured during filling with the Marmet ILCS model for a 24-ft lift 


\section{Second McAlpine ILCS Model Study}

Another laboratory investigation was conducted for the 1,200-ft lock addition planned at the McAlpine Navigation Project. In the previous model study for the new McAlpine Project, the intakes and outlets were located in the upper and lower miter gate sills, respectively. The Louisville District conducted further evaluation of the valve maintenance requirements, since they would have to be located underwater. As a result, the design for the intakes and discharge outlets was changed. A second model study was necessary to verify the performance of the filling and emptying system with the new intakes and outlets. The results of this study are presented in Hite (2000), and the initial ILCS design is shown in Figure 6.

The model results from this study indicated that a variable-speed valve operation provided faster filling times and lower hawser forces than the operations with a constant speed valve. Additional port extensions were also necessary on some of the downstream ports to prevent excessive water-surface turbulence during filling. The width of the wall baffles was increased to provide additional energy dissipation and help distribute the flow more evenly in the chamber. The hawser forces measured during filling with a 37-ft lift and the original and recommended chamber designs are shown in Figure 7. The twospeed valve operation allowed the lock to fill in $11.3 \mathrm{~min}$ and maintain longitudinal hawsers less than 5 tons for the $37-\mathrm{ft}$ lift design condition. These changes were minimal compared with the first McAlpine ILCS study, but they do demonstrate the need for additional research to better understand the ILCS design.

The through-the-sill intake and the ILCS lock model studies showed that the ILCS was a feasible design. The research reported herein was performed to develop generalized design guidance for the ILCS for use in developing design alternatives. The recommended chamber design from Hite (2000) was used for some of the initial ILCS research. This design was chosen for additional research since it performed satisfactorily for the highest lift project on the Ohio River. 


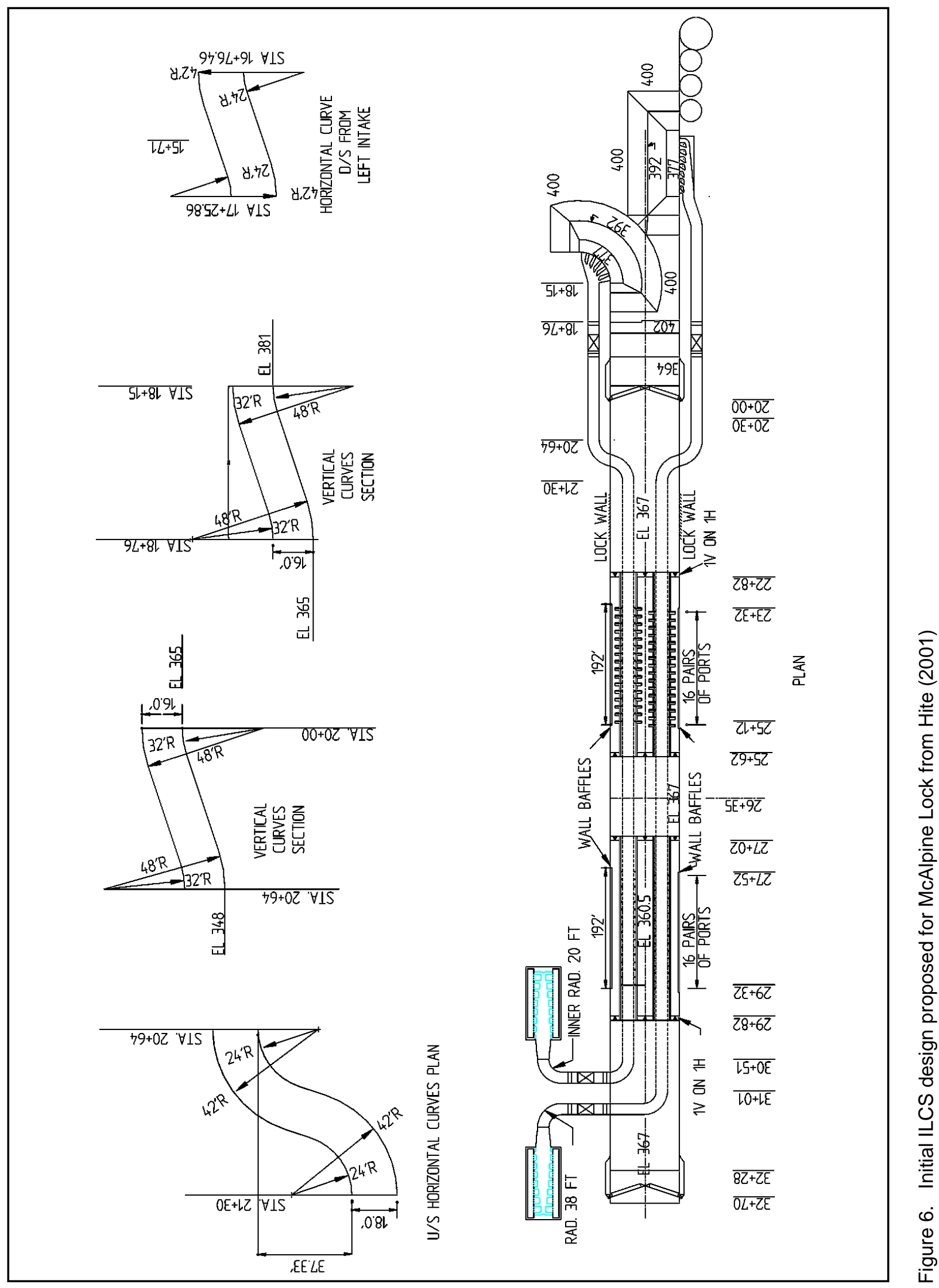



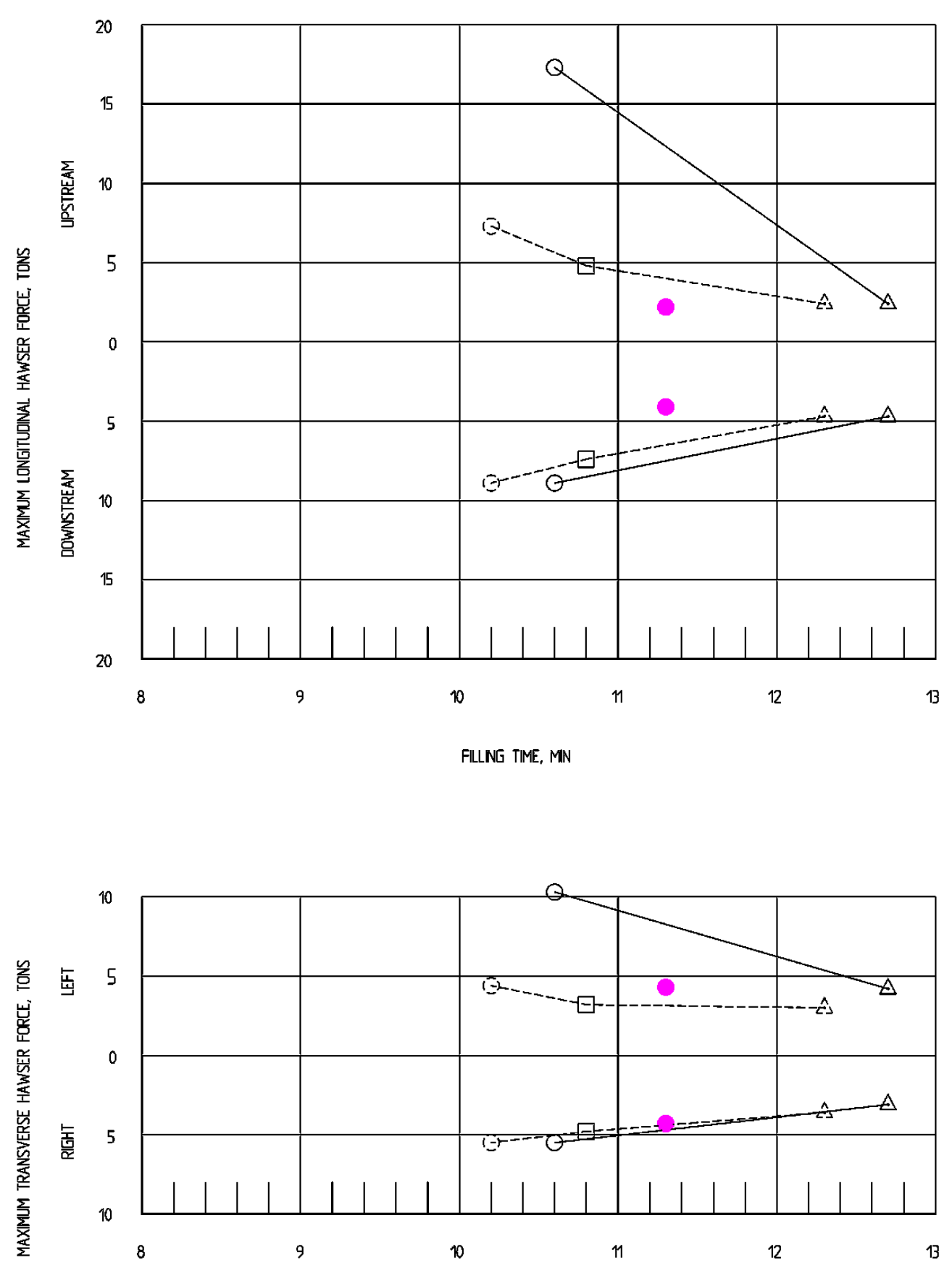

\begin{tabular}{|c|c|}
\hline \multicolumn{2}{|c|}{ LEGEND } \\
\hline SYMBOL & VALVE SCHEDUE, MIN \\
\hline$O$ & 4 \\
\hline$\square$ & 5 \\
\hline$\triangle$ & 8 \\
\hline$\bigcirc$ & VARIABLE VALVE \\
\hline LNE TYPE & DESIGN TYPE \\
\hline & Original \\
\hline------ & Recommended \\
\hline
\end{tabular}

FILLNG TIME, MNN

Figure 7. Comparison of hawser forces measured during filling with a 37-ft lift from Hite (2001) 


\section{Lock Filling and Emptying Design Considerations}

\section{Background}

The filling and emptying system for a lock project has historically been designed based on the chamber performance necessary to meet the transit time requirement. The time required to raise or lower (fill or empty) the lock water surface is one time component included in the determination of the total transit time. The total transit as defined in EM 1110-2-1604 (HQDA 1995a) is the total time required for a tow to move into a lock from a waiting point (arrival point), be raised or lowered, and then proceed out of the lock to a position where it will not interfere with any other tow that needs to transit the lock. The transit time is derived from capacity/economic studies and is a specific design objective for a navigation project.

Chamber performance, which is also referred to as the "within-chamber navigation constraint on rapid filling," is normally evaluated using physical hydraulic models. Performance indicators include

a. Surface currents and turbulence.

b. Drift of free tows.

c. Hawser forces.

Guidance for these indicators is found in EM 1110-2-1604. The accepted guidance for hawser forces is no forces greater than 5 tons, as extrapolated from a physical hydraulic model for barge tows of various sizes and numbers in any location in the lock chamber. Previous model studies of lock filling and emptying systems designed for barge traffic have targeted maximum hawser forces of 5 tons as a design objective. System design and operation are optimized such that a full tow at design draft produces hawser forces of 5 tons or less during lock operations at the design pool conditions. This limiting maximum hawser force guidance is provided in paragraph 8-6 of EM 1110-2-2602 (HQDA 1995b), in paragraph E-2 of EM 1110-2-1604 (HQDA 1995a), and also in the discussion of permissible filling times in paragraph D-15 of EM 1110-2-1604. 
Davis (1989) summarizes the findings of physical model studies in this way:

In working with models to determine hawser stresses, it must be noted that when a hawser stress of only 5 tons is achieved in a model it does not necessarily follow that the hawser stress on the prototype lock will be no greater than the value measured in the model. On a performance basis it has been found that when the model hawser stress is no greater than 5 tons, the prototype lock will perform very well and no surging or severe turbulence will occur.

For projects with two culverts, the choice of lateral culverts as compared with side ports has been an economic consideration. Structural costs, chamber maintenance, and excavation costs are major factors. The side-port filling and emptying system has been found to be generally best suited for lifts below $30 \mathrm{ft}$. The design philosophy of the ILCS is to try and produce chamber performance similar to the side-port filling and emptying system. Operation times near 8 min have been the target for many of the filling and emptying systems developed from model and prototype tests and design studies. This report focuses on chamber performance during filling operations since these conditions are generally more severe than those experienced during emptying.

\section{Lock Coefficient}

An indicator of the performance of a filling and emptying system is the lock coefficient. An equation typically used to compute the overall lock coefficient is

$$
C_{L}=\frac{2 A_{L} \sqrt{H+d}-\sqrt{d}}{A_{c}\left(T-k t_{v}\right) \sqrt{2 g}}
$$

where

$$
\begin{aligned}
A_{L} & =\text { area of lock chamber, } \mathrm{ft}^{2} \\
H & =\text { initial head, } \mathrm{ft} \\
d & =\text { overtravel, } \mathrm{ft} \\
A_{c} & =\text { area of culverts, } \mathrm{ft}^{2} \\
T & =\text { filling time, sec } \\
k & =\text { a constant } \\
t_{v} & =\text { valve opening time, sec } \\
g & =\text { acceleration due to gravity, } \mathrm{ft} / \mathrm{sec}^{2}
\end{aligned}
$$

For more information on the development of this equation, refer to Davis (1989). The term $T-k t_{v}$ is the lock filling or emptying time for the hypothetical case of instantaneous valve operation and can be determined from laboratory or 
field data. Lock coefficients have been determined for several filling and emptying system models tested in previous years. Table 1 provides these coefficients for typical side-port systems and the values determined from the ILCS models for comparison. The side-port systems are slightly more efficient than the ILCS. The computed coefficients for the ILCS Type 11 chamber design (Hite 2000) from the equation above are $\mathrm{C}_{\mathrm{L}}=0.65$ for filling and $C_{L}=0.57$ for emptying with a lift of $37 \mathrm{ft}$.

\begin{tabular}{|c|c|c|c|c|c|}
\hline \multicolumn{6}{|c|}{$\begin{array}{l}\text { Table } 1 \\
\text { Lock Coefficients from Previous Model Studies }\end{array}$} \\
\hline Project & $\begin{array}{l}\text { Filling and } \\
\text { Emptying } \\
\text { System } \\
\end{array}$ & $\begin{array}{l}\text { Initial } \\
\text { Head, ft }\end{array}$ & $\begin{array}{l}\text { Lock } \\
\text { Coefficient } \\
\text { Filling } \\
\end{array}$ & Emptying & Reference \\
\hline \multirow{4}{*}{$\begin{array}{l}\text { Cannelton Model } \\
\text { Type 45 Port } \\
\text { Arrangement }\end{array}$} & \multirow[t]{4}{*}{ Side Port } & 20 & 0.74 & 0.57 & \multirow{4}{*}{$\begin{array}{l}\text { Ables and Boyd } \\
(1966 a)\end{array}$} \\
\hline & & 26 & 0.74 & 0.60 & \\
\hline & & \begin{tabular}{|l|}
30 \\
\end{tabular} & 0.73 & 0.61 & \\
\hline & & 40 & 0.74 & 0.60 & \\
\hline \multirow{3}{*}{$\begin{array}{l}\text { Cannelton Model } \\
\text { Type } 100 \text { Port } \\
\text { Arrangement }\end{array}$} & \multirow[t]{3}{*}{ Side Port } & 20 & 0.71 & 0.56 & \multirow{3}{*}{$\begin{array}{l}\text { Ables and Boyd } \\
\text { (1966a) }\end{array}$} \\
\hline & & 30 & 0.73 & 0.56 & \\
\hline & & \begin{tabular}{|l|}
40 \\
\end{tabular} & 0.74 & 0.56 & \\
\hline $\begin{array}{l}\text { Arkansas River } \\
\text { Model }\end{array}$ & Side Port & $10-50$ & 0.73 & 0.67 & $\begin{array}{l}\text { Ables and Boyd } \\
\text { (1966b) }\end{array}$ \\
\hline \multirow{3}{*}{$\begin{array}{l}\text { Marmet Model } \\
\text { Type } 5 \text { Chamber } \\
\text { Design }\end{array}$} & \multirow[t]{3}{*}{ ILCS } & 14 & 0.63 & & \multirow[t]{3}{*}{\begin{tabular}{|l|} 
Hite (1999) \\
\end{tabular}} \\
\hline & & 24 & 0.63 & & \\
\hline & & 34 & 0.63 & & \\
\hline $\begin{array}{l}\text { McAlpine Model } \\
\text { Type } 1 \text { Chamber } \\
\text { Design }\end{array}$ & ILCS & 37 & 0.63 & 0.56 & Hite (2000) \\
\hline $\begin{array}{l}\text { McAlpine Model } \\
\text { Type } 11 \text { Chamber } \\
\text { Design }\end{array}$ & ILCS & 37 & 0.65 & 0.57 & Hite (2000) \\
\hline
\end{tabular}

Laboratory modeling of lock filling and emptying systems is not entirely quantitative since the flow is unsteady and the system consists of pressure flow conduits and open-channel components. Fortunately, engineers have been conducting large-scale physical model studies of filling and emptying systems for around 50 years and have had opportunities to compare these laboratory results with prototype performance. The knowledge and experience gained from these previous laboratory and field studies provide the basis for designing filling and emptying systems using laboratory models. Table 2 provides a comparison of the lock coefficients determined from laboratory and field studies for several Corps projects. The prototype values are higher and illustrate the unsteady-flow effects and frictional differences encountered in a laboratory investigation.

The permissible filling time determined from model studies for filling and emptying systems is the fastest the lock can be filled without exceeding the 5-ton hawser force criteria in EM 1110-2-1604 (HQDA 1995a). Figure 8 shows these filling times for lifts between 10 and $40 \mathrm{ft}$ determined for side-port systems. Permissible fill times for the ILCS with lifts over $40 \mathrm{ft}$ start to increase significantly, indicating the practical upper limit of lift based on chamber performance for the ILCS is around $40 \mathrm{ft}$. 


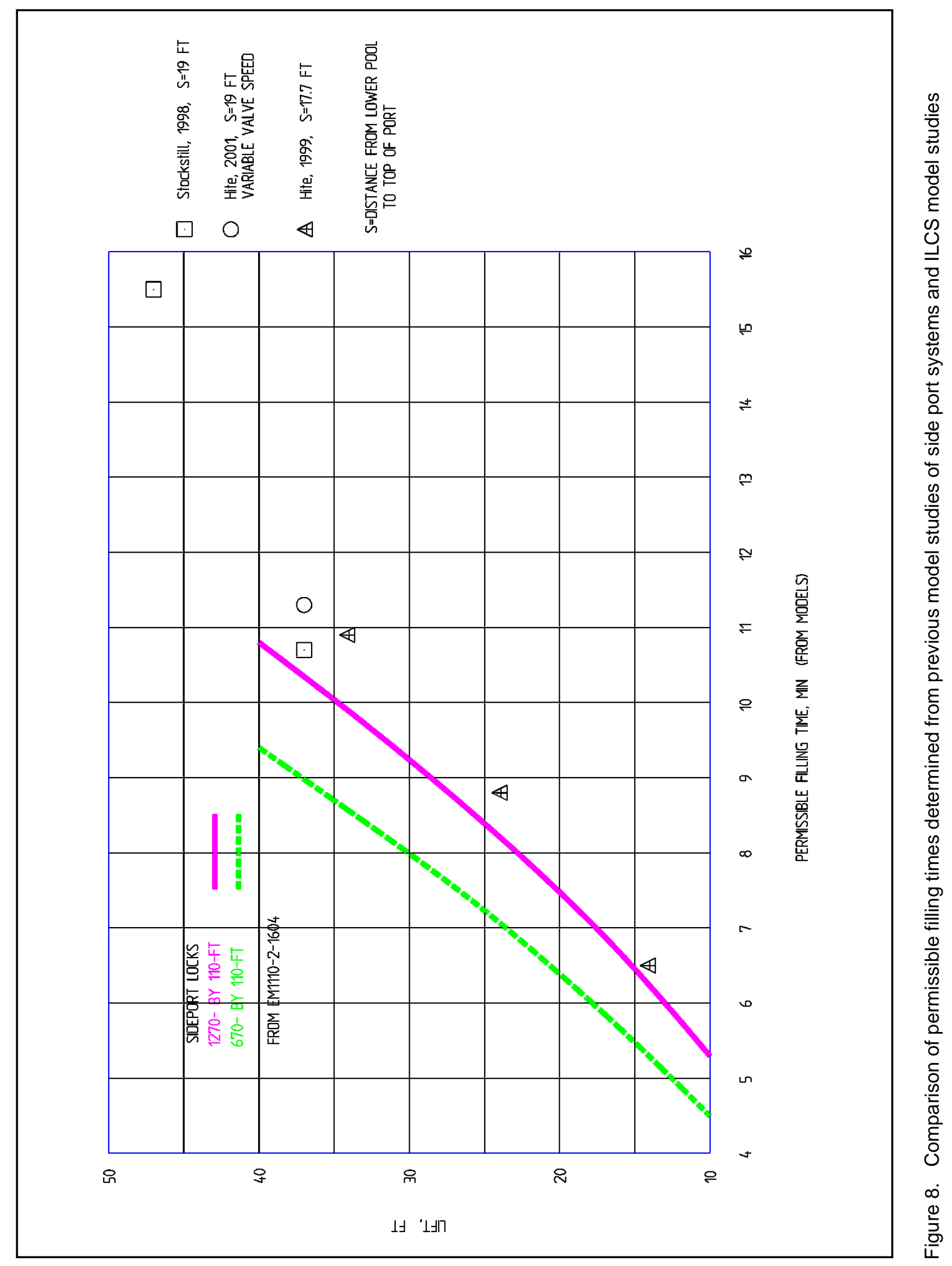




\begin{tabular}{|l|l|l|l|l|l|l||}
\hline \hline \multicolumn{7}{|l||}{$\begin{array}{l}\text { Table } 2 \\
\text { Comparison of Model and Prototype Lock Coefficients }\end{array}$} \\
\hline \hline \multirow{2}{*}{$\begin{array}{l}\text { Lock } \\
\text { Project }\end{array}$} & Model & Prototype & \% Difference & Model & Prototype & $\%$ Difference \\
\hline \hline Bankhead & 0.66 & 0.78 & 15 & 0.56 & 0.69 & 19 \\
\hline Lower Granite & 0.77 & 0.93 & 17 & 0.66 & 0.78 & 15 \\
\hline Bay Springs & 0.63 & 0.75 & 16 & 0.52 & 0.59 & 12 \\
\hline New Bonneville & 0.61 & 0.72 & 15 & 0.47 & 0.56 & 16 \\
\hline Barkley ${ }^{1}$ & 0.75 & 0.84 & 11 & NA & 0.62 & NA \\
\hline Greenup ${ }^{1}$ & 0.57 & 0.62 & 8 & 0.51 & 0.59 & 14 \\
\hline \hline Barkley and Greenup locks were tested in 3:100-scale models; all others were 1:25-scale. \\
\hline
\end{tabular}




\section{Laboratory Model}

\section{Description of Research Model}

The ILCS laboratory model was designated as a 1:25-scale model for convenience in discussing lock dimensions and hydraulic parameters. Most previous filling and emptying model studies have been performed at this scale. All dimensions in this report are also reported at prototype for convenience, unless otherwise stated. A schematic of the initial design ILCS model used in this study is shown as Figure 9, and a view of the laboratory model looking downstream is shown as Figure 10. For the ILCS model, the upper and lower lock approaches, lock chamber floor and walls, and the miter gates were constructed of plastic-coated plywood. The filling and emptying system, including the intakes, filling and emptying culverts, and the discharge outlet manifolds, were constructed of plastic, and the filling and emptying valves were built from brass.

The model filling and emptying system reproduced a lock chamber $1,270 \mathrm{ft}$ (387.1 m) long from pintle to pintle and $110 \mathrm{ft}$ (33.53 m) wide. The model contained two intakes and two outlets. The left intake (looking downstream) was located on the left guide wall, approximately $327.5 \mathrm{ft}(99.82 \mathrm{~m})$ from the upstream pintle and consisted of eight ports $16 \mathrm{ft}(4.88 \mathrm{~m})$ high with the top of the intake at el 14.1 The right intake was located approximately $189 \mathrm{ft}(57.61 \mathrm{~m})$ upstream from the pintle at the end of the right wall with the top of the intake also at el 14. The right intake was semicircular shaped and contained six ports, $16 \mathrm{ft}$ (4.88 m) high. The port-to-culvert area ratio for the right intake was 2.7 (port intake area $=6$ ports $\left.\times 8 \mathrm{ft} \times 16 \mathrm{ft}=768 \mathrm{ft}^{2}\right)\left(71.35 \mathrm{~m}^{2}\right.$ ). The port-to-culvert area ratio for the left intake was 2.9 (port intake area $=8$ ports $\times 6.5 \mathrm{ft} \times 16 \mathrm{ft}$ $\left.=832 \mathrm{ft}^{2}\right)\left(77.30 \mathrm{~m}^{2}\right)$. Both intakes transitioned to 16 -ft-high by 18 -ft-wide (4.88-m by $5.49-\mathrm{m}$ ) culverts located in the lock walls.

The culverts contained a vertical transition between 185 and $124 \mathrm{ft}$ (56.38 and $37.79 \mathrm{~m}$ ) upstream from the upper pintle. The floor elevation drops from -2 to -18 at this transition. Another vertical transition is located between the upper pintle (Sta 0+00) ${ }^{1}$ and $64 \mathrm{ft}(19.51 \mathrm{~m})$ upstream from the upper pintle where the invert lowers to el -35 . The filling valve wells and bulkhead slots were located between 124 and $68 \mathrm{ft}$ (37.79 and $20.73 \mathrm{~m}$ ). Both culverts contain horizontal curves between Sta $0+64$ and Sta 1+30, where the culverts turned into the lock chamber.

\footnotetext{
${ }^{1}$ All elevations and stations are in feet unless stated otherwise.
} 


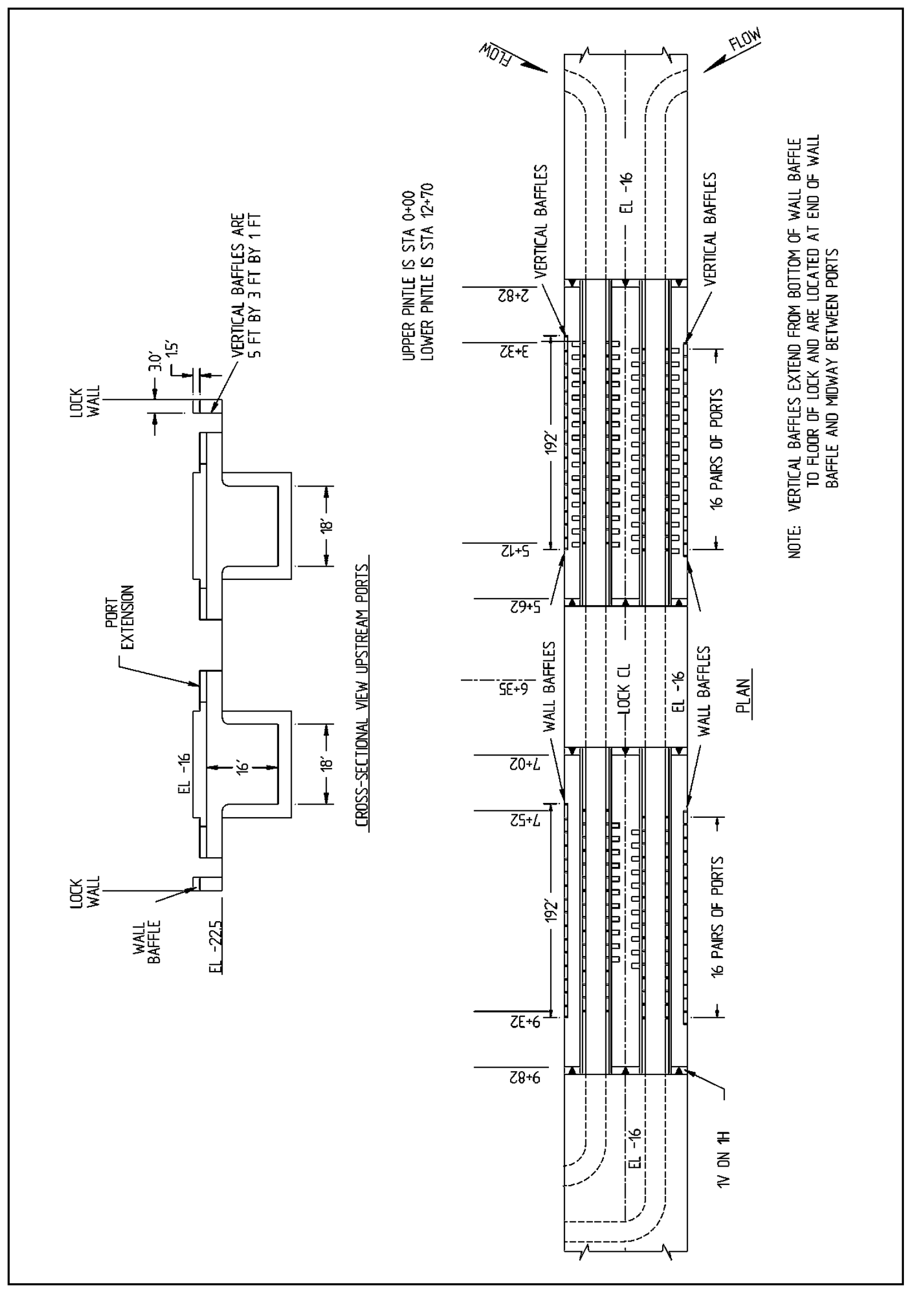

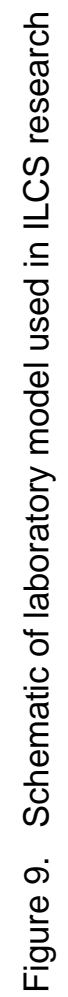




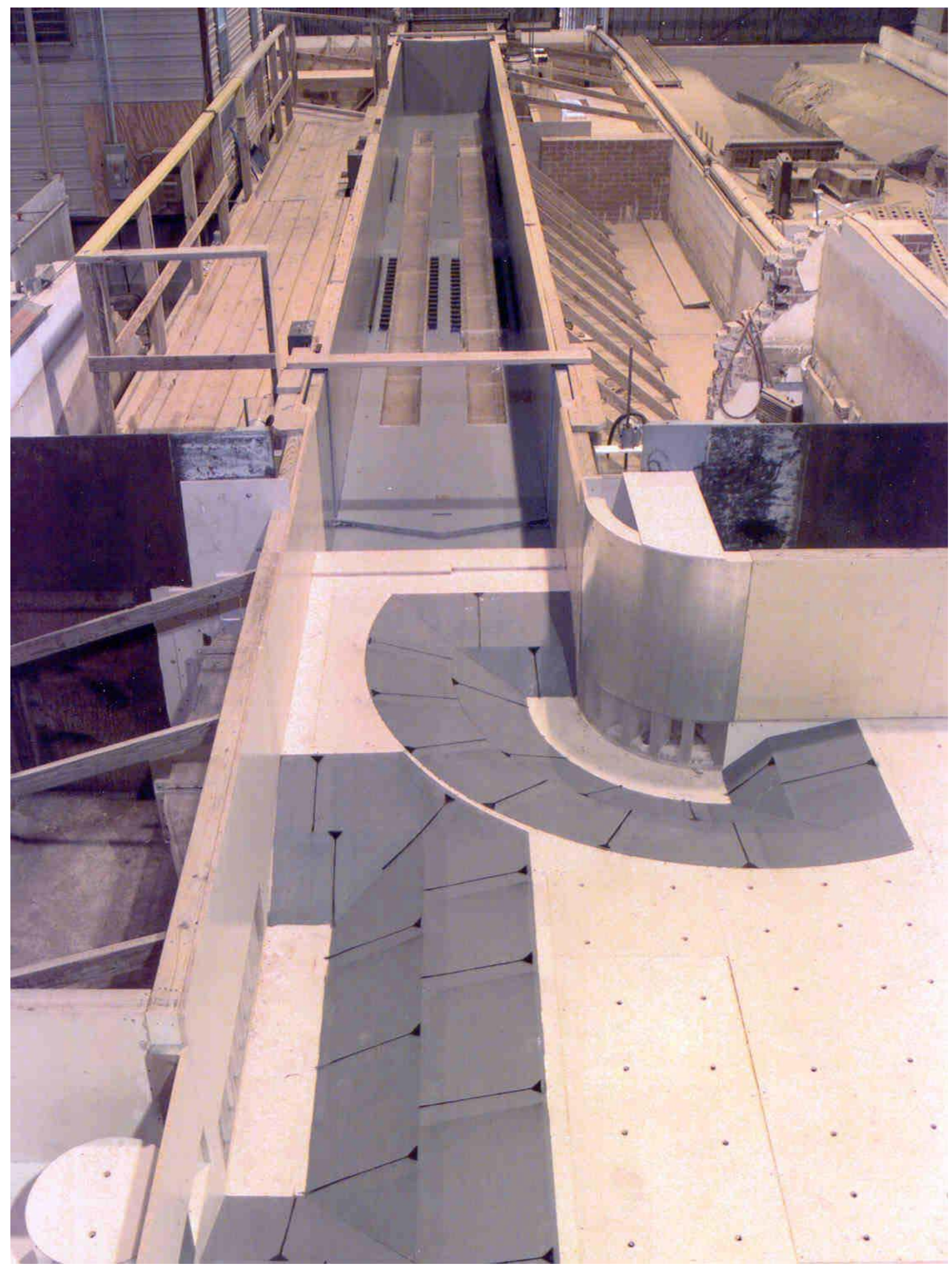

Figure 10. View of ILCS modeling looking downstream 
Lock stations are referenced to the upper pintle, which was designated Sta 0+00. Both chamber culverts begin at Sta $1+30.04$. The left culvert extended to Sta 11+01 and the right culvert to Sta 10+51, where they turned outside the right lock wall. The filling and emptying manifold port-to-culvert area ratio was 0.97. The discharge outlets were the manifold type with an outlet manifold port-toculvert area ratio of $1.8\left(16\right.$ ports $\left.\times 8 \mathrm{ft} \times 4 \mathrm{ft}=512 \mathrm{ft}^{2}\right)\left(47.57 \mathrm{~m}^{2}\right)$.

\section{Appurtenances and Instrumentation}

Water was supplied to the model through a circulating system. The upper and lower pools were maintained at near-constant elevations during the filling and emptying operations using constant head skimming weirs in the model headbay and tailbay. During a typical filling operation, excess flow was allowed to drain over the weirs at the beginning of the fill operation and minimal flow over the weir was maintained at the peak discharge, thereby minimizing the drawdown in the upper reservoir. This operation was reversed during lock emptying.

Upper and lower pool elevations were set to the desired level by adjusting the skimming weirs and reading piezometers placed in calm areas of the upper and lower pools. Water-surface elevations inside the chamber were determined from electronic pressure cells located in the middle and on each end of the lock chamber. Pressure cells were also used to measure instantaneous pressures in the culvert just downstream of the filling and emptying valves. Histories of the endto-end water-surface differential were also recorded during filling and emptying operations. Dye and confetti were used to study subsurface and surface current directions. Pressures throughout the systems were measured with piezometers (open-air manometers). Pressures obtained in this manner are considered average pressures because of the reduction in frequency response resulting from the use of nylon tubing.

An automated data acquisition and control program was used to control valve operations and collect pressure and strain gauge data. Thirteen data channels were used: four for control of the filling and emptying valves, six for pressure data, and three for collecting strain gauge information. Generally, the data were collected at a sampling rate of $50 \mathrm{~Hz}$. However, some of the hawser force and lock filling and emptying data were collected at $10 \mathrm{~Hz}$. These data were then processed to determine lock filling and emptying times, longitudinal and transverse hawser forces, and pressures downstream from the filling and emptying valves.

A hawser-pull (force links) device used for measuring the longitudinal and transverse forces acting on a tow in the lock chamber during filling and emptying operations is shown in Figure 11. Three such devices were used: one measured longitudinal forces, and the other two measured transverse forces on the downstream and upstream ends of the tow, respectively. These links were machined from aluminum and had SR-4 strain gauges cemented to the inner and outer edges. When the device was mounted on the tow, one end of the link was pinconnected to the tow while the other end was engaged to a fixed vertical rod. While connected to the tow, the link was free to move up and down with changes 


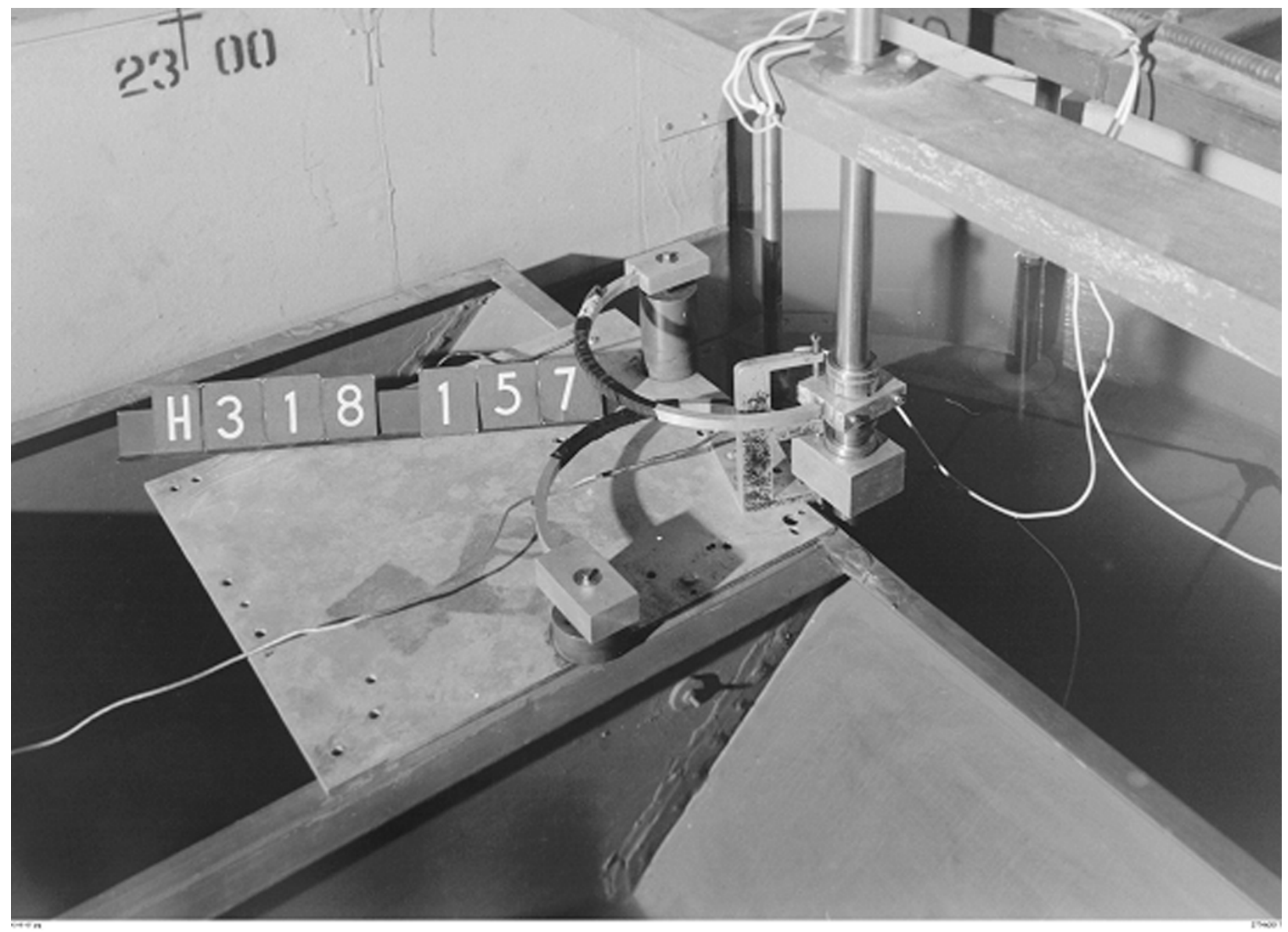

Figure 11. Hawser-pull (force links) measuring device

in the water surface in the lock. Any horizontal motion of the tow caused the links to deform and vary the signal, which was recorded with a personal computer using an analog-to-digital converter. The links were calibrated by inducing deflection with known weights. Instantaneous pressure and strain gauge data were recorded digitally with a personal computer.

\section{Similitude Considerations}

\section{Kinematic similitude}

Kinematic similarity is an appropriate method for modeling free-surface flows when the viscous stresses are negligible. Kinematic similitude requires that the ratio of inertial forces $\left(\rho V^{2} L^{2}\right)$ to gravitational forces $\left(\rho g L^{3}\right)$ in the model is equal to those of the prototype. Here, $\rho$ is the fluid density, $V$ is the fluid velocity, $L$ is a characteristic length, and $g$ is the acceleration due to gravity. This ratio is gener-ally expressed as the Froude number $\left(N_{F}\right)$ : 


$$
N_{F}=\frac{V}{\sqrt{g L}}
$$

where $L$, the characteristic length, is usually taken as the flow depth in openchannel flow.

The Froude number can be viewed in terms of the flow characteristics. Because a surface disturbance travels at celerity of a gravity wave, $(g h)^{1 / 2}$, where $h$ is the flow depth, it is seen that the Froude number describes the ratio of advection speed to the gravity wave celerity. Evaluation of the lock chamber performance primarily concerns modeling of hawser forces on moored barges during filling and emptying operations. The tow's bow-to-stern water-surface differentials are the result of long period seiches or oscillations in the lock chamber. Seiching is gravity waves traveling in the longitudinal direction from the upper miter gates to the lower miter gates. Equating Froude numbers in the model and prototype is an appropriate means of modeling the lock chamber.

\section{Dynamic similitude}

Modeling of forces is a significant purpose of the laboratory investigation. Appropriate scaling of viscous forces requires that the model be dynamically similar to the prototype. Dynamic similarity is accomplished when the ratios of the inertia forces to viscous forces $(\mu V L)$ of the model and prototype are equal. Here, $\mu$ is the fluid viscosity.

This ratio of inertia to viscous forces is usually expressed as the Reynolds number $\left(N_{R}\right)$ :

$$
N_{R}=\frac{V L}{v}
$$

where $v$ is the kinematic viscosity of the fluid $(v=v / \rho)$, and the pipe diameter is usually chosen as the characteristic length, $L$, in pressure flow analysis.

\section{Similitude for lock models}

Complete similitude in a laboratory model is attained when geometric, kinematic, and dynamic similitudes are satisfied. Physical models of hydraulic structures with both internal flow (pressure flow) and external flow (free surface) typically are scaled using kinematic (Froudian) similitude at a large enough scale so that the viscous effects in the scaled model can be neglected. More than 50 model and 10 prototype studies of lock filling and emptying systems have been investigated (Pickett and Neilson 1988). The majority of these physical model studies used a scale of 1 to 25 (model to prototype). Lock model velocities scaled using kinematic similitude (model Froude number equal to prototype Froude number) in a 1:25-scale model have maximum Reynolds numbers at peak discharges on the order of $10^{5}$ yet the corresponding prototype values are on the 
order of $10^{7}$, indicating there are some Reynolds effects in this type of model.

Boundary friction losses in lock culverts are empirically described using the "smooth- pipe" curve of the Darcy-Weisbach friction factor where the head loss is expressed as

$$
H_{f}=f \frac{L}{D} \frac{V^{2}}{2 g}
$$

where

$$
\begin{aligned}
H_{f} & =\text { head loss due to boundary friction } \\
f & =\text { Darcy-Weisbach friction factor } \\
L & =\text { culvert length } \\
D & =\text { culvert diameter }
\end{aligned}
$$

The Darcy-Weisbach friction factor for turbulent flow in smooth pipes is given in an implicit form (Vennard and Street 1982)

$$
\frac{1}{\sqrt{f}}=2.0 \quad \log \left(N_{R} \sqrt{f}\right)-0.8
$$

given in an implicit form (Vennard and Street 1982).

Because $f$ decreases with increasing $N_{R}$, the model is hydraulically "too rough.” The scaled friction losses in the model will be larger than those experienced by the prototype structure. Consequently, the scaled velocities (and discharges) in the model will be less, and the scaled pressures within the culverts will be higher than those of the prototype. Prototype filling and emptying times for similar designs will be less than those measured in a 1:25-scale lock model.

Modeling of lock filling and emptying systems is not entirely quantitative. The system is composed of pressure flow conduits and open-channel components. Further complicating matters, the flow is unsteady. Discharges (therefore, $N_{F}$ and $N_{R}$ ) vary from no flow at the beginning of an operation to peak flows within a few minutes, and then return to no flow at the end of the cycle. Fortunately, though, engineers now have about 50 years of experience in conducting large-scale models and subsequently studying the corresponding prototype performance. This study used a 1:25-scale Froudian model in which the viscous differences were small and could be estimated based on previously reported model-to-prototype comparisons. Setting the model and prototype Froude numbers equal results in the following relations between the dimensions and hydraulic quantities: 


\begin{tabular}{||l|l|l||}
\hline Characteristic & Dimension1 & $\begin{array}{l}\text { Scale Relation } \\
\text { Model : Prototype }\end{array}$ \\
\hline \hline Length & $\mathrm{L}_{\mathrm{r}}=\mathrm{L}$ & $1: 25$ \\
\hline Pressure & $\mathrm{P}_{\mathrm{r}}=\mathrm{L}_{\mathrm{r}}$ & $1: 25$ \\
\hline Area & $\mathrm{A}_{\mathrm{r}}=\mathrm{L}_{\mathrm{r}}{ }^{2}$ & $1: 625$ \\
\hline Velocity & $\mathrm{V}_{\mathrm{r}}=\mathrm{L}_{\mathrm{r}}{ }^{1 / 2}$ & $1: 5$ \\
\hline Discharge & $\mathrm{Q}_{\mathrm{r}}=\mathrm{L}_{\mathrm{r}}{ }^{5 / 2}$ & $1: 3,125$ \\
\hline Time & $\mathrm{T}_{\mathrm{r}}=\mathrm{L}_{\mathrm{r}}^{12}$ & $1: 5$ \\
\hline Force & $\mathrm{F}_{\mathrm{r}}=\mathrm{L}_{\mathrm{r}}{ }^{3}$ & $1: 15,625$ \\
\hline \hline
\end{tabular}

These relations were used to transfer model data to prototype equivalents, and vice versa.

\section{Experimental Procedures}

Evaluation of the various elements of the lock system was based on data obtained during typical filling and emptying operations. Performance was based primarily on hawser forces on tows in lockage, roughness of the water surface, pressures, and time required for filling and emptying. Quantification of energy loss coefficients was made using fixed-head (steady-flow) conditions with the culvert valve and/or miter gates fully opened or closed. 


\section{Laboratory Model Experiments and Results}

\section{Original Design ILCS}

Numerous experiments were performed to evaluate the performance of the ILCS for a range of lift and submergence conditions expected on the Ohio and Upper Mississippi Rivers. A schematic illustrating lift and submergence is shown as Figure 12.

The primary technique used to evaluate the performance of the ILCS was to measure the hawser forces on a 3-wide by 6-long barge arrangement. The dimensions of each barge were $35 \mathrm{ft}$ wide by $195 \mathrm{ft}$ long, drafted to $9 \mathrm{ft}$. The barges were placed inside the chamber and centered at Sta 6+35. The upstream and downstream longitudinal hawser forces and the upstream and downstream transverse forces were measured during the lock operation for the desired lift, submergence, and valve schedule. The normal-speed valve operation curves used for the reverse tainter valve in the ILCS model are shown in Figure 13. This figure also shows the permissible filling times determined for previous ILCS models.

\section{Original design filling experiments}

During a typical experiment, time-histories of the longitudinal and transverse hawser forces and the lock water-surface elevation at the middle and both ends of the chamber were measured. Results from a typical experiment to determine the lock performance during filling with a 37-ft lift, 19-ft submergence, and 5-min valve schedule are shown in Figure 14. The fill curve (which indicates that the lock reached the upper pool elevation in $10.8 \mathrm{~min}$ ) was determined from the average of the three water-surface measurements made during the experiment.

The top time-history shown in Figure 14 is the longitudinal hawser force. Immediately after the valve was opened, a small force in the upstream direction was observed, followed by a force of 7.4 tons in the downstream direction at approximately 1 min into the filling operation. An upstream longitudinal hawser force results when the water surface in the lower end of the chamber is higher than the water surface in the upper end. Likewise, a downstream longitudinal hawser force results when the water surface in the upper end of the chamber is 


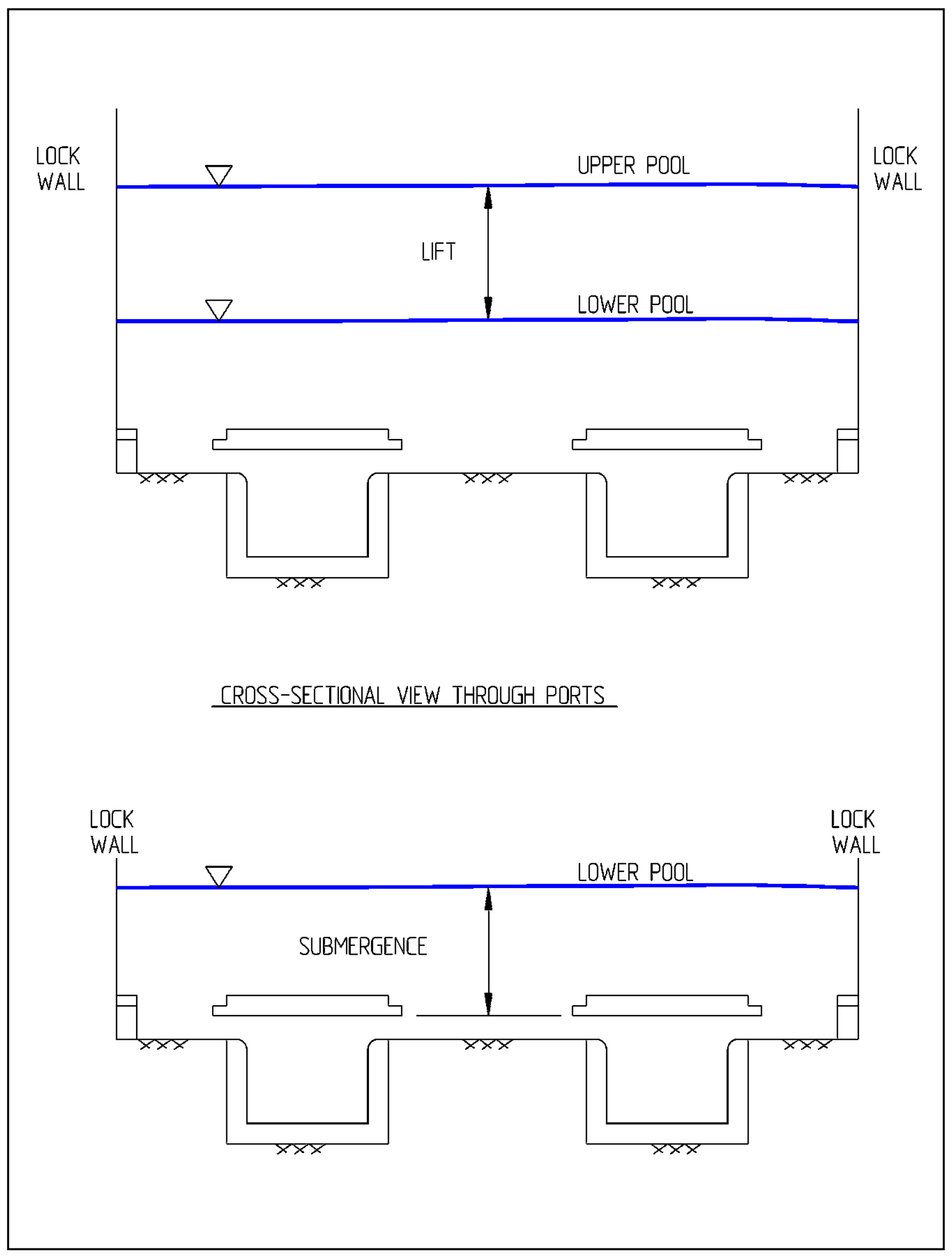

Figure 12. Lift and submergence definitions for the ILCS investigation 


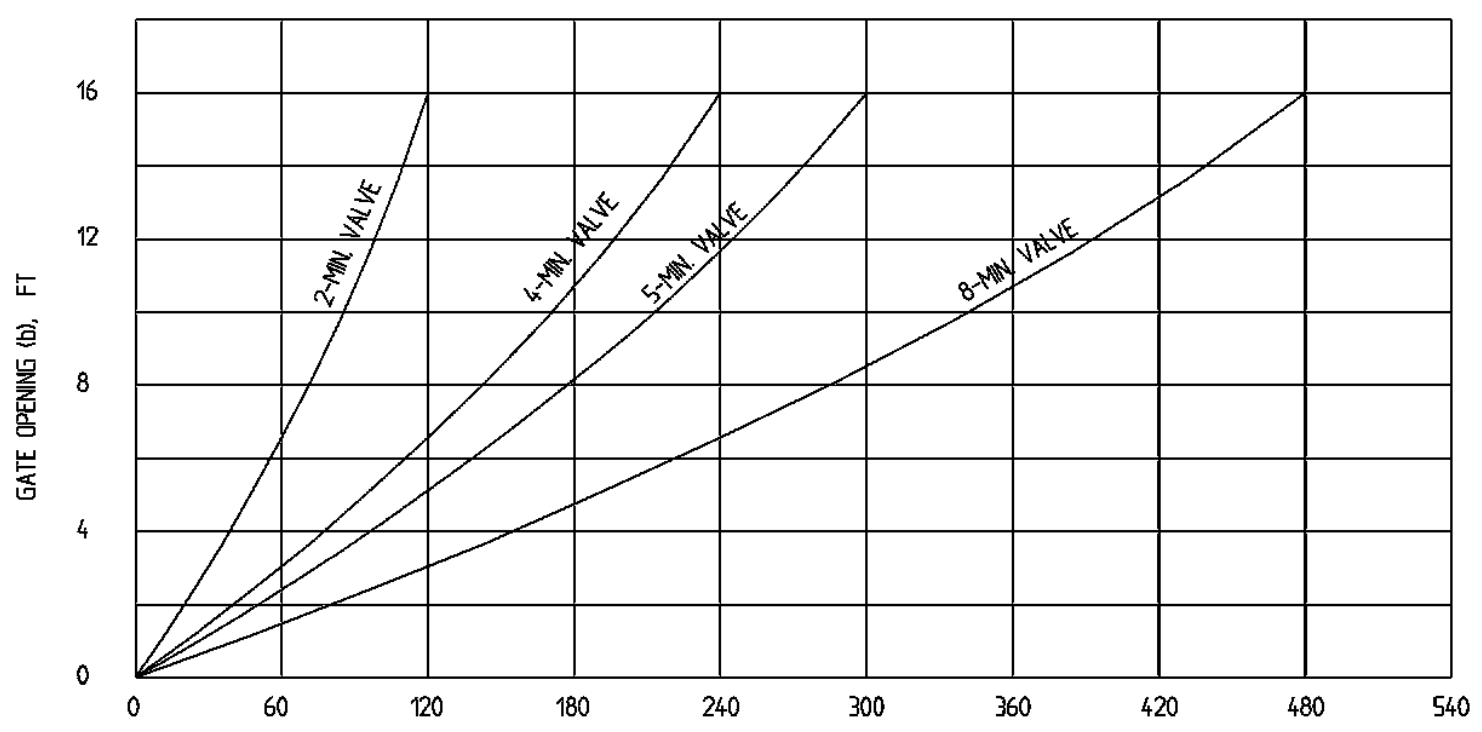

TMME, SEC

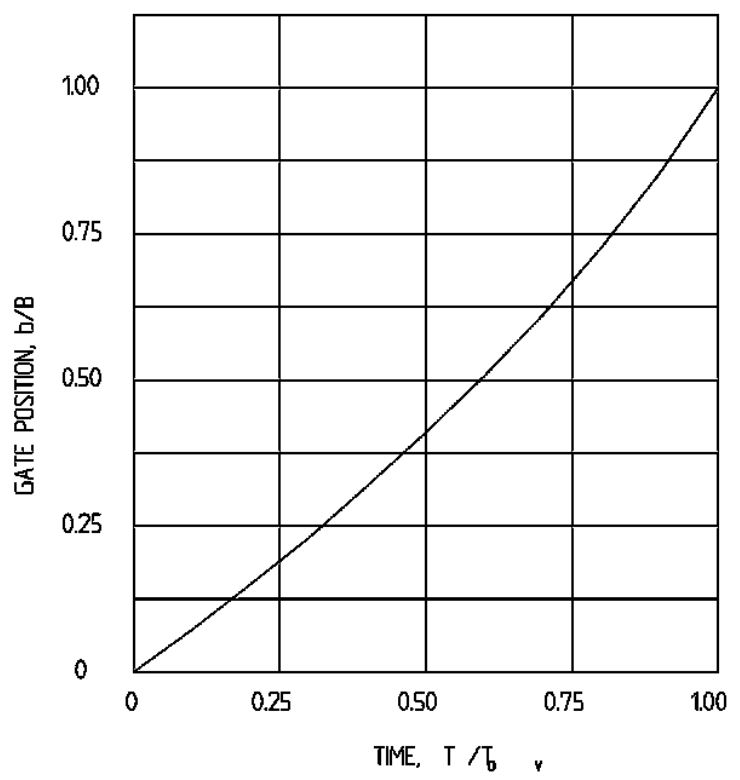

\begin{tabular}{|c|c|}
\multicolumn{1}{c}{$\mathrm{b} / \mathrm{B}$} & $\mathrm{T} / \mathrm{T}_{\mathbf{0}}$ \\
\hline 0 & 0 \\
\hline 0.073 & 0.10 \\
\hline 0.150 & 0.20 \\
\hline 0.230 & 0.30 \\
\hline 0.317 & 0.40 \\
\hline 0.410 & 0.50 \\
\hline 0.506 & 0.60 \\
\hline 0.611 & 0.70 \\
\hline 0.727 & 0.80 \\
\hline 0.854 & 0.90 \\
\hline 1.000 & 1.00 \\
\hline
\end{tabular}

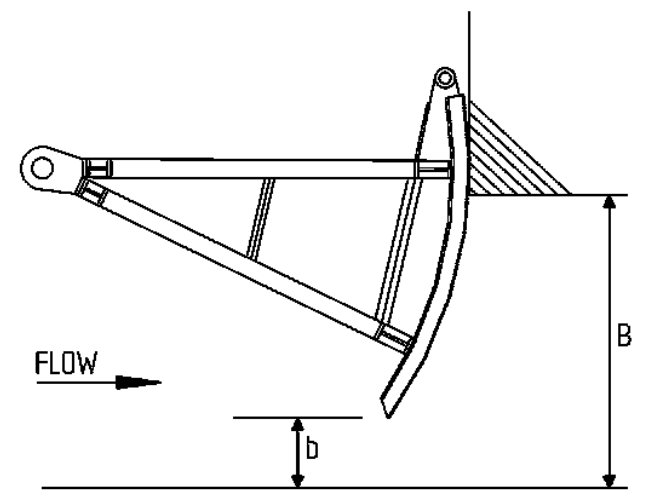

REVERSE TAINTER VALVE

$T==_{0} T$ TME SINCE OPENING BEGAN

$T=$ TIME TO DPEN FULL

$B=16 \mathrm{FT}$

$b=$ VERTILAL DIST. FROM LIP TO FLOOR

Figure 13. Valve opening curves for the ILCS model 


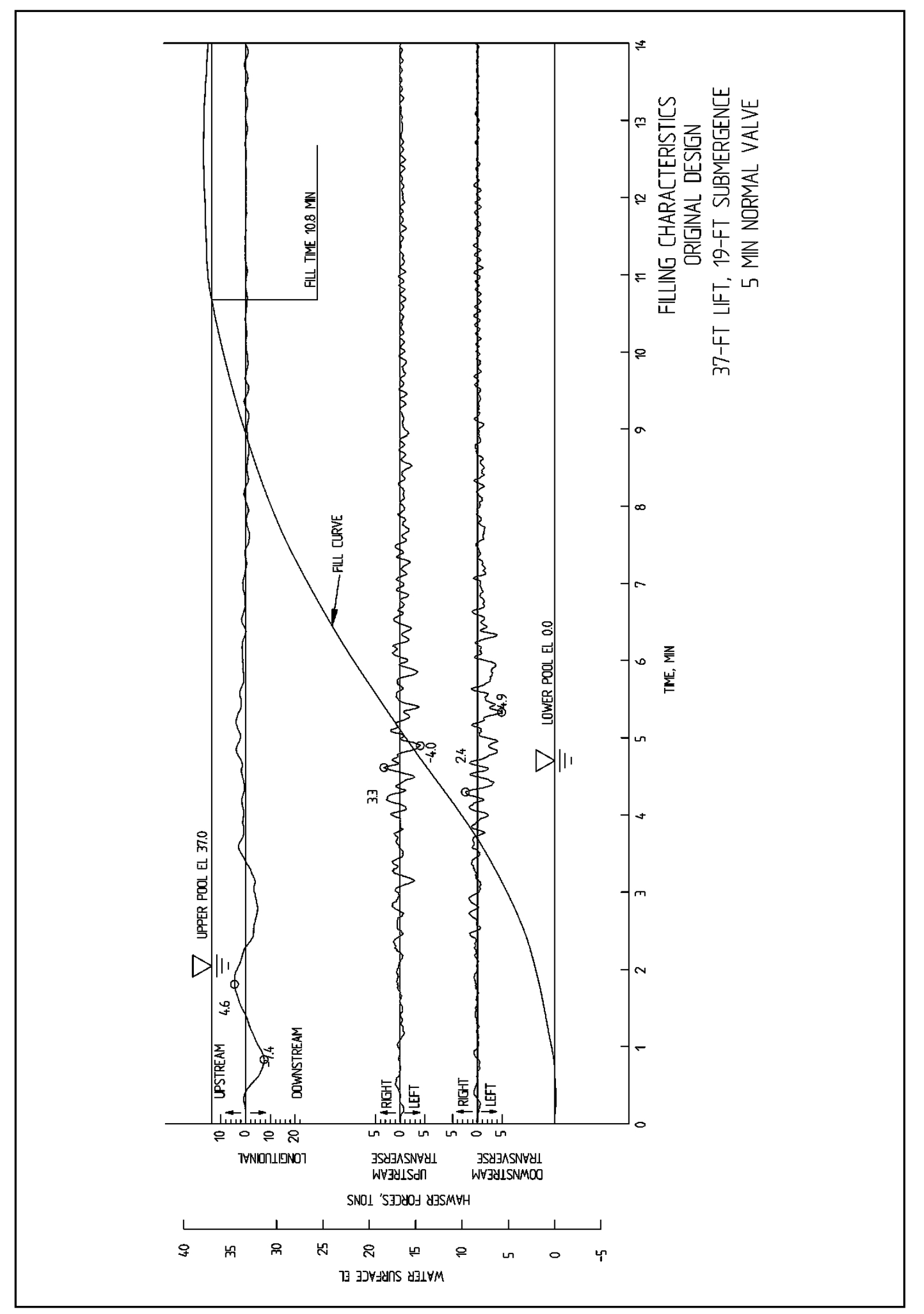

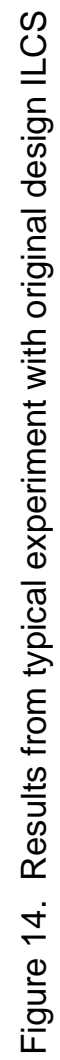


higher than the water surface in the lower end of the chamber. The maximum upstream longitudinal hawser was 4.6 tons and was measured at 2 min into the filling operation. The transverse hawser forces ranged from 2.4 tons (measured on the downstream right side of the chamber) to -4.9 tons on the downstream left side of the chamber. Directions are looking downstream, and the negative sign was assigned to transverse hawser on the left side of the chamber.

In most balanced Corps filling and emptying systems, it is common for the transverse hawser forces to be less than the longitudinal hawser forces during normal valve operations. The hawser results shown in Figure 14 indicate that the downstream longitudinal hawser force is greater than desired for the conditions with the 37-ft lift, 19-ft submergence, and 5-min valve operation.

To determine acceptable filling performance, hawser forces and operation times were measured for lifts between 10 and $40 \mathrm{ft}$, with submergence conditions between 19 and $29 \mathrm{ft}$ for different normal valve schedules. The average maximum forces were determined for these experiments by averaging the maximum hawser forces measured during an individual experiment (such as the one shown in Figure 14). Typically, the average of three experiments was computed. Figure 15 shows these average maximum hawser forces in graphical form for the experiments with lifts between 20 and $40 \mathrm{ft}$ and a 19-ft submergence. Figure 15 was then used to determine the filling times for the various lifts where the average maximum force was 5 tons.

The longitudinal hawser forces were the controlling hawser forces for the 5-ton hawser force for these experiments. For example, to maintain longitudinal hawser forces less than or equal to 5 tons, a filling time of 10.7 min was necessary for a lift of $30 \mathrm{ft}$ with a submergence of $19 \mathrm{ft}$. Figure 16 presents the average maximum hawser forces determined with the 19-ft submergence and lifts of 15 and $10 \mathrm{ft}$.

The average maximum hawser forces determined during filling with a 24-ft submergence and lifts from 10 to $30 \mathrm{ft}$ are shown in Figure 17. The acceptable filling times with this submergence were slightly less than those determined with the 19-ft submergence. Figure 18 shows the average maximum hawser forces determined with a 29-ft submergence and lifts between 10 and $30 \mathrm{ft}$.

\section{Original design emptying experiments}

Emptying experiments were performed in a manner similar to the filling experiments. The average maximum emptying times for lifts between 10 and $40 \mathrm{ft}$ with submergences of 19, 24, and $29 \mathrm{ft}$ are shown in Figures 19-21, respectively. The acceptable filling times were based on the longitudinal hawser forces, and the transverse hawser forces for all conditions observed were much less than 5 tons. 

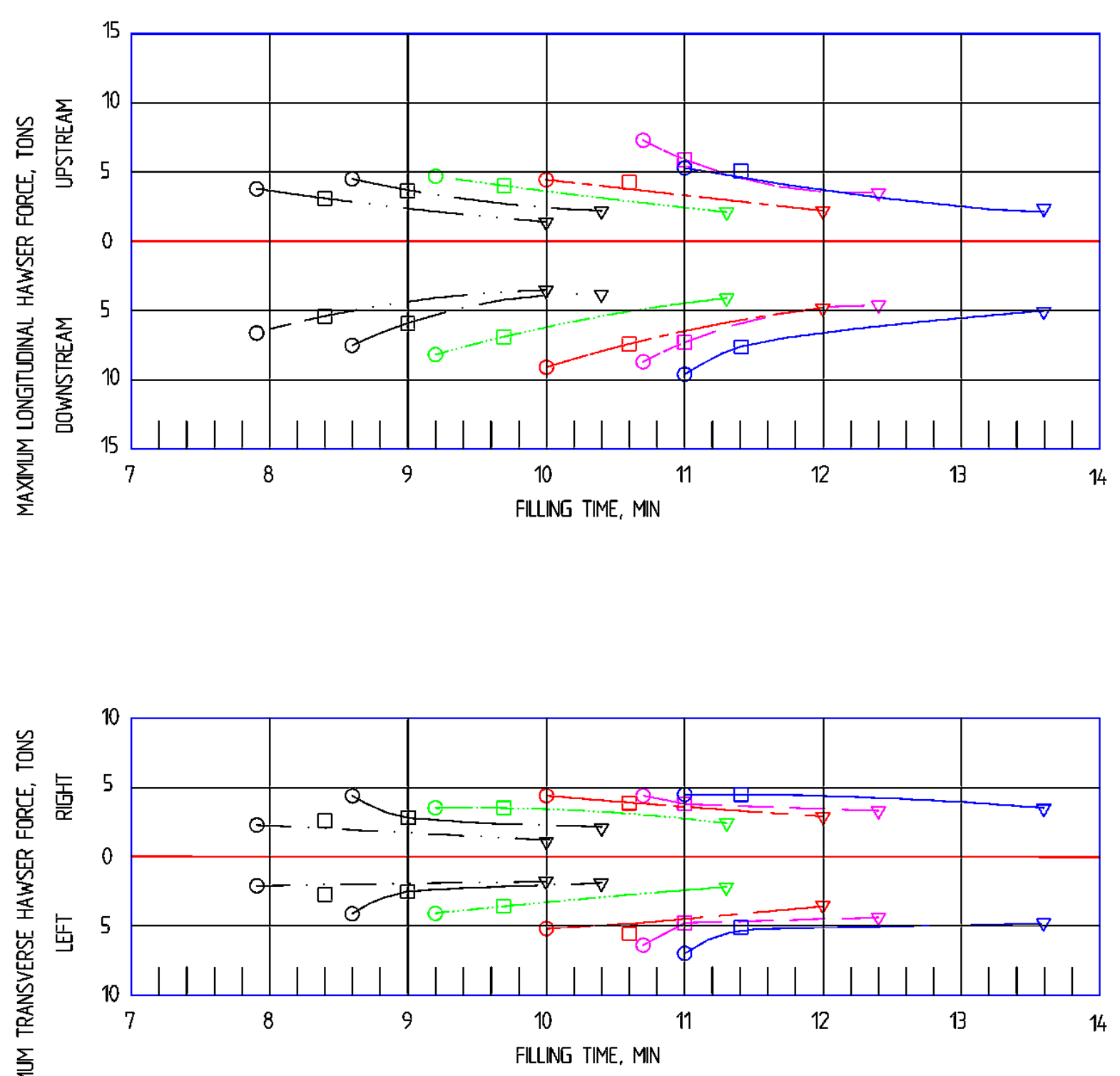

Figure 15. Hawser forces during filling with Original Design ILCS model, lifts between 20 and $40 \mathrm{ft}$ and 19-ft submergence 

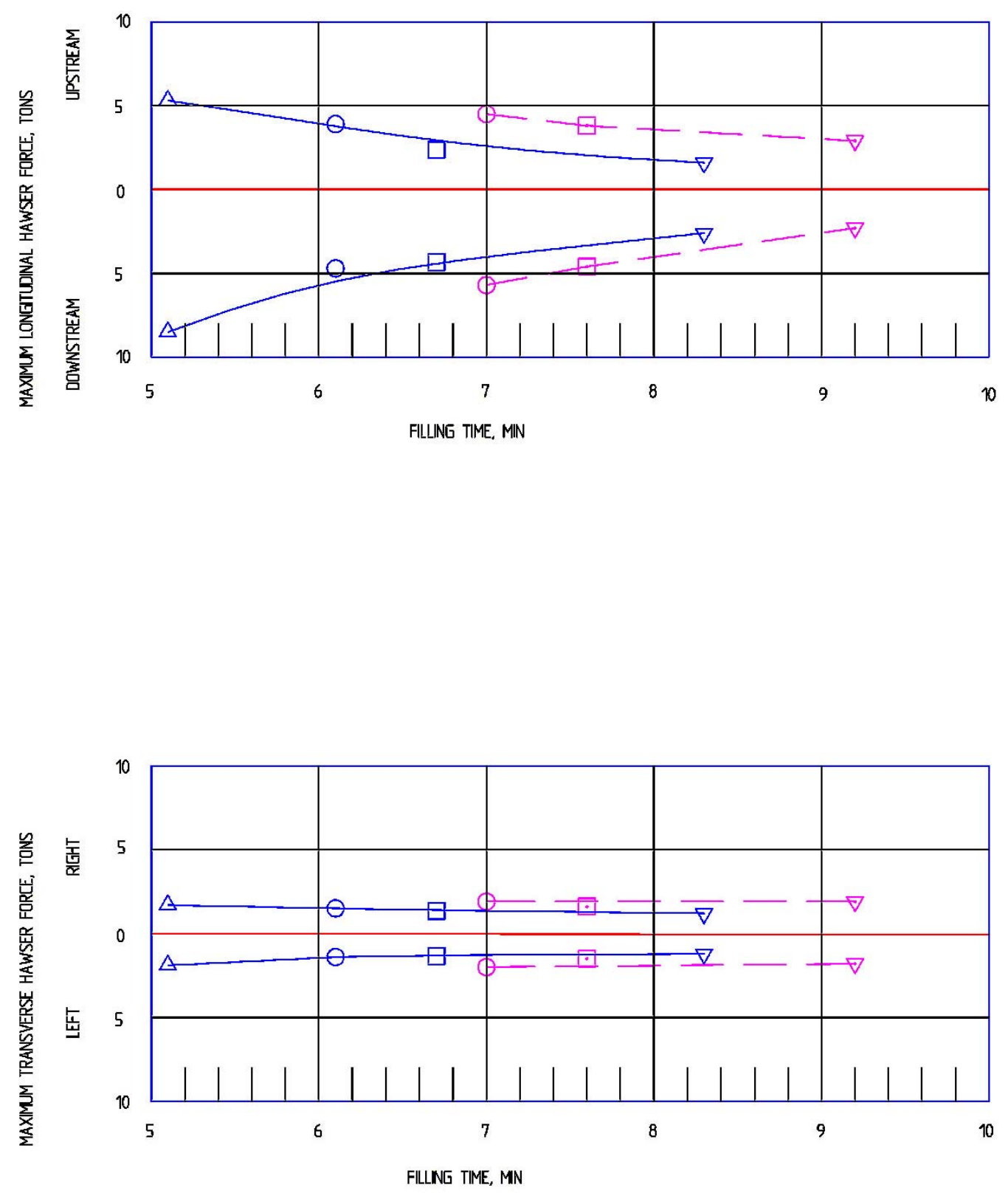

\begin{tabular}{|c|c|}
\hline \multicolumn{2}{|c|}{ LEGEND } \\
\hline SYMBOL & VALVE SCHEDULE, MN \\
\hline$\triangle$ & 2.0 \\
\hline$\bigcirc$ & 4.0 \\
\hline$\square$ & 5.0 \\
\hline$\nabla$ & 8.0 \\
\hline LINETYPE & LIFT, FT \\
\hline- & 10 \\
\hline- & 15 \\
\hline & \\
\hline
\end{tabular}

Figure 16. Hawser forces during filling with Type 2 intake design in ILCS model, lifts of 10 and $15 \mathrm{ft}$ and 19-ft submergence 

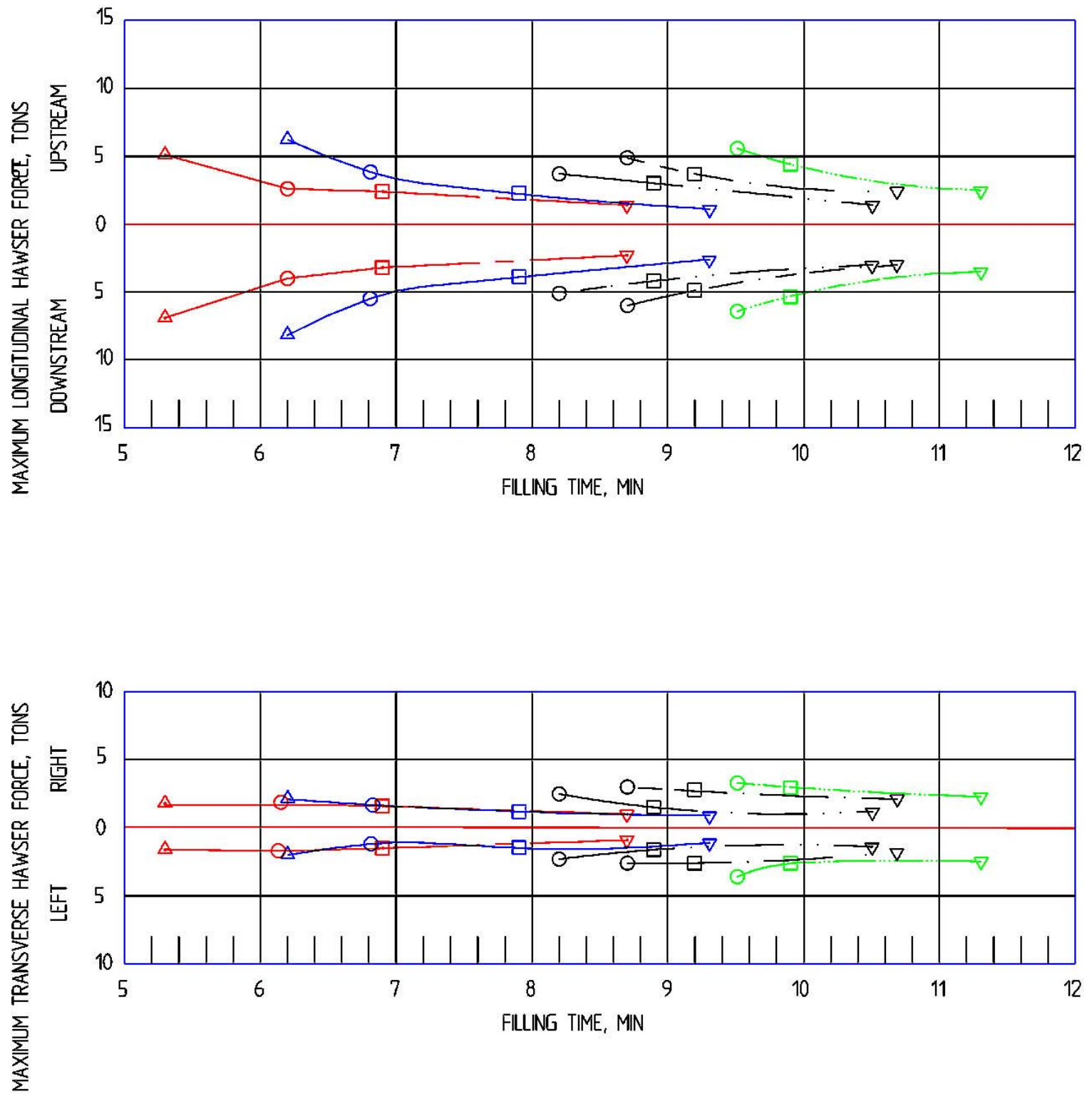

\begin{tabular}{|c|c|}
\hline \multicolumn{2}{|c|}{ LEGEND } \\
\hline SYMBOL & VALVE SCHEDULE, MIN \\
\hline$\Delta$ & 2.0 \\
\hline 0 & 4.0 \\
\hline$\square$ & 5.0 \\
\hline$\nabla$ & 8.0 \\
\hline LINETYYE & LET, FT \\
\hline- & 30 \\
\hline$-\cdots-$ & 25 \\
\hline$-\cdots-$ & 20 \\
\hline \hline--- & 15 \\
\hline-- & 10 \\
\hline
\end{tabular}

Figure 17. Hawser forces during filling with Original Design ILCS model, lifts between 10 and $30 \mathrm{ft}$ and 24-ft submergence 

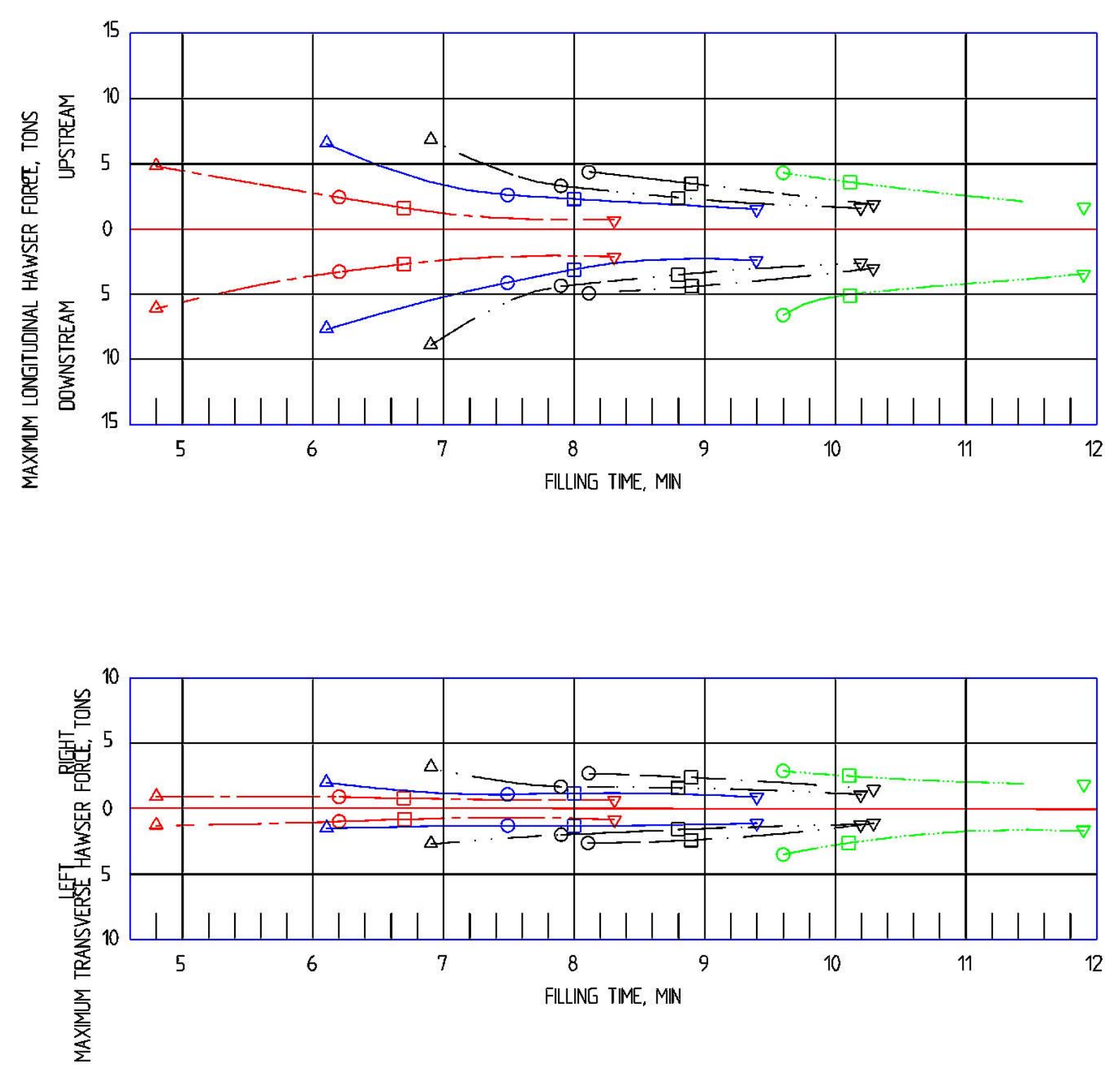

\begin{tabular}{|c|c|}
\hline \multicolumn{2}{|c|}{ LEGENO } \\
\hline SYMBOL & VALVE SCHEDULE, MIN \\
\hline$\triangle$ & 2.0 \\
\hline 0 & 4.0 \\
\hline$\square$ & 5.0 \\
\hline$\nabla$ & 8.0 \\
\hline LINETYPE & LIFT, FT \\
\hline$-\cdots-$ & 30 \\
\hline$-\cdot-\cdot-$ & 25 \\
\hline$-\cdots-$ & 20 \\
\hline- & 15 \\
\hline---- & 10 \\
\hline
\end{tabular}

Figure 18. Hawser forces during filling with Original Design ILCS model, lifts between 10 and $30 \mathrm{ft}$ and 29-ft submergence 

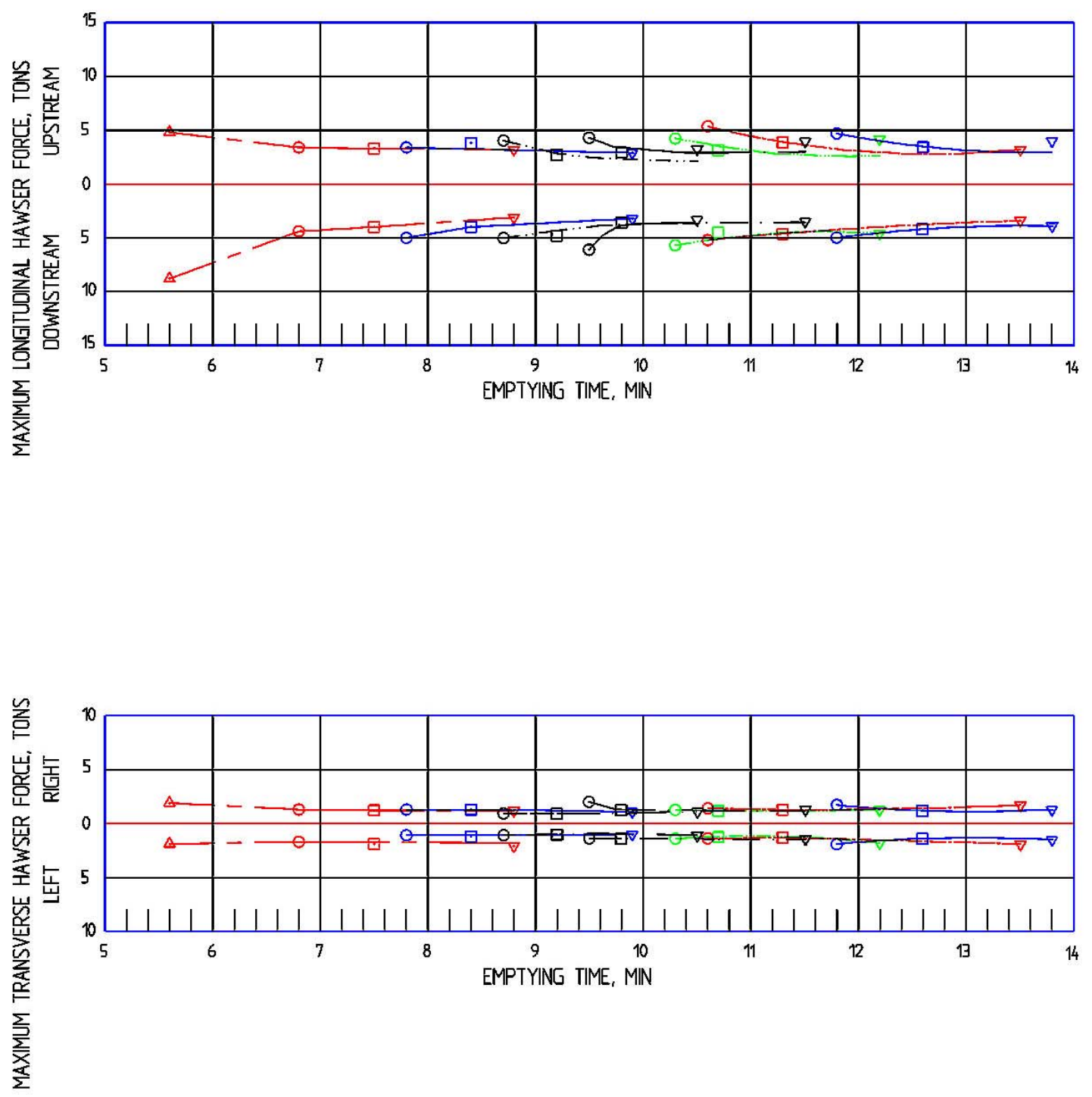

\begin{tabular}{|c|c|}
\hline \multicolumn{2}{|c|}{ LEGEND } \\
\hline SYMBOL & VALVE SCHEDULE, MIN \\
\hline$\Delta$ & 2.0 \\
\hline 0 & 4.0 \\
\hline$\square$ & 5.0 \\
\hline$\nabla$ & 8.0 \\
\hline LINETYPE & LIFT, FT \\
\hline- & 40 \\
\hline$-\cdots-$ & 35 \\
\hline$-\cdots-$ & 30 \\
\hline$-\cdot-\cdot$ & 25 \\
\hline$-\cdots-\cdots-$ & 20 \\
\hline- & 15 \\
\hline---- & 10 \\
\hline
\end{tabular}

Figure 19. Hawser forces during emptying with ILCS model, lifts between 10 and $40 \mathrm{ft}$ and 19-ft submergence 

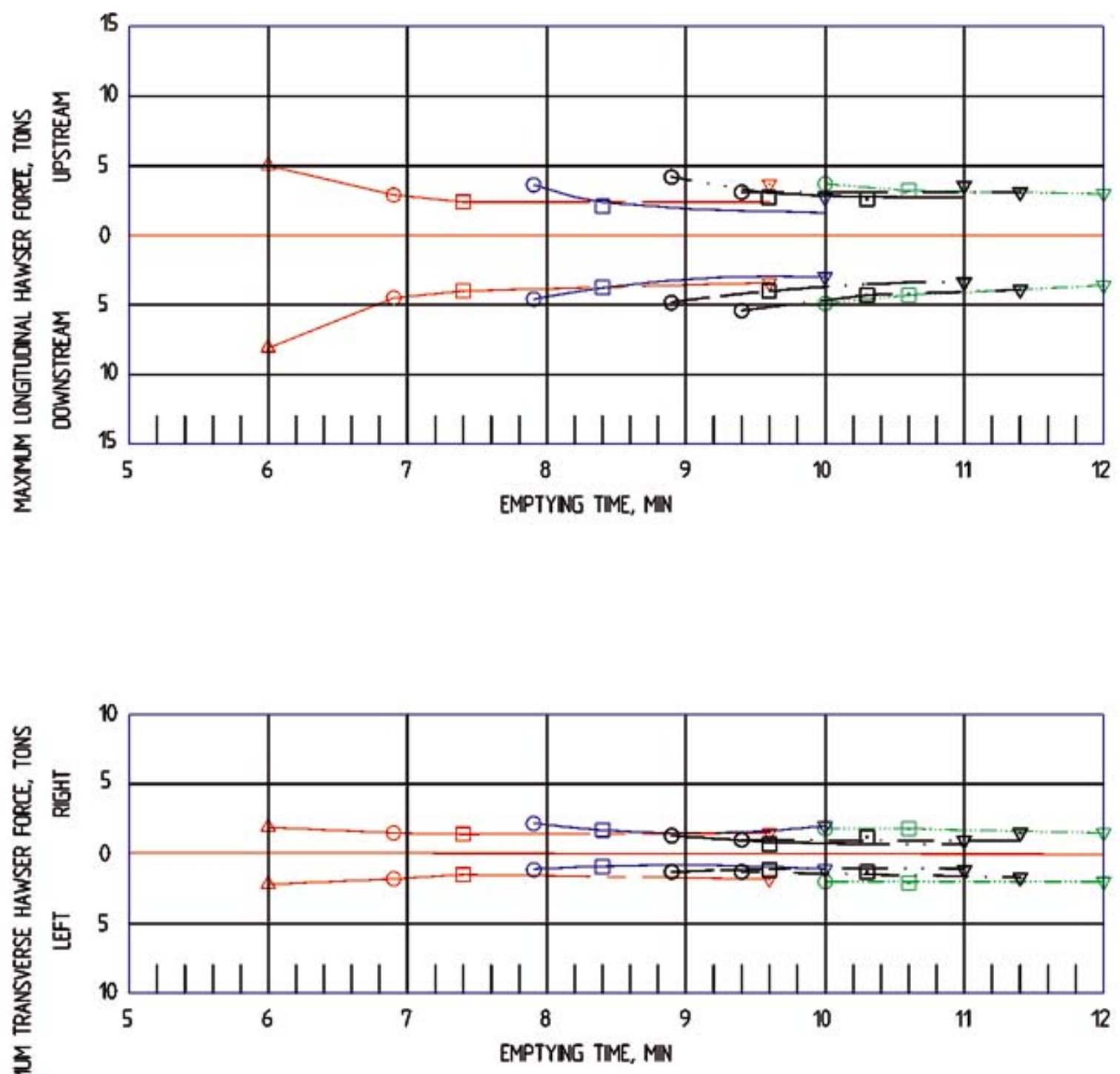

Figure 20. Hawser forces during emptying with ILCS model, lifts between 10 and $30 \mathrm{ft}$ and 24-ft submergence 

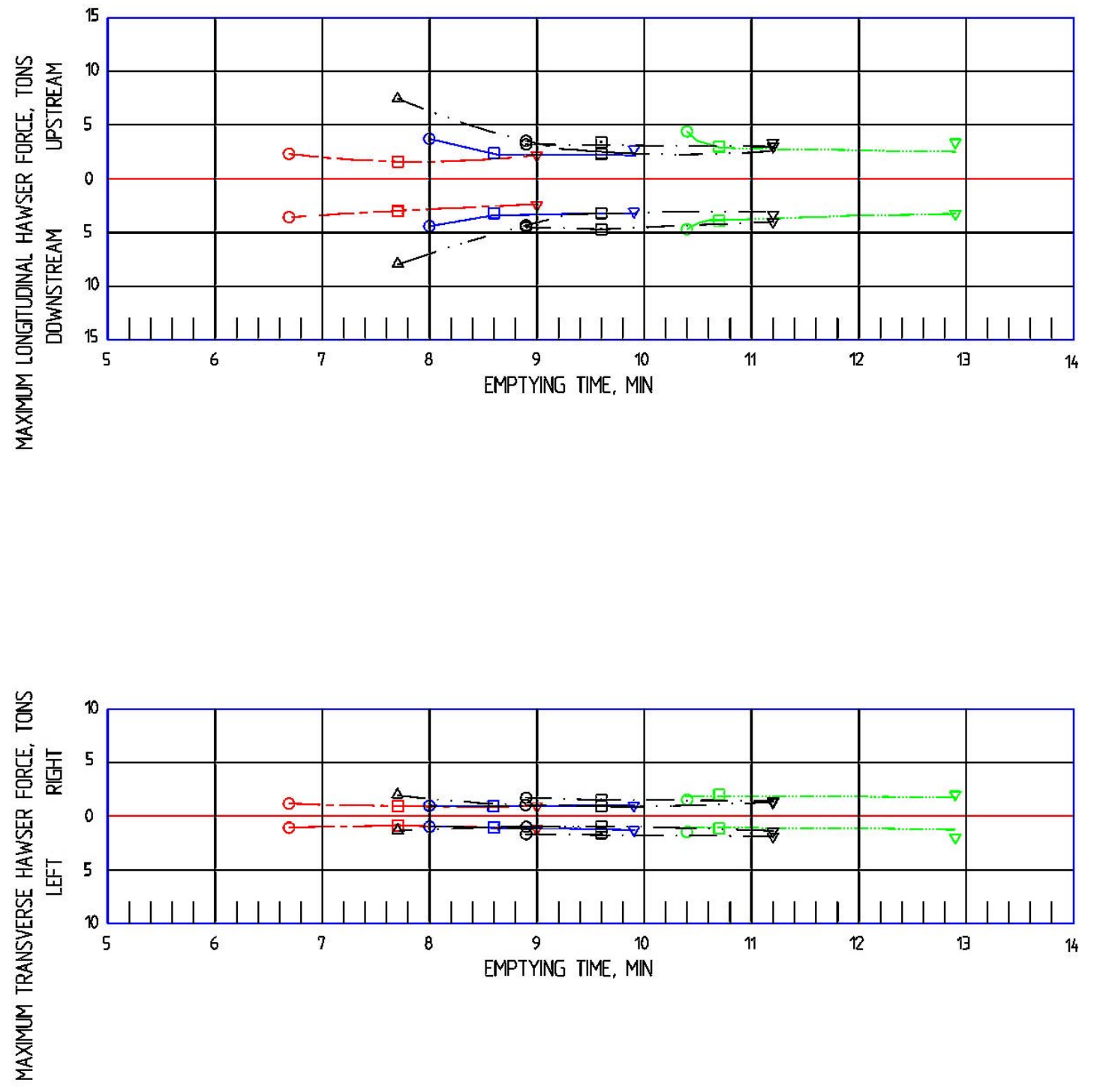

\begin{tabular}{|c|c|}
\hline \multicolumn{2}{|c|}{ LEGEND } \\
\hline SYMBOL & VALVE SCHEDULE, MIN \\
\hline$\Delta$ & 2.0 \\
\hline 0 & 4.0 \\
\hline$\square$ & 5.0 \\
\hline$\nabla$ & 8.0 \\
\hline LINETYPE & LIFT, FT \\
\hline$-\cdots--$ & 30 \\
\hline$-\cdot-\cdot-$ & 25 \\
\hline$\cdots-\cdot-$ & 20 \\
\hline- & 15 \\
\hline--- & 10 \\
\hline
\end{tabular}

Figure 21. Hawser forces during emptying with ILCS model, lifts between 10 and $30 \mathrm{ft}$ and 29-ft submergence 


\section{Original design performance data}

The data from the curves shown in Figures 15-18 were used to develop the performance curves shown in Figure 22. The curves provide the permissible filling times based on the 5-ton hawser force criterion and represent the fastest filling times allowable to maintain hawser forces under 5 tons for the lift and submergence conditions shown.

For example, if a project were being designed for a $20-\mathrm{ft}$ lift with a $24-\mathrm{ft}$ submergence, the fastest filling time determined from the ILCS model data is $8.1 \mathrm{~min}$. As mentioned earlier, this range of lift and submergence values covers those on the Upper Mississippi and Ohio Rivers.

The procedures described above were also used to obtain the performance guidance during emptying operations. The guidance developed for emptying is shown in Figure 23. The ILCS design is slower during emptying compared with filling for lifts up to $30 \mathrm{ft}$. For a 20 -ft lift and 24 -ft submergence, the fastest emptying time to maintain hawser forces of 5 tons or less was determined to be 8.7 min.

The performance of the ILCS compared with conventional side-port filling systems is illustrated in Figure 24. The ILCS is slightly slower compared with the 1,270 - $\mathrm{ft}$ side port, but the overall performance is considered acceptable due to the reduction in construction costs.

\section{Design Guidance for the Hydraulic Features of the ILCS}

The main hydraulic features of the ILCS are the longitudinal culverts, ports, port extensions, and wall baffles. The following general guidance is provided based on information obtained from reviewing previous studies and the research results.

\section{Port size}

The port size was developed based on the smallest practical sizes currently in use for Corps projects with bottom lateral systems. The individual port crosssectional area, $A p_{i}$, for these laterals generally varied from 4 to $5 \mathrm{ft}^{2}$. An important consideration for port sizing is the ability for a person to move in and out of it for maintenance or inspection purposes. A practical port size was found to be $4.4 \mathrm{ft}^{2}$ (1.25 ft wide by $3.5 \mathrm{ft}$ high), based on Stockstill (1998). This port size performed well for the McAlpine Lock models, the Marmet Lock model, and the ILCS research model. It should be noted that the lock widths proposed for all these projects was $110 \mathrm{ft}$. 


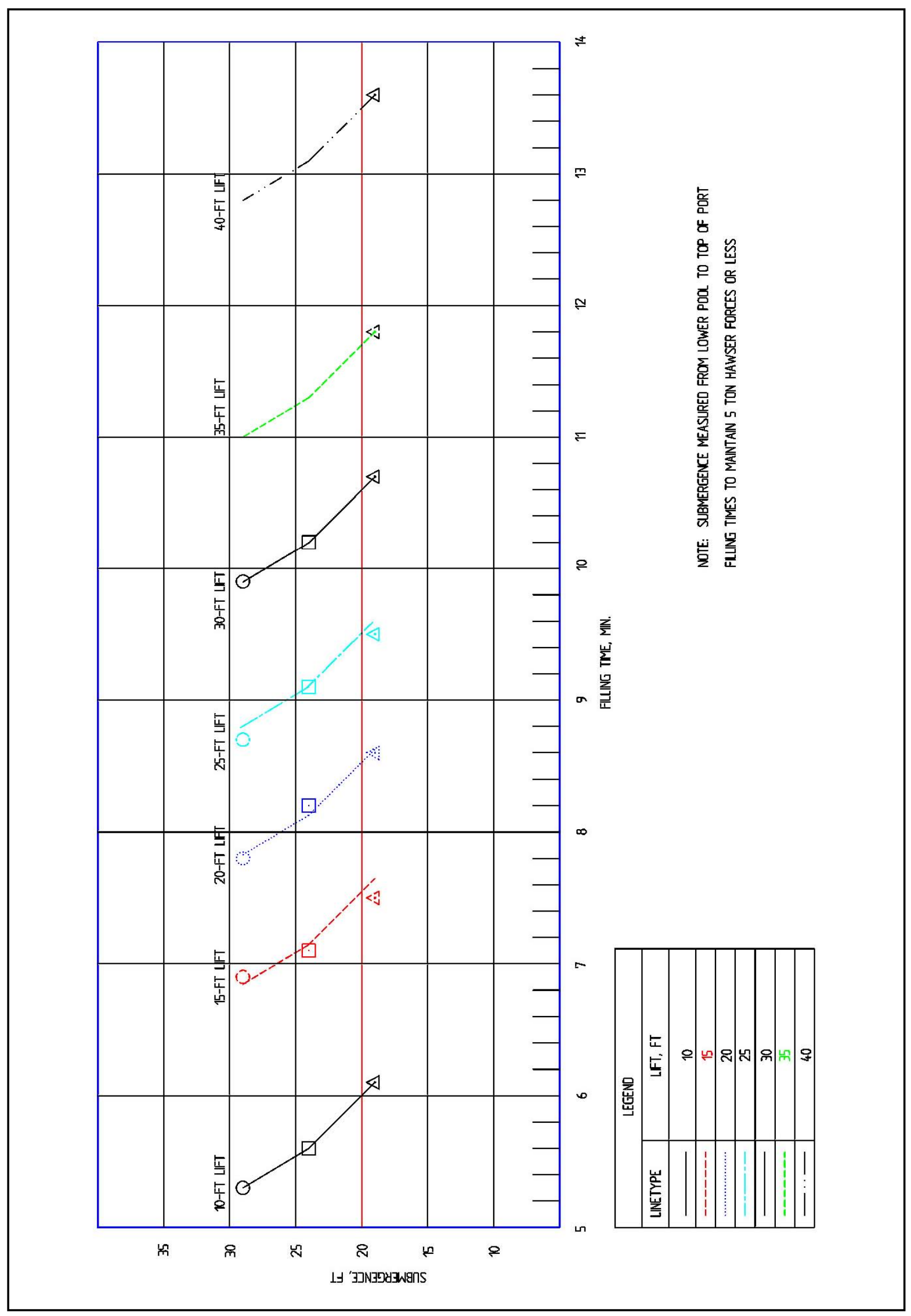

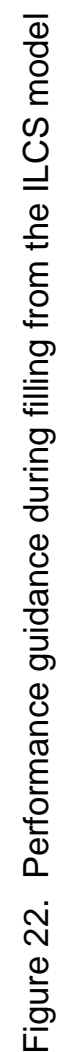




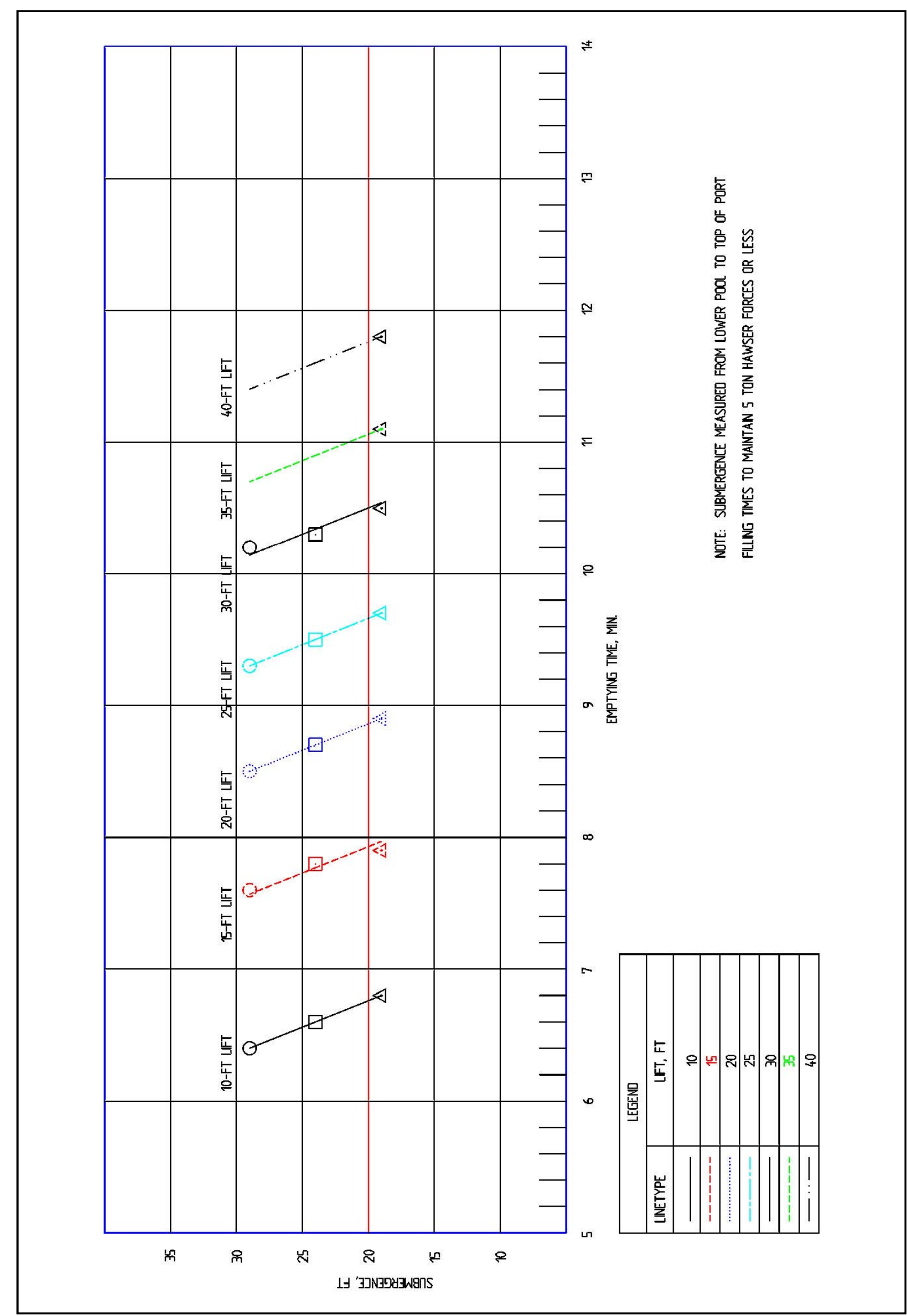

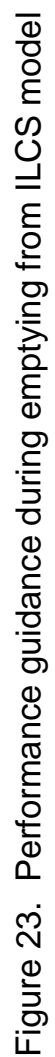




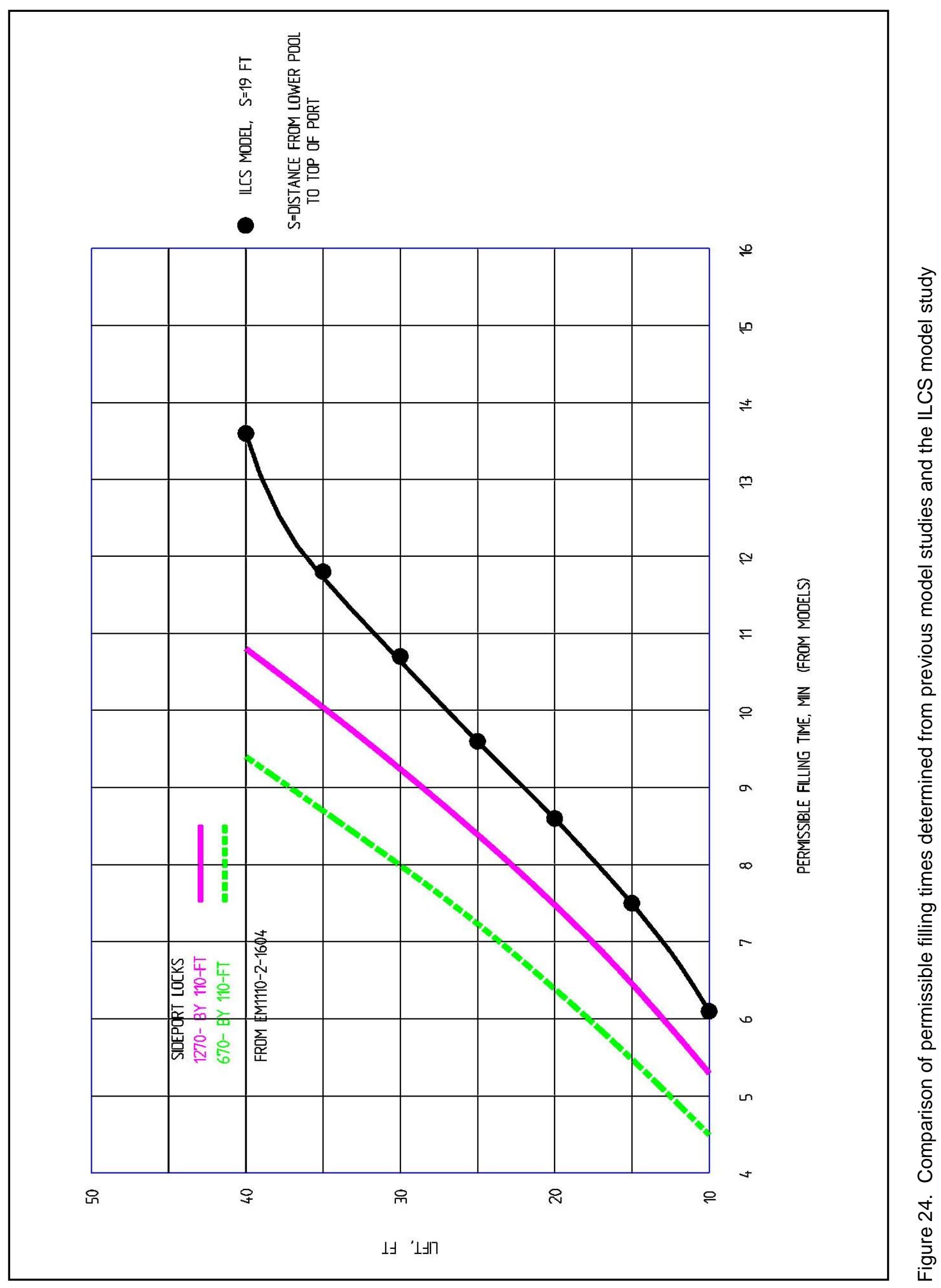




\section{Port spacing}

Port spacing, along with port size, determines the distribution of turbulence within the chamber. For a given lock width, there is a combination of port size and spacing that will result in an optimum distribution of turbulence. The port spacing design was developed based on an analysis of turbulent momentum jets (Albertson et al. 1950). The location of the culverts within the chamber affects the diffusion of the jets discharging from the ports. Good flow conditions within the lock chamber are achieved when the ports are spread out appropriately and when an even distribution of port flow along the culvert occurs. From a construction standpoint, the best location for two culverts within the chamber is placing the center of the culverts near the quarter points (width-wise) of the chamber. This puts the normal distance from the center of the culvert to the wall of the chamber at about $27.5 \mathrm{ft}$ and the distance from the center of one culvert to the center of the other at $55.0 \mathrm{ft}$.

Based on the discharge and geometry of the McAlpine culverts, which were designed for a lift of $37 \mathrm{ft}$, the port spacing determined by Stockstill (1998) from an idealized analysis of the jet was $12.2 \mathrm{ft}$, and a port spacing of $12 \mathrm{ft}$ was used in the study. This spacing provided minimal interaction between the jets and favorable flow conditions in the chamber. Lower lifts and smaller culverts will have farther spacing due to port location along the culvert. Experimental results of chamber performance indicate that the ports should be located within the middle half of the chamber and with half the total number of ports centered about the third points lengthwise of the chamber. Ports on the inside wall of one culvert should be staggered with respect to the ports on the inside wall of the other culvert. The ports on the outside wall of the culvert should be located at the same longitudinal station as the inside ports. The location of the port groupings in the chamber will affect the port spacing as discussed below.

\section{Number and location of ports}

The number of ports for the two-culvert ILCS system depends on the culvert area. Similar to the side-port design, it is recommended that the sum of the port areas in the culvert (sum of $A_{p i}$ ) be equal to or slightly less than the area of the culvert, $A_{c}$. The ratio of port area to culvert area for the ILCS should be between 0.95 and 0.97 . This helps provide flow control at the ports for normal valve operations (no long valve times) and helps reduce flow instabilities. The location of the ports was studied extensively by Stockstill (1998). The recommended location was to begin the upstream port grouping at a distance equivalent to 0.26 the pintle-to-pintle length of the chamber from the upstream pintle. The downstream port in the downstream port grouping should also be located between 0.26 and 0.27 the pintle-to-pintle length of the chamber from the downstream pintle. The center of the port grouping should be located at nearly the one-third points of the chamber. It is important that the distance from the upstream port to the downstream port be approximately 50 percent of the chamber length to avoid high hawsers for a tow that does not occupy the entire chamber. A schematic showing a plan view of the port location is presented as Figure 25. 


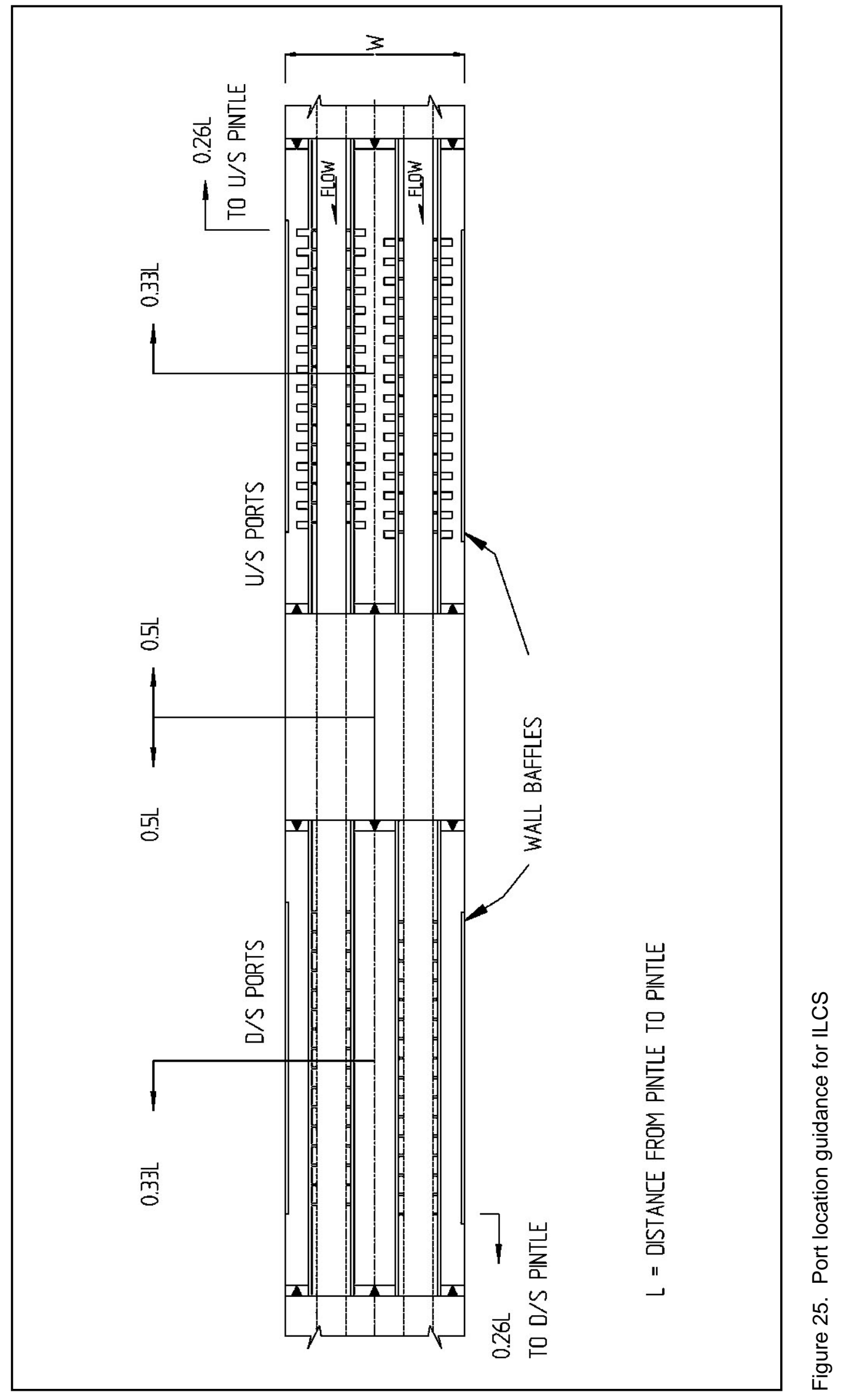




\section{Port extensions}

Port extensions are needed on the upstream port group to help direct the jet flow normal to the lock center line. This helps distribute the flow more evenly in the upper end of the chamber and provides a more balanced flow over the entire length of the chamber. Inertia effects during filling cause flow to enter the chamber through the most upstream ports and then to start through the other ports in the downstream direction. The water surface in the upper end of the chamber rises, resulting in a tilt. An oscillation sets up, which continues throughout the filling operation. Near peak flows and shortly thereafter, there is a tendency for more flow to discharge from the downstream ports, resulting in another tilt in the water surface, this time with the downstream water surface higher than the upstream water surface. This tilt develops more slowly and occurs over a longer period of time. This tilt can result in upstream flow near the water surface. The goal for a filling and emptying design is to balance the distribution of flow into the chamber and avoid excessive tilts in the water surface and strong surface currents.

Port extensions on the upper ports direct the flow toward the center of the chamber, as illustrated in Figure 26, which helps distribute the flow more evenly. The thickness of the ports in the ILCS design depends on the culvert thickness, which is generally less than desired for good hydraulic performance. A port thickness of $8 \mathrm{ft}$ (minimum) is recommended for the side-port system. The culvert wall thickness for an ILCS will probably be from 2 to $3 \mathrm{ft}$, and this thickness will cause the jet to have more of a downstream component than desired during filling (Figure 26). A 9-ft-long port extension was used for the McAlpine Lock, and an 8.5-ft-thick port extension was used for the Marmet Lock. A port extension length equal to 0.5 times the culvert width $\left(C_{w}\right)$ is recommended. A schematic of the port extensions is shown in Figures 27 and 28.

\section{Roof overhang}

A roof overhang of at least $2 \mathrm{ft}$ is recommended for the ports, and this length is included in the port extension length for the ports requiring extensions. The jets discharging from ports located at the top of the culvert have a vertical component, which the roof overhang helps to redirect laterally. A sectional view of the roof overhang is shown as Figure 27.

\section{Wall baffles}

A wall baffle is recommended for the ILCS to help diffuse the port jets near the lock floor and prevent flow from upwelling along the lock walls. The baffle is simply a horizontal shelf that protrudes out from the lock walls in the areas where the ports are located, as shown in Figures 27 and 28. A 3-ft-wide baffle is recommended and should be placed at the same elevation as the top of the longitudinal culvert. 


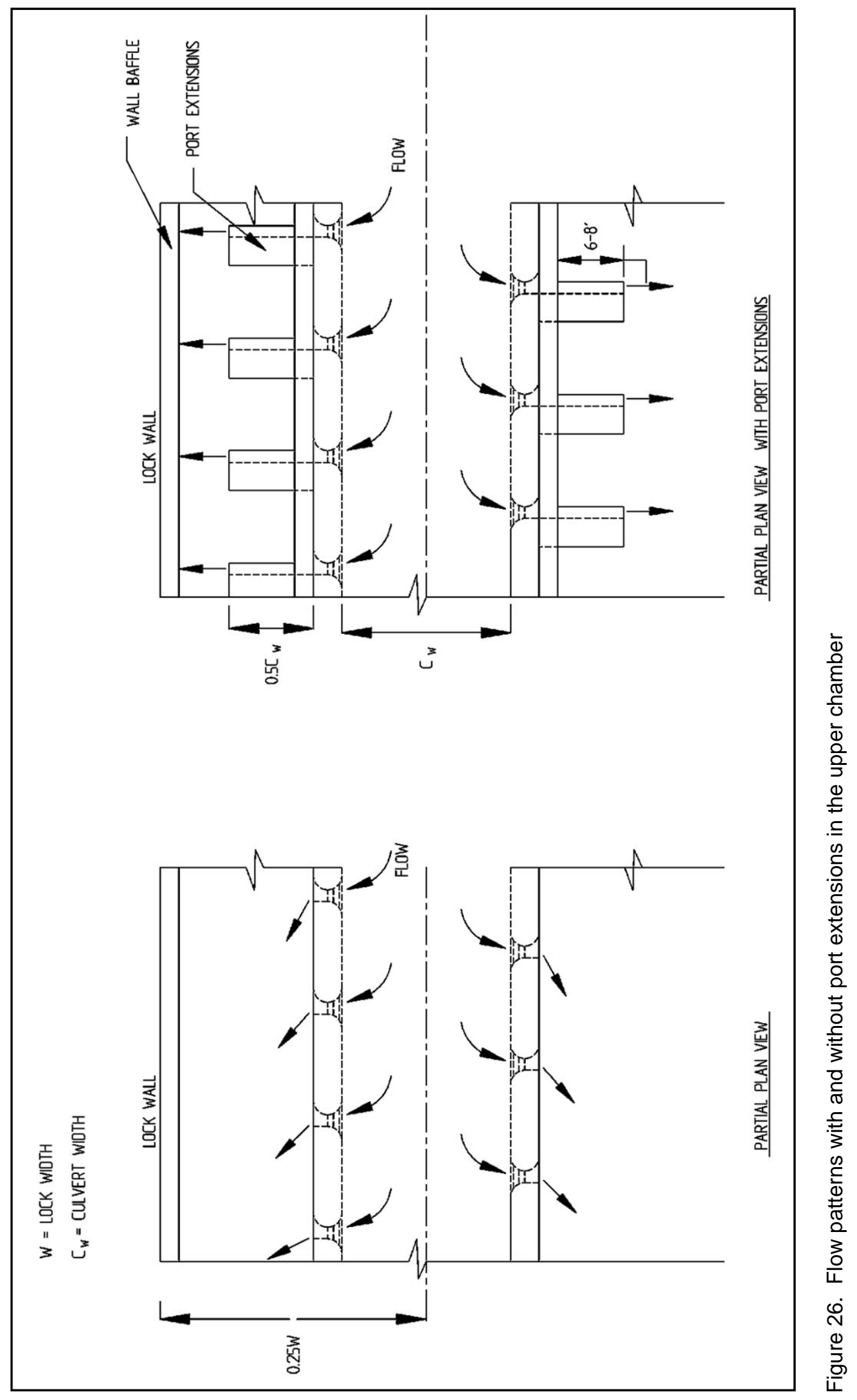




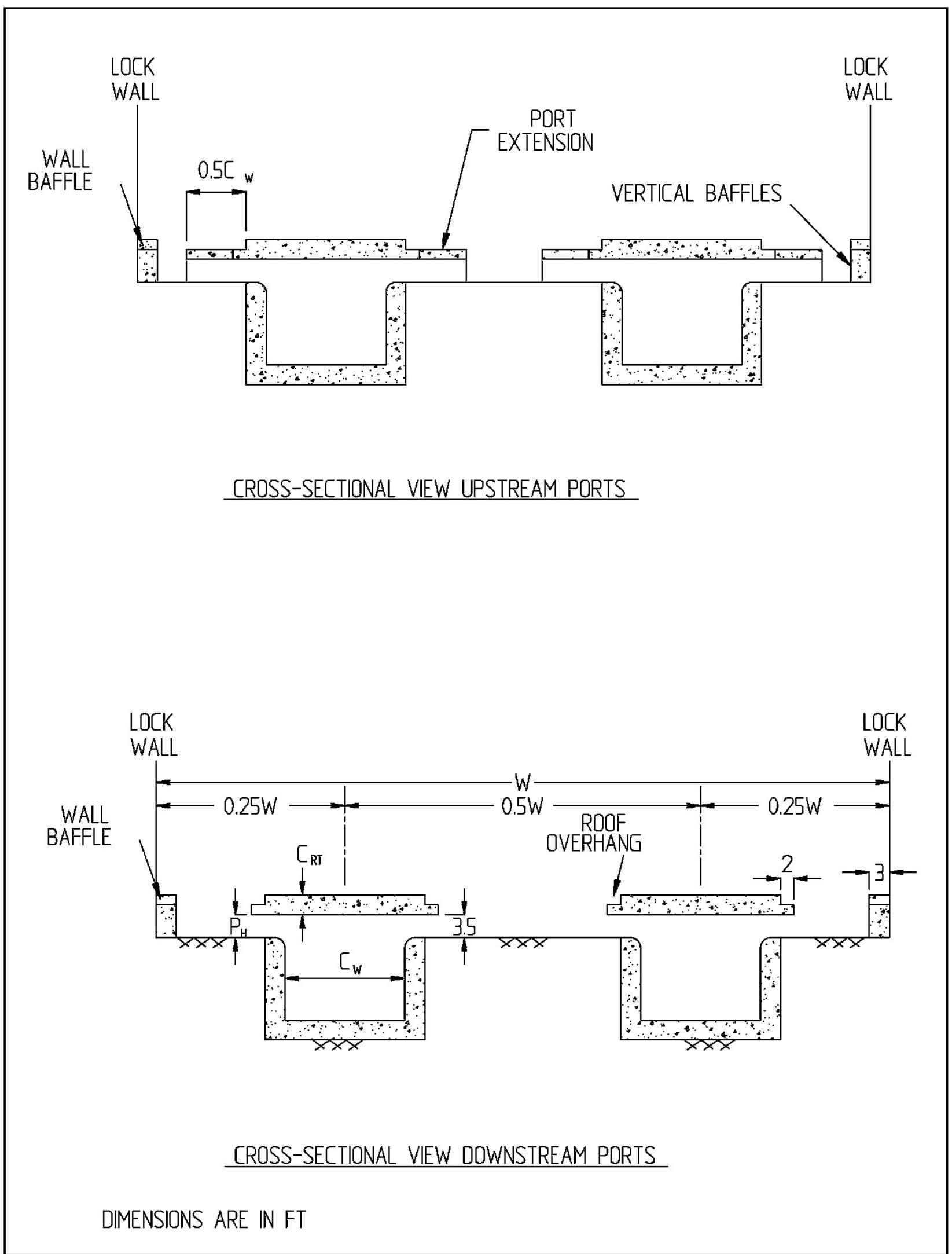

Figure 27. Cross-sectional view of ILCS ports 


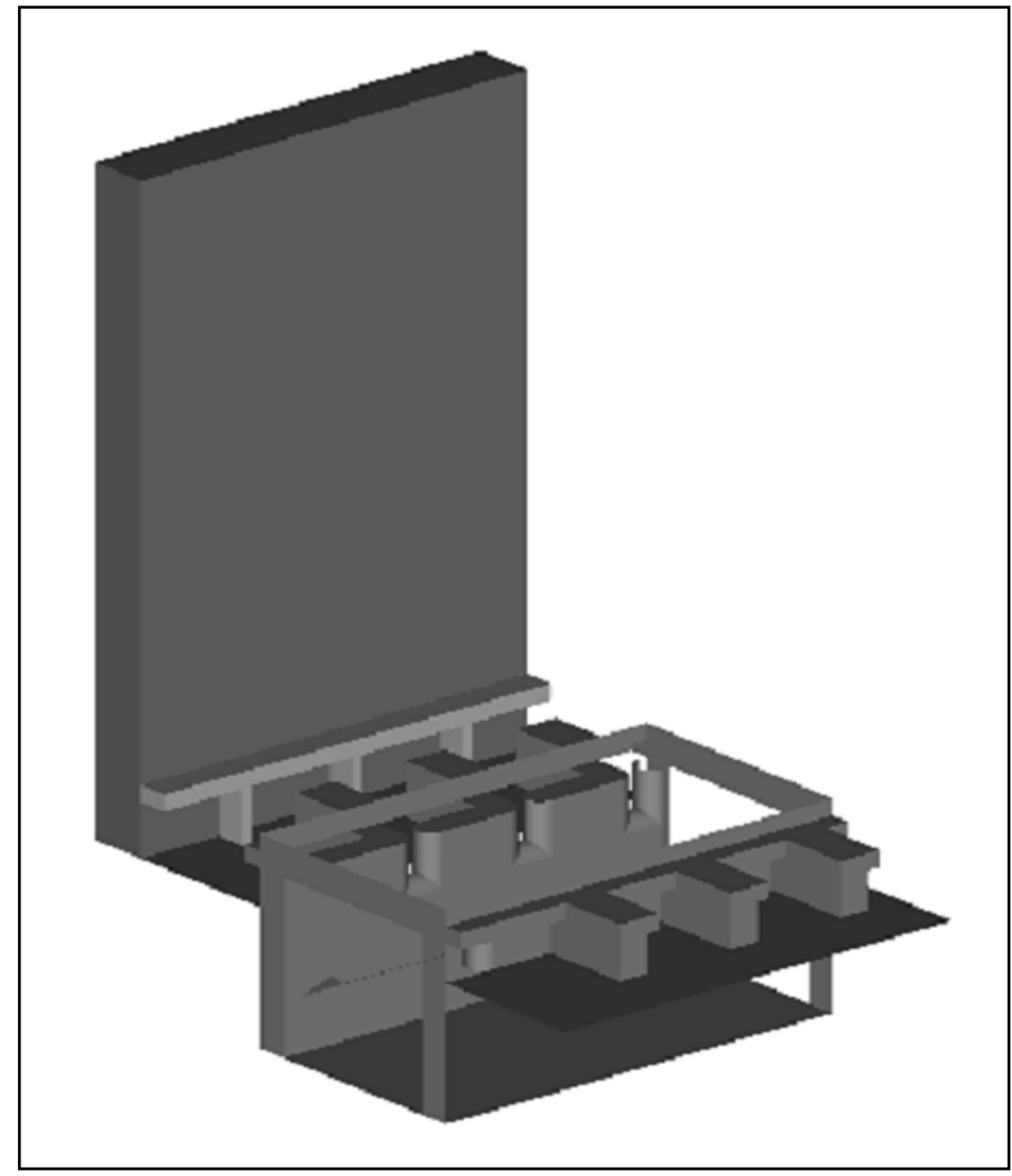

Figure 28. Partial view of port extensions

Vertical baffles underneath the wall baffles are also recommended to aid in energy dissipation and to enhance the structural support of the wall baffle. The vertical baffles should be located along the lock walls halfway between the ports and at a distance of one half the port spacing upstream and downstream from the first and last ports, respectively.

\section{Valve operations}

Acceptable filling times and chamber performance for the ILCS have been achieved with normal valve speeds from 4 to $8 \mathrm{~min}$. The performance of the ILCS is sensitive to valve operation, and valve speeds faster than 4 min are not desirable, especially for lifts over $15 \mathrm{ft}$. Fast valve operations cause excessive downstream hawsers shortly after the valve is opened, indicating the water 
surface in the upper end of the lock is higher than that in the lower end. This is inherent in a longitudinal culvert system where flow enters at the upstream end of the chamber. Single-valve operations require very slow speeds to avoid excessive hawser forces. During single-valve operations, the barges in the chamber will be pushed to the side of the chamber where the valve is in operation. Valve type and operation will be discussed in more detail in subsequent sections.

\section{Modified ILCS Operation and Design}

\section{Single-valve experiments}

Experiments were performed to evaluate the chamber performance with single-valve operations. This operation would occur if one of the culvert filling valves is out of operation or if maintenance in the culvert is necessary. Results from a typical experiment to determine the lock performance during filling with a 37-ft lift and left (10-min) single-valve operation are shown in Figure 29. The fill curve indicates the lock reached the upper pool elevation in $21.3 \mathrm{~min}$. The maximum downstream longitudinal hawser was 2.7 tons and was measured at $1 \mathrm{~min}$ into the filling operation; the maximum upstream longitudinal hawser was 2.2 tons, measured at 9 min into the filling operation. The maximum transverse hawser forces ranged from 0.7 ton, measured on the upstream right side of the chamber, to 8.0 tons on the upstream left side of the chamber. The filling time was $21.3 \mathrm{~min}$.

In most Corps filling and emptying systems, it is common for the transverse hawser forces to be less than the longitudinal hawser forces during normal valve operations. The hawser results shown in Figure 29 indicate that the transverse hawser forces are larger than the longitudinal hawser forces for single-valve operations. The time-histories showed that the left transverse forces, both upstream and downstream, were the largest hawser forces with the left singlevalve operation. The maximum upstream left transverse hawser force, 8.0 tons, was higher than the maximum left downstream hawser force, 4.6 tons. Filling characteristics observed with the right single valve were similar to the left side. The transverse hawser forces were larger than the longitudinal hawser forces, and the right transverse forces were the highest hawser forces.

The experiments with single-valve operations indicated that the transverse hawser forces were higher than the longitudinal forces, and slow valve speeds were necessary to maintain hawser forces of 5 tons or less inside the chamber. The transverse hawser forces on the side that the single valve operated were the highest forces measured during filling. The filling time required to maintain hawser forces of 5 tons or less with the 37-ft lift and a single-valve operation was 24 min, as interpolated from Figure 30. The valve opening time that produced a filling time of 24 min was between 13 and $14 \mathrm{~min}$. The filling time to maintain hawser forces of 5 tons or less for normal valve operations with a 37-ft lift was $12.2 \mathrm{~min}$, and the valve opening time that produced a filling time of $12.2 \mathrm{~min}$ for normal valves and a $37-\mathrm{ft}$ lift was $7.5 \mathrm{~min}$. The valve-opening and filling times that provided acceptable forces in the chamber with single-valve operations were 


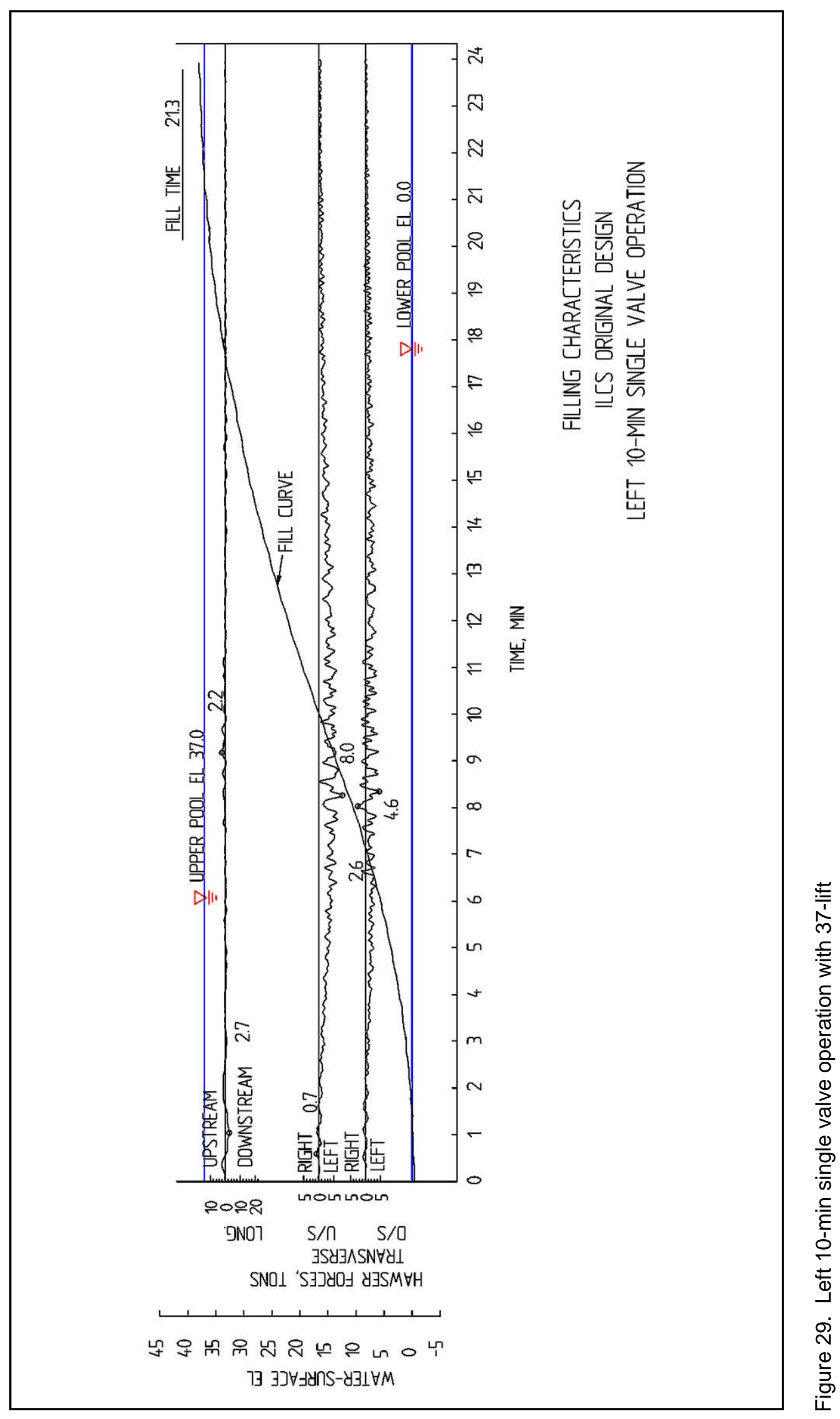



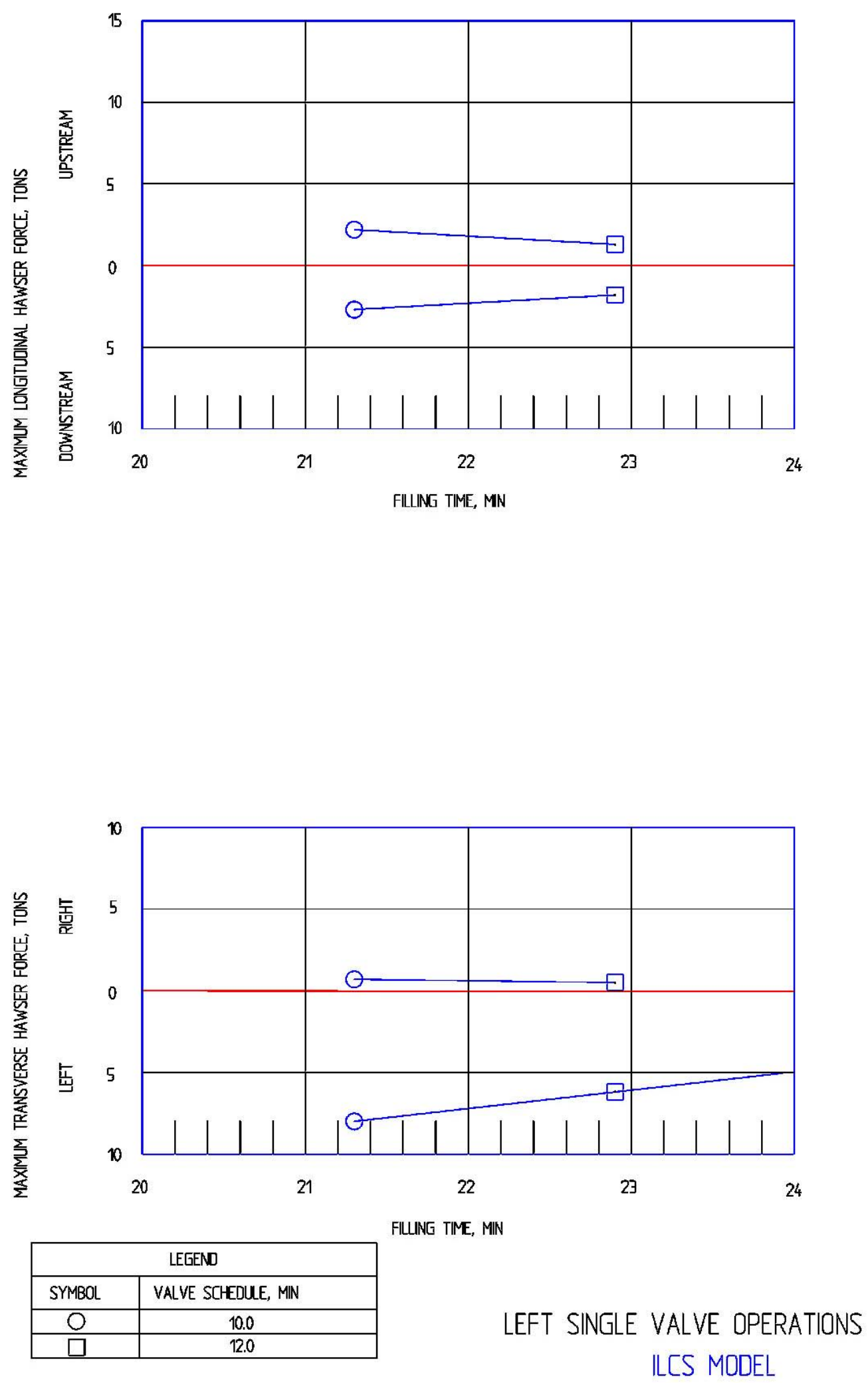

Figure 30. Hawser forces determined with left single valve operation and 37-ft lift and 19-ft submergence 
approximately twice those required with normal valves. The controlling hawser forces for acceptable chamber performance were the longitudinal hawser forces with the normal valve operation and the transverse hawser forces with the singlevalve operations.

\section{Intake designs}

The effect of intake location on the ILCS was evaluated for three different intake locations. The first location was with the intake located at the face of the upper miter gate sill, as shown in Figure 31. This intake consisted of four rectangular intakes $12 \mathrm{ft}$ wide by $12 \mathrm{ft}$ high. Butterfly valves of the same dimensions were mounted on the face of the intakes to control flow. This design was designated the sill intake. The second location represented more conventional intake designs, as shown in Figure 32. The left intake was face-mounted along the left lock wall, and the right intake was mounted in a semicircular fashion in the right approach wall. This design was designated the normal intake design. The third location was similar to the normal intakes in plan view; however, both intakes were lowered $16 \mathrm{ft}$. This design was designated the Type 2 intake design.

Typical time-histories of the three intake designs with a 37-ft lift and 5-min valve operation are shown in Figures 33-35. Essentially no difference was observed in the filling characteristics between the normal and Type 2 intake designs. The maximum downstream longitudinal hawser forces occurred at just less than 1 min into the filling operation, and the maximum transverse hawser forces occurred at about the same time the valves were fully open. The filling times were nearly the same (10.8 and $11 \mathrm{~min})$, which suggests that the head losses through the intakes for these two designs during filling were similar. The filling time with the sill-mounted design was not much different from the other two designs, indicating that the total head losses from the upper pool to the manifold throughout the filling cycle were nearly the same.

The hawser forces (both longitudinal and transverse) were lower with the sill-mounted design than the other two designs. This was due more to the valve characteristics than the intake location. The valve-opening curves used for these experiments are shown in Figure 36. The reverse tainter valve opens faster at the initial portion of the operation than the butterfly valve. With a fast normal valve operation, the amount of flow entering the chamber caused high downstream longitudinal hawser forces. Due to the geometry of the butterfly valve, the amount of flow entering the chamber during the initial portion was less than the reverse tainter valve, and resulted in the lower longitudinal hawser forces shown in Figure 33.

The average maximum hawser forces determined for the three intake locations and the 37-ft lift are shown in Figure 37. The results from the experiments indicate that with the intakes at the upper miter sill with butterfly valves, the filling time to maintain hawser forces of 5 tons or less was faster (10.8 min) compared with the normal and Type 2 intakes (12 min). These filling times were determined from the downstream longitudinal hawser forces. This difference was attributed 


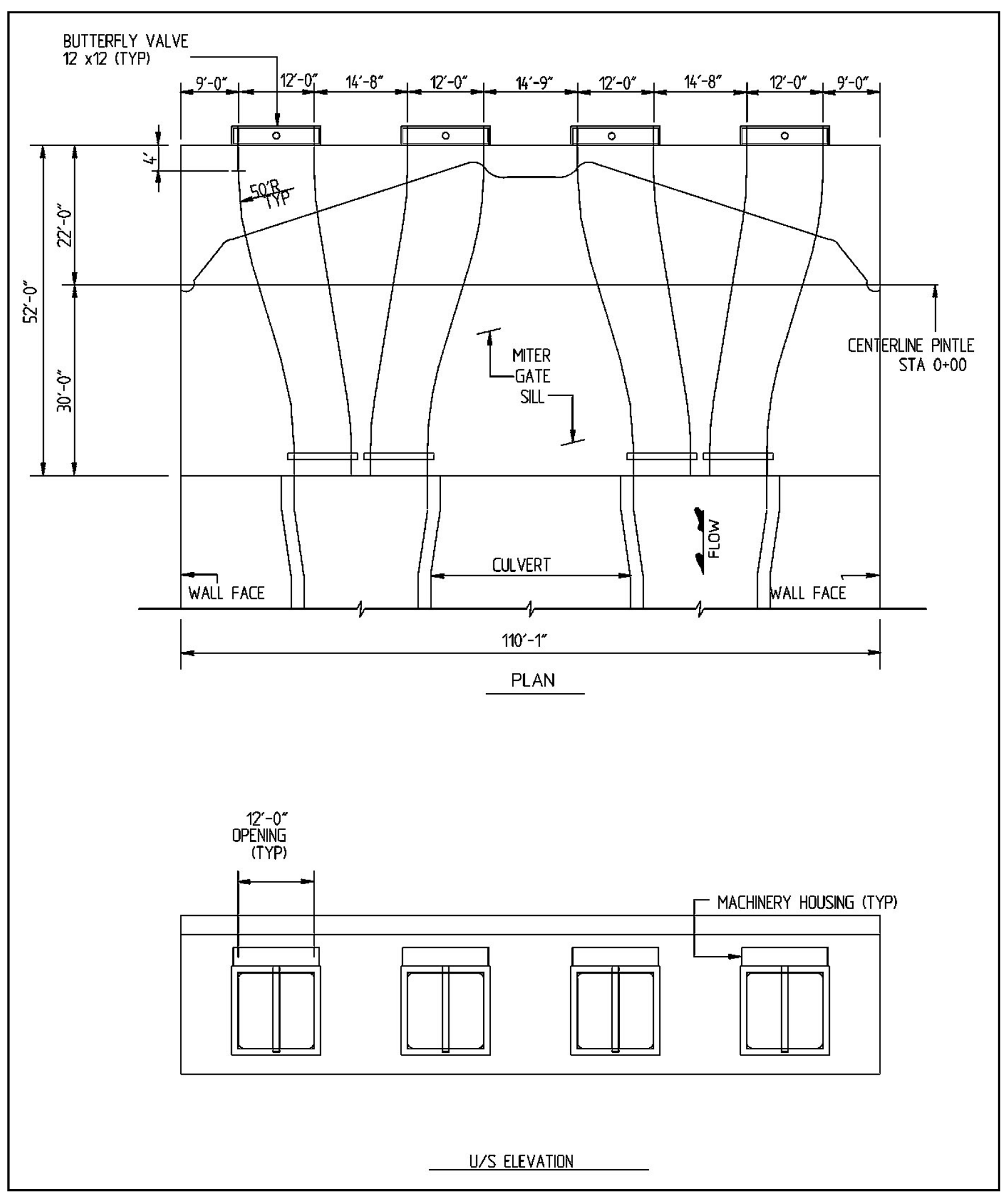

Figure 31. Views of intake located at upper miter sill 


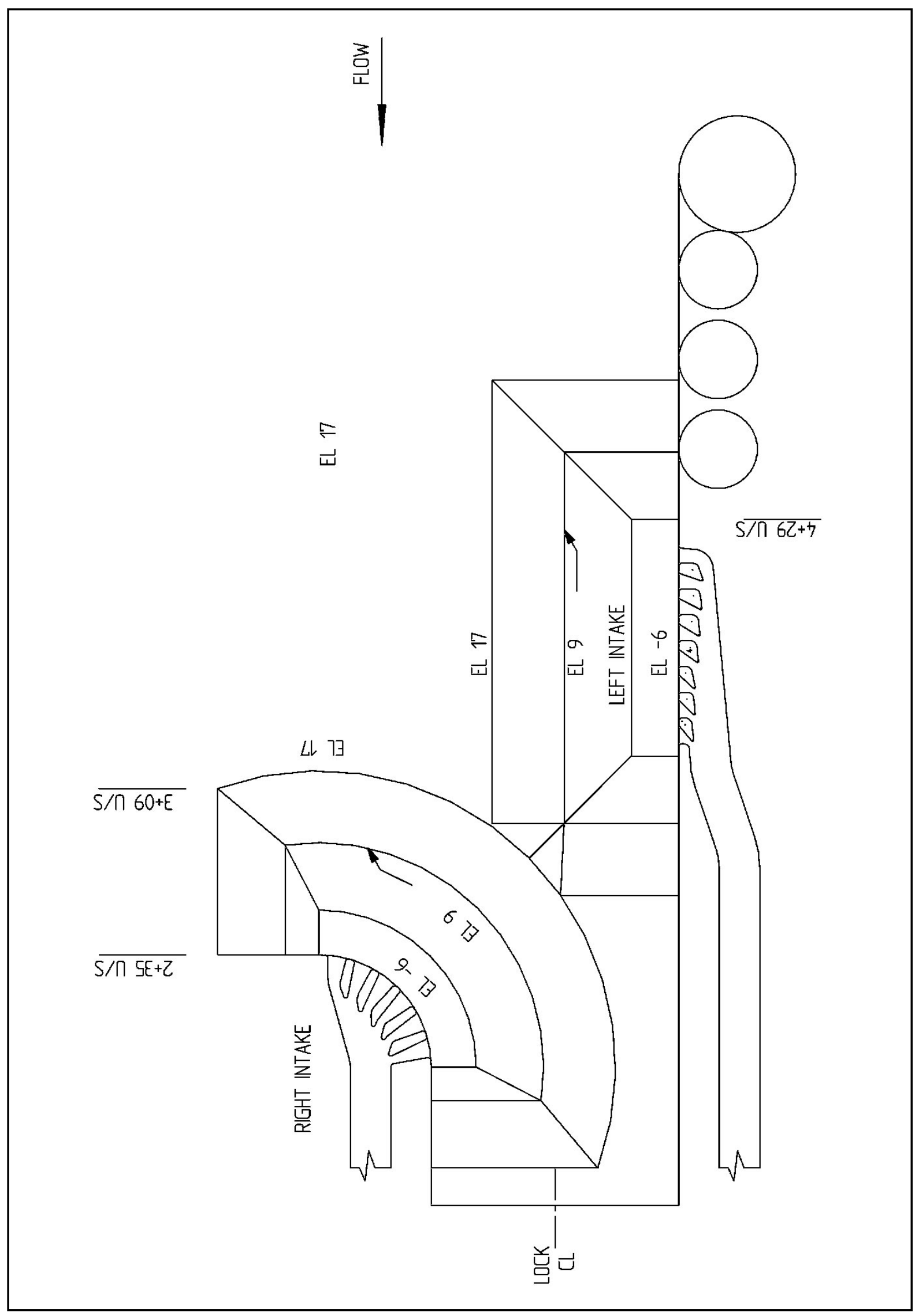

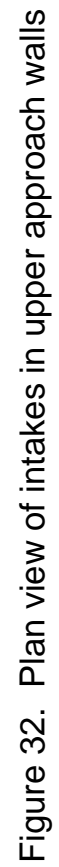




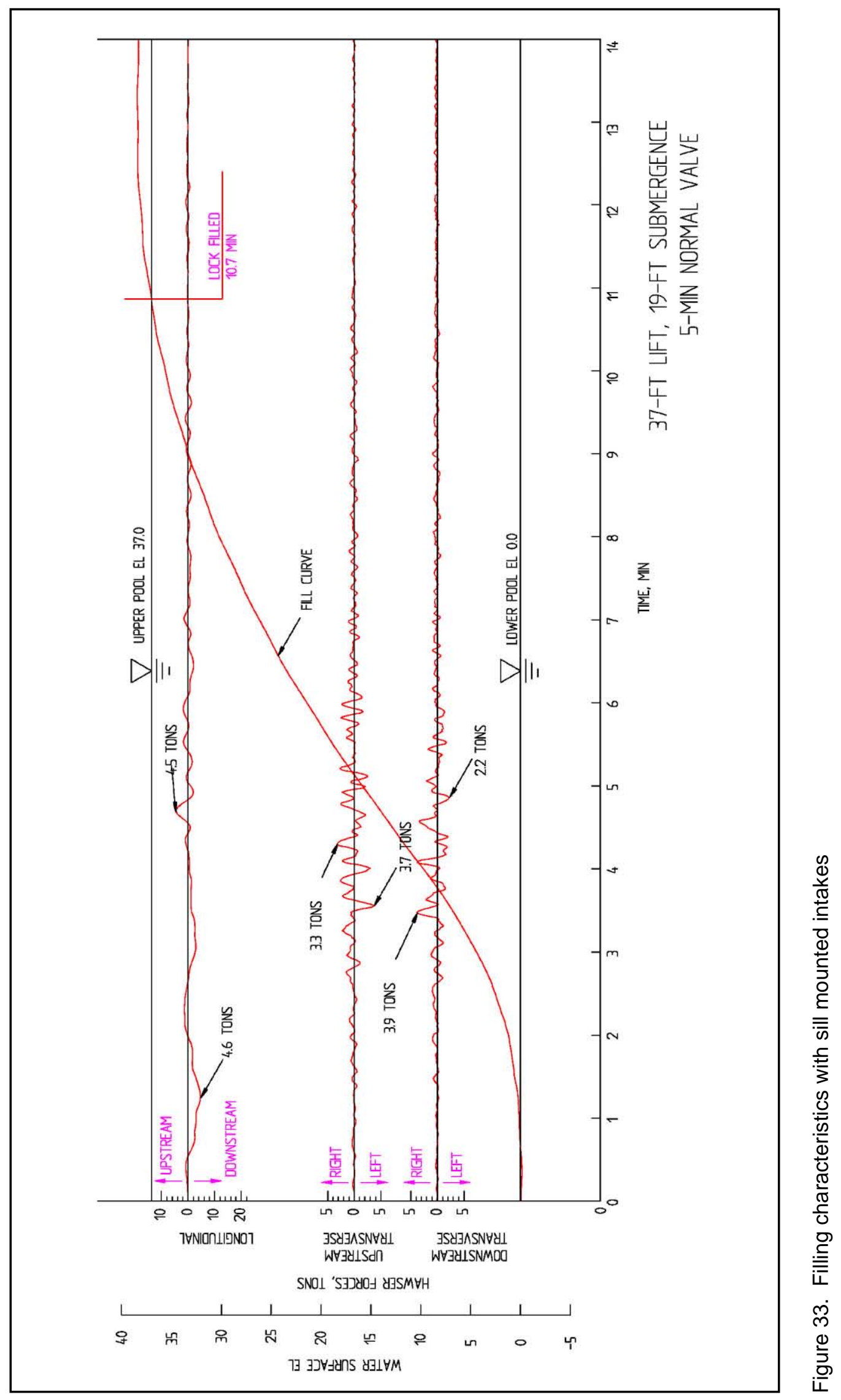




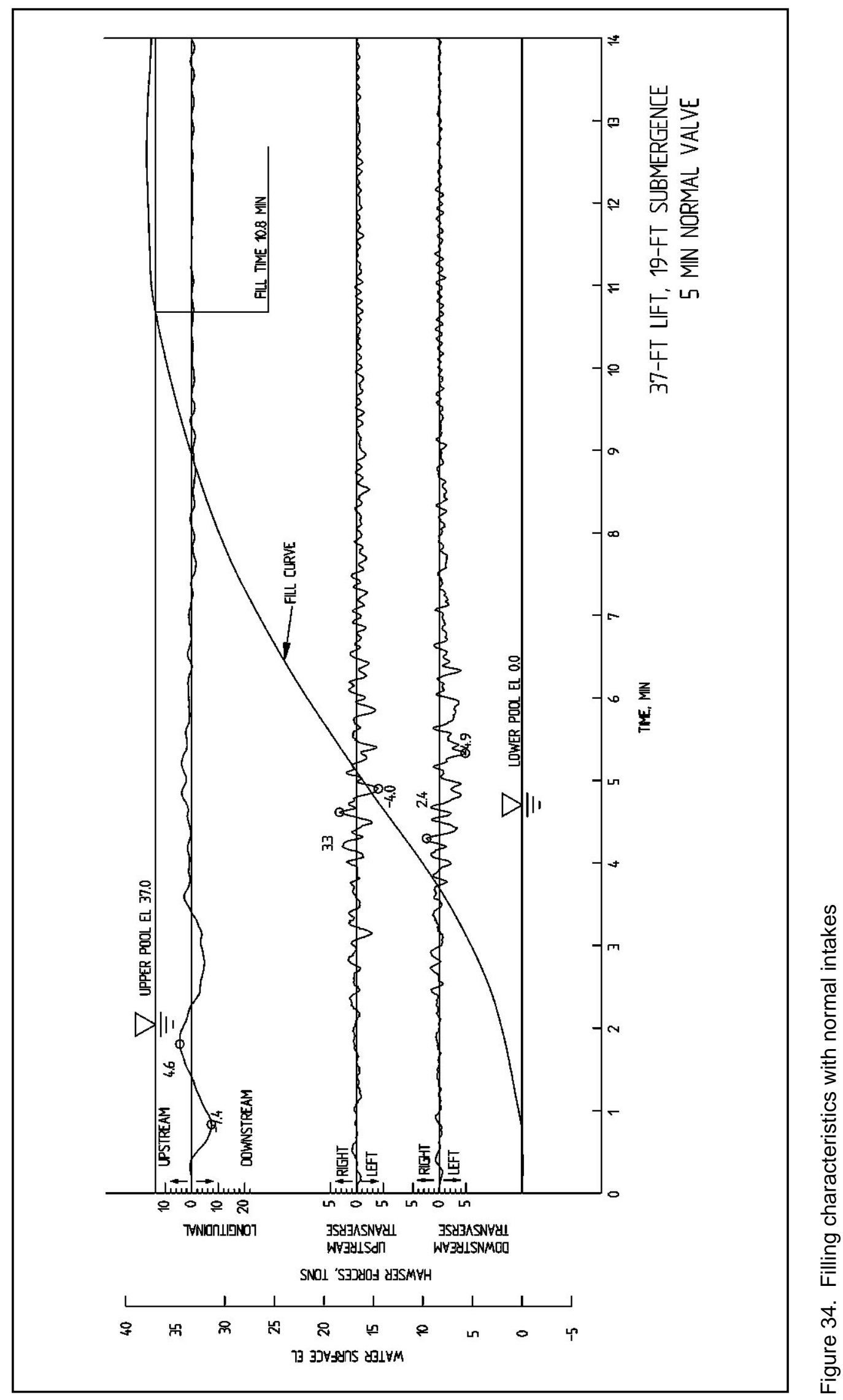




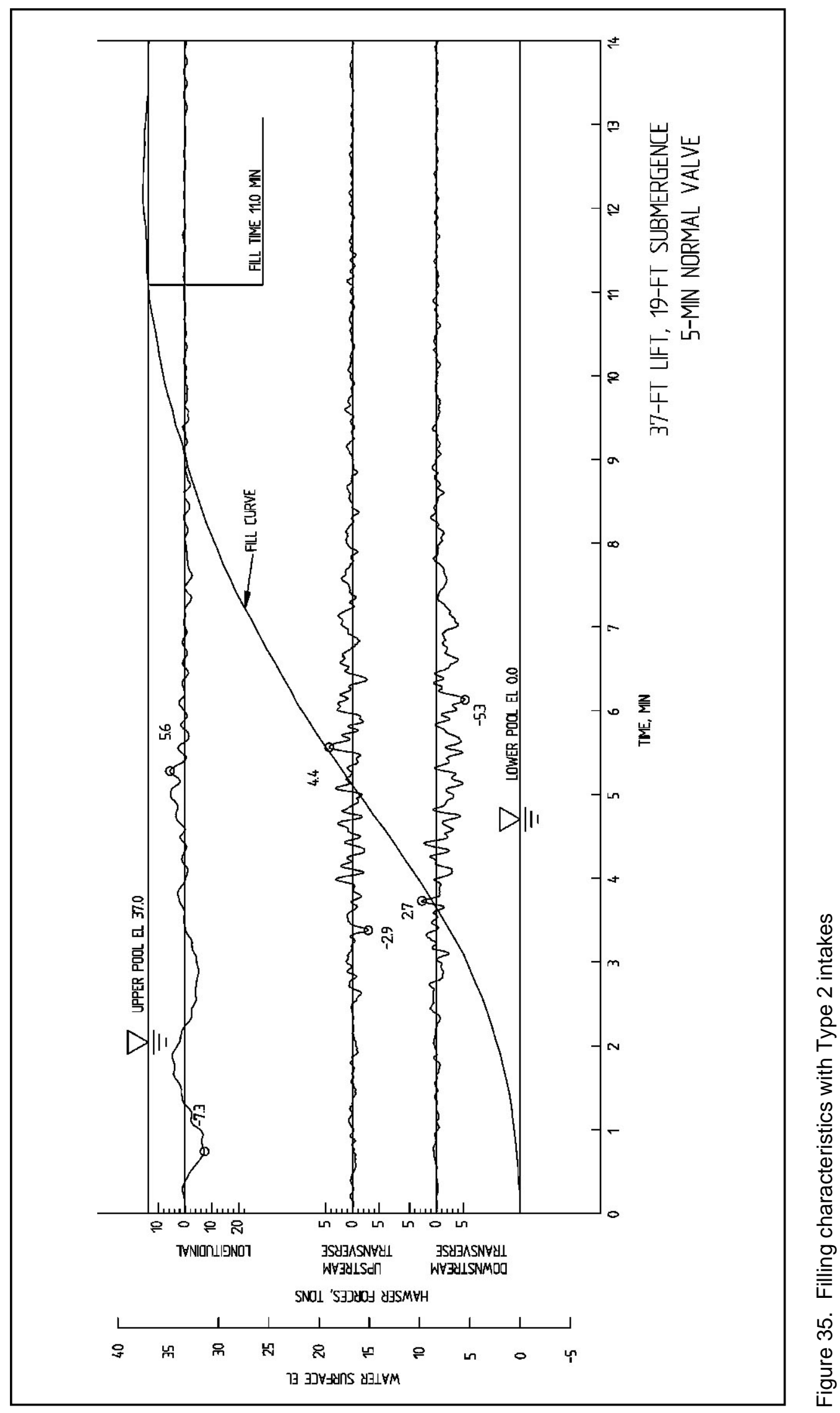



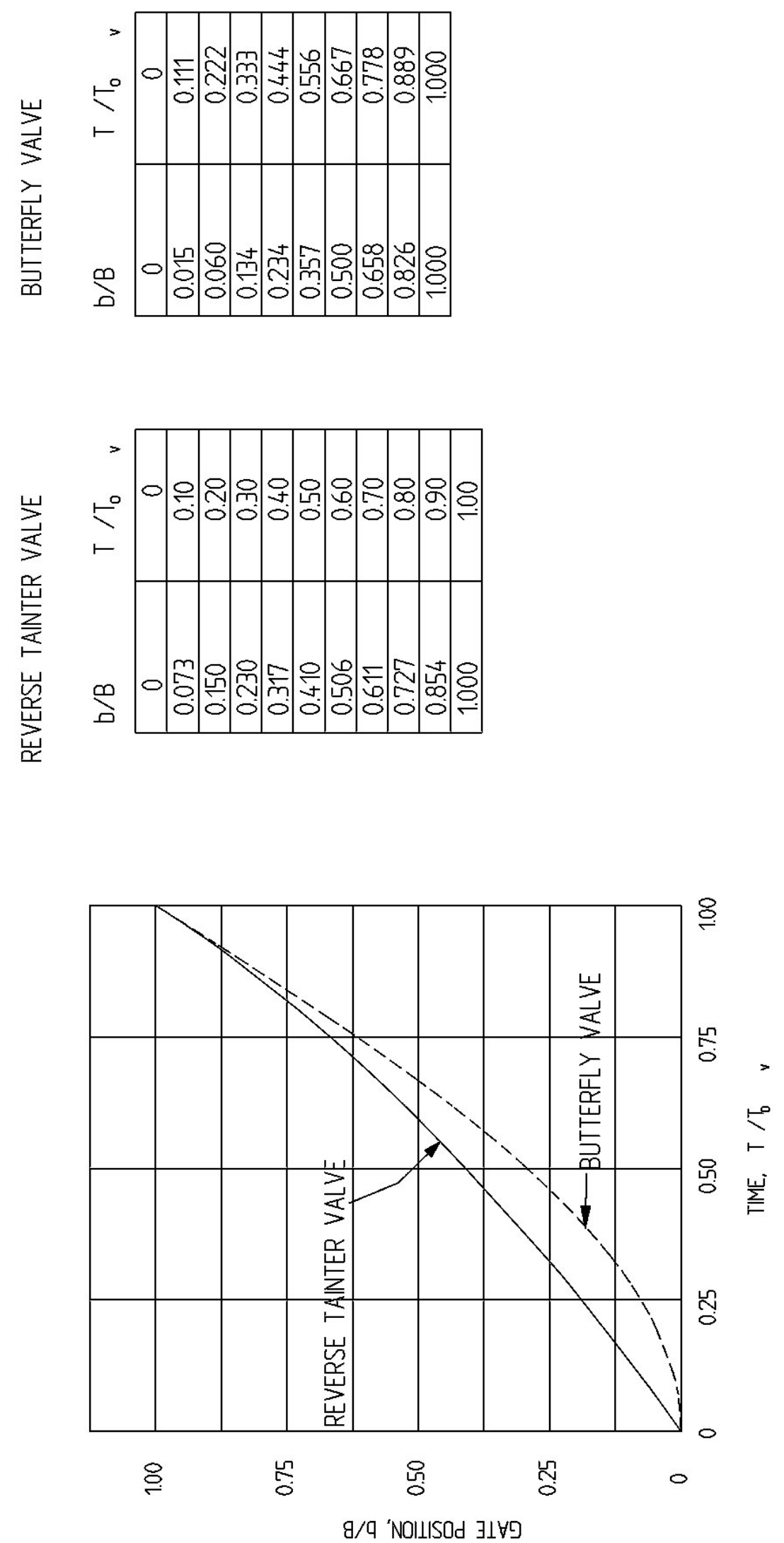

$\stackrel{\mathrm{J}}{\mathrm{s}}$

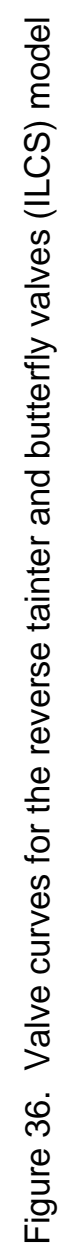



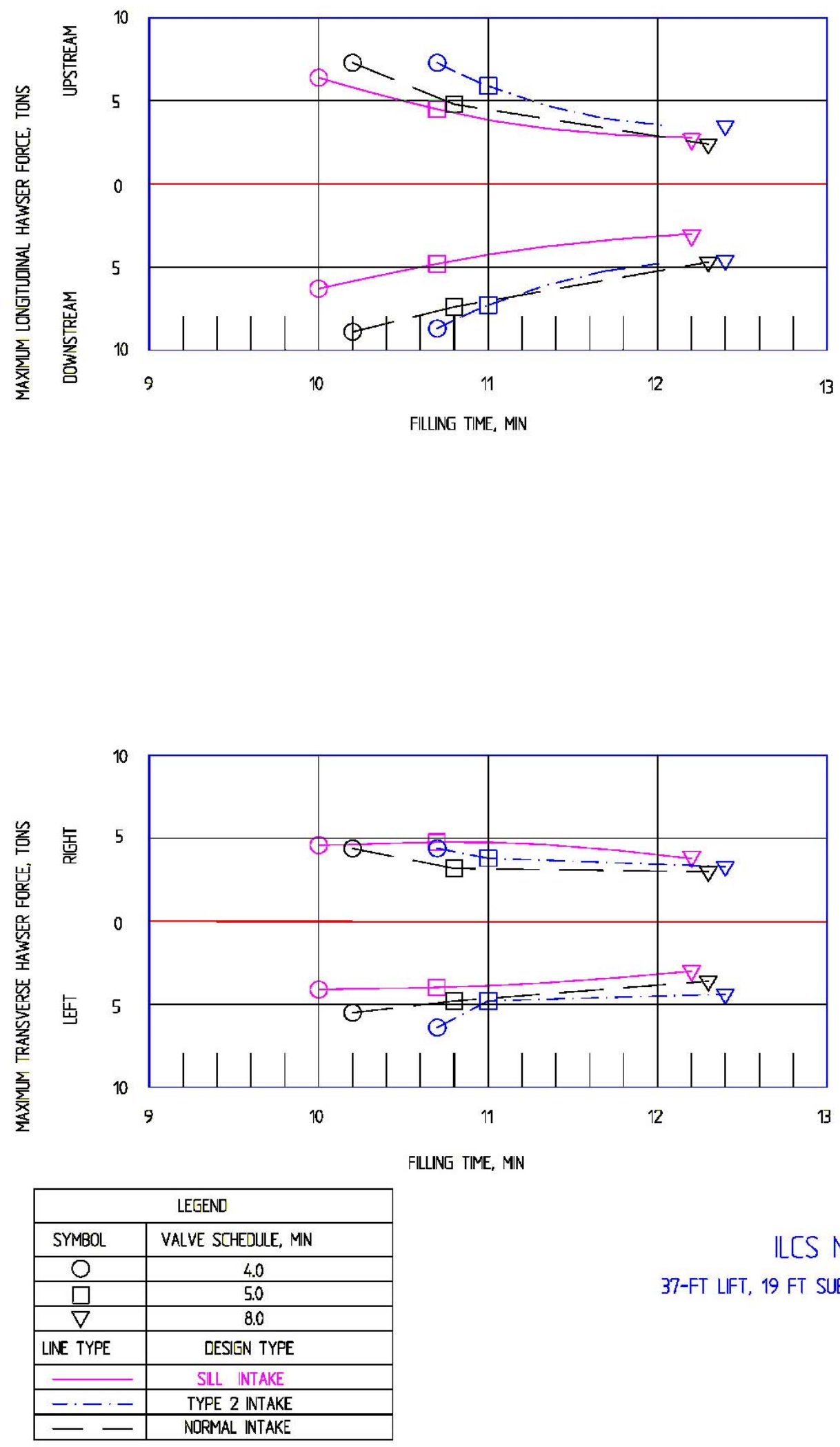

ILCS MODEL

37-FT LIFT, 19 FT SUBMERGENCE

Figure 37. Hawser forces determined with different intake locations 
more to the valve type than the intake location. The intake type, transitions from the intake to the filling culverts, length of culvert upstream from the manifold, and the type valve selected for the filling operations were considered more important factors in the performance of the ILCS than the intake location.

\section{No inner ports}

Experiments were performed with the inside ports of the culverts blocked. This reduced the port-to-culvert area ratio from the recommended value of 0.97 to 0.485 . These experiments were conducted to gain insight into unusual modifications to the ILCS and were performed since the culverts were going to be modified for additional testing. Typical time-histories with a 5-min normal valve opening are shown in Figure 38 for the $37-\mathrm{ft}$ lift. The maximum longitudinal hawser forces with the 5-min valve were 8.7 tons upstream and 5.4 tons downstream. The transverse hawser forces ranged from 4.0 tons on the downstream right side to 8 tons on the downstream left side. The maximum transverse hawser forces measured with 5- and 8-min valve operations were just as large as the longitudinal hawser forces. The average maximum hawser forces measured with the 37-ft lift and 4-, 5-, and 8-min valve operations are shown in Figure 39. The filling time required to maintain hawser forces of 5 tons or less, determined from Figure 39, was $18.1 \mathrm{~min}$ and was determined from the average maximum transverse hawser forces.

The experiments demonstrated the importance of introducing the flow into the chamber as uniformly as possible. The high transverse forces and the pronounced period of upstream longitudinal hawser forces (see Figure 38) are indications of poorly distributed flow in the chamber during filling.

Hawser forces during emptying with no inner ports were much less than those observed during filling. Average maximum hawser forces measured during emptying with the 37-ft lift and 4-, 5-, and 8-min valve operations are shown in Figure 40. The longitudinal hawser forces were higher than the transverse hawser forces. The emptying time to maintain hawser forces of 5 tons or less was $15 \mathrm{~min}$.

\section{Ports on top of culvert}

Chamber performance experiments were performed with circular ports located on the roof of the culverts. The port-to-culvert ratio was maintained at 1.0 by placing 163 ports (1.5-ft diam) in the top of the culvert, as shown in Figure 41. Typical time-histories of the filling characteristics with a 5-min valve operation are shown in Figure 42. The longitudinal hawser forces react similarly to the normal ILCS design for the first few minutes into the filling operation. Initially, a small upstream longitudinal hawser force occurred, followed by a larger downstream hawser force, which was then followed by an upstream hawser force much larger than the previous one. After this upstream force was observed, the dominant direction for the longitudinal hawser force was downstream and occurred for all three valve operations tested. 


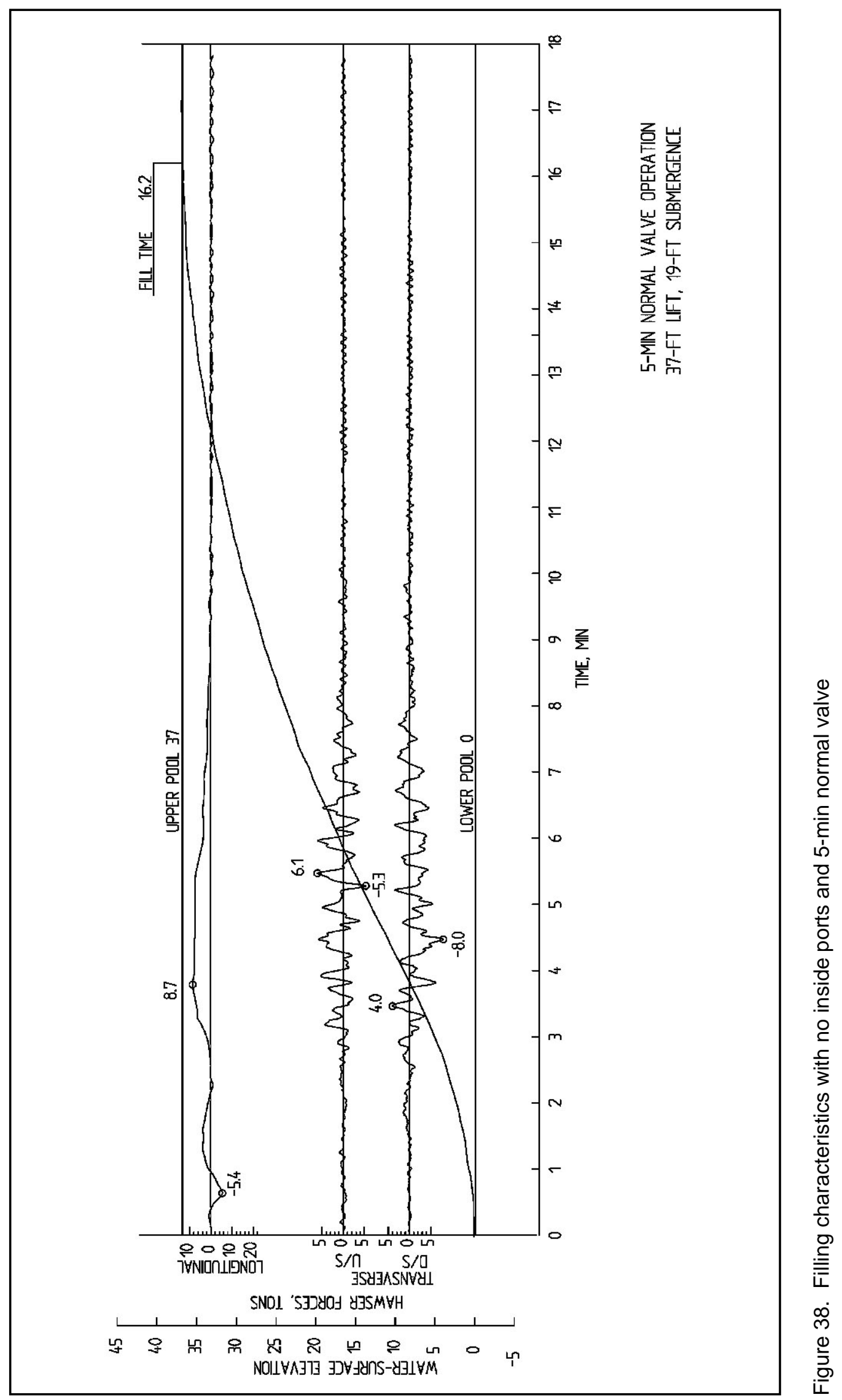



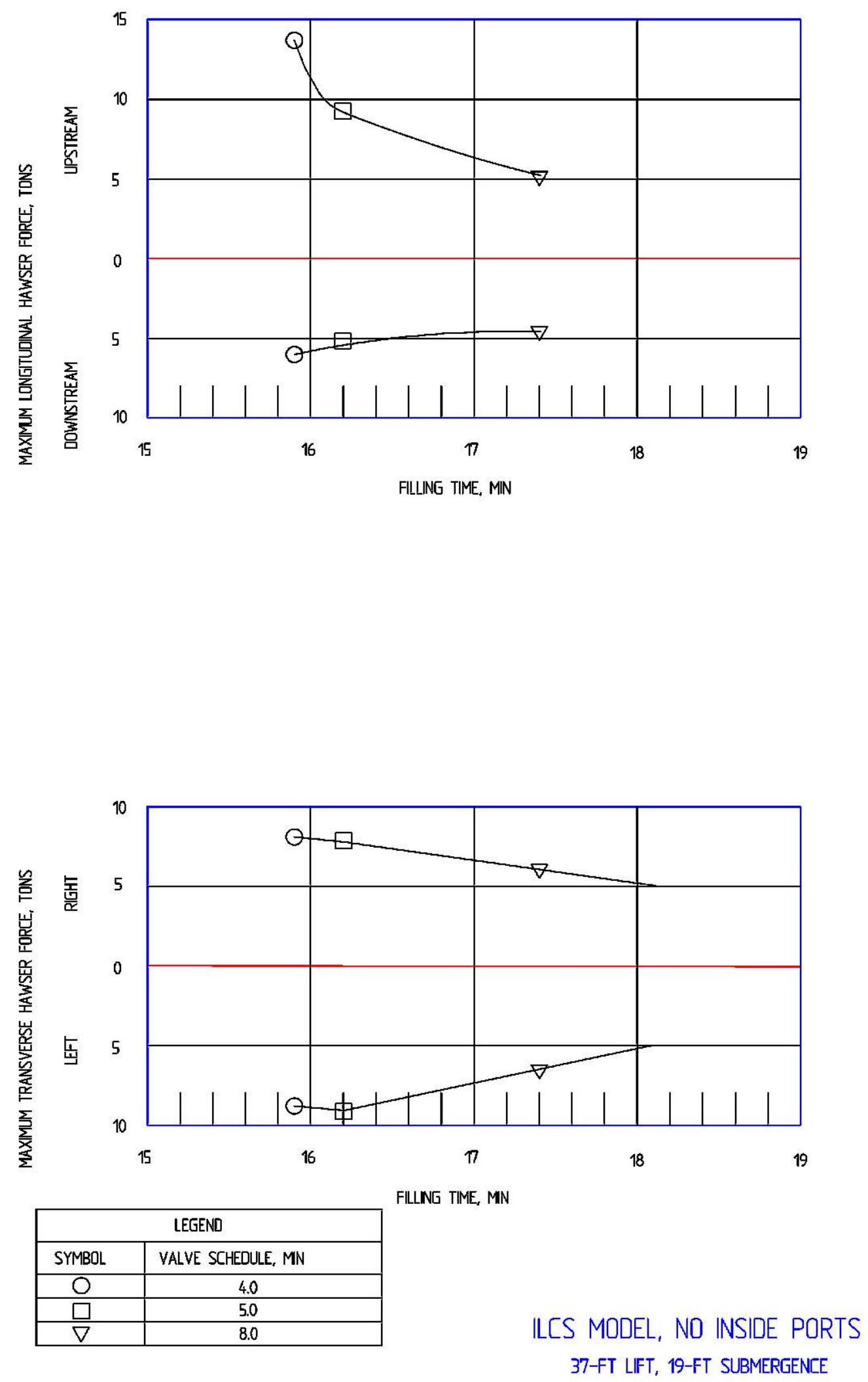

Figure 39. Hawser forces determined with no inside ports 

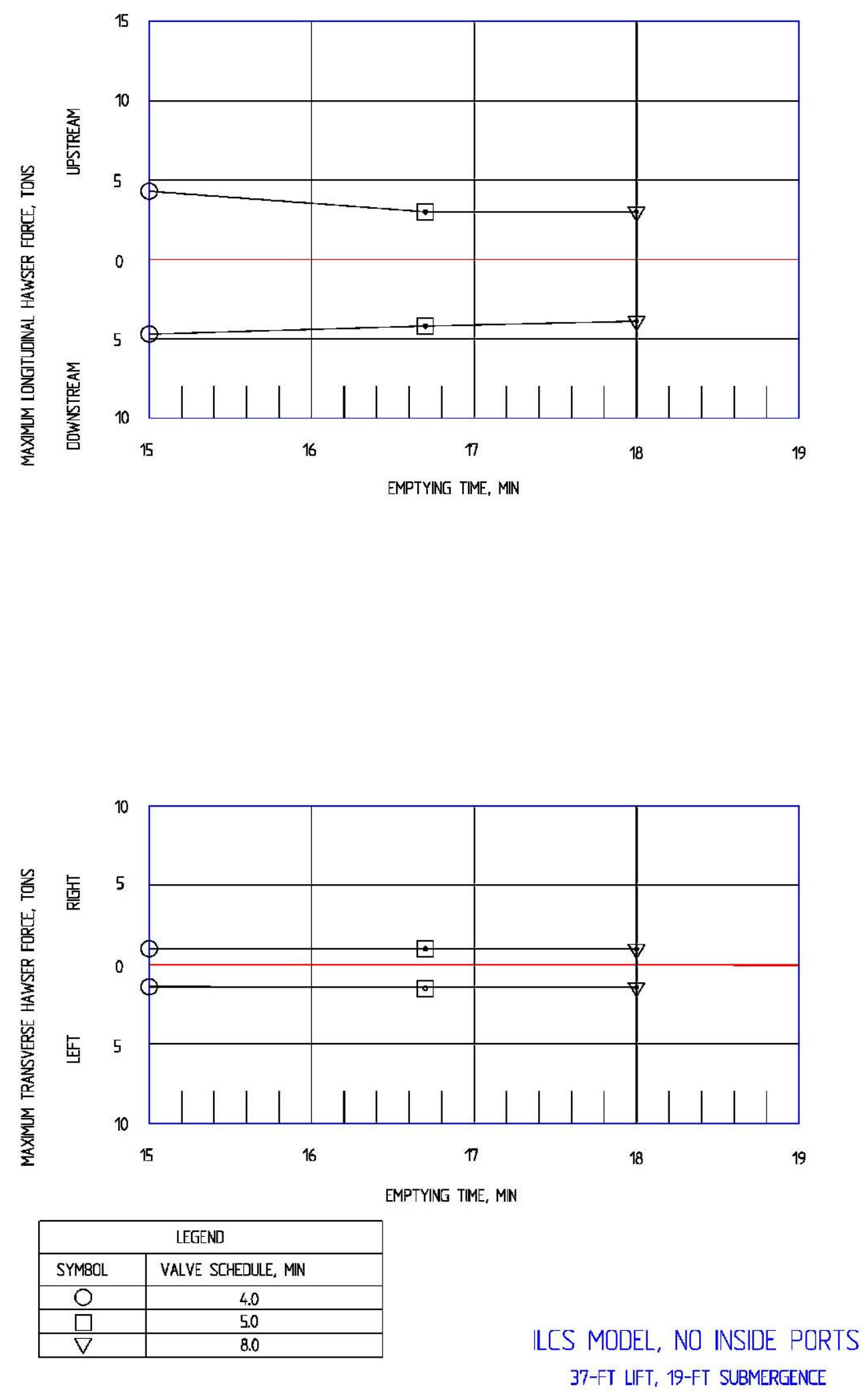

Figure 40. Hawser forces determined during emptying with no inside ports 


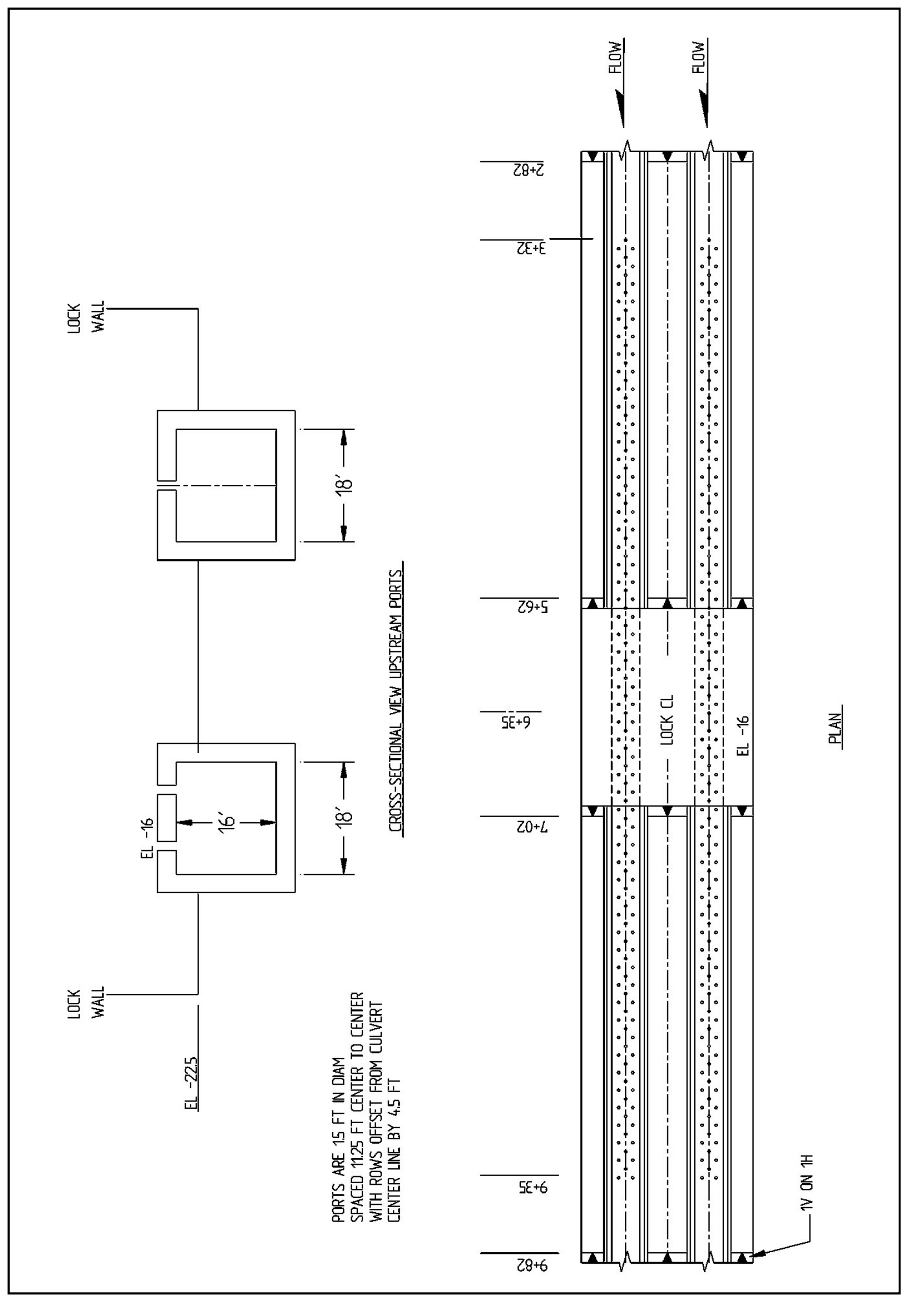

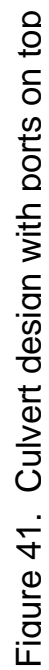




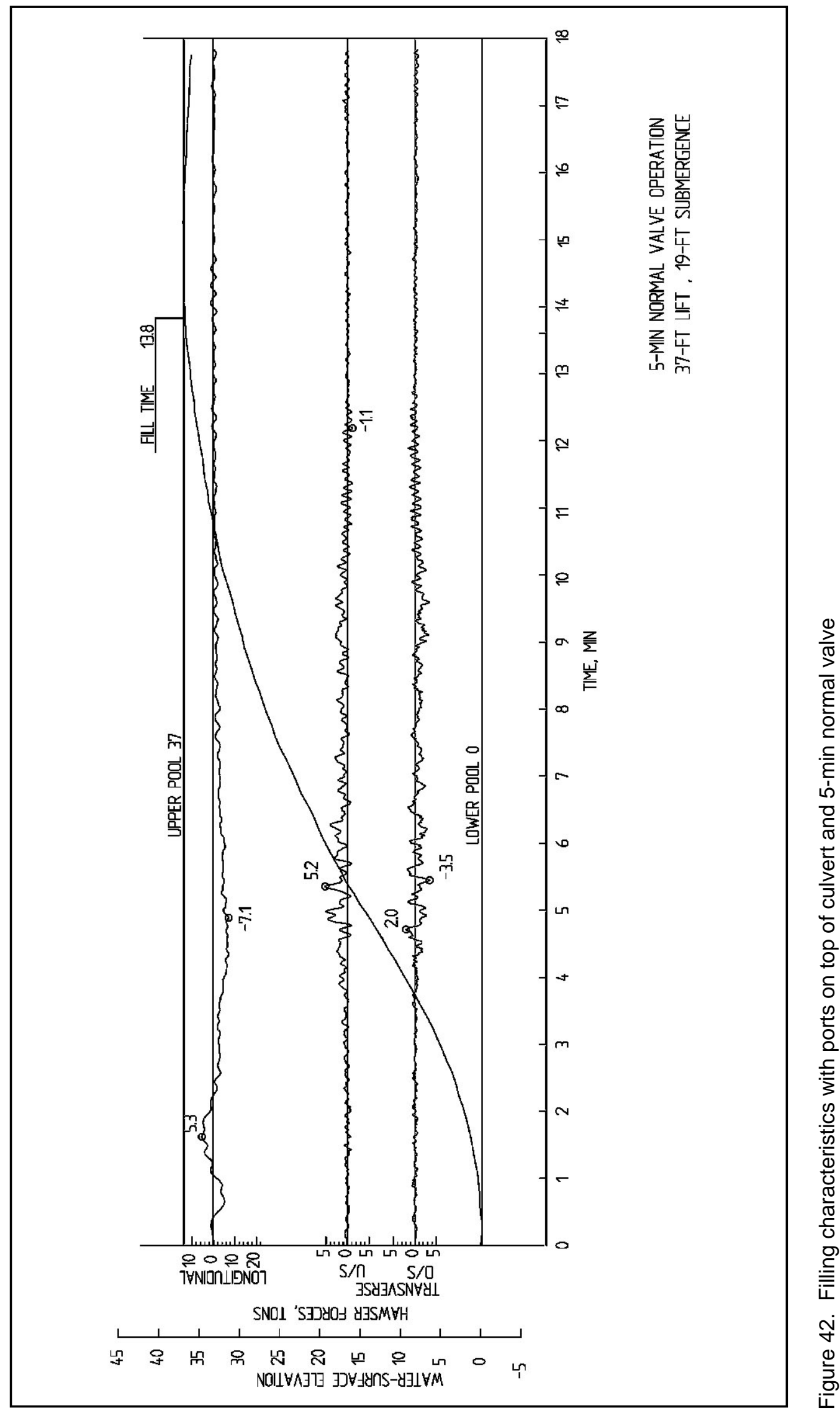


The maximum longitudinal hawser force observed was the downstream hawser, and it occurred near the time the valve was completely open. At about this same time, the transverse hawser forces reached maximum values. The higher upstream transverse hawser forces were measured on the right side, and the higher downstream transverse hawser forces were measured on the left side.

These filling characteristics demonstrate that, even though the ports were located evenly in the middle of the chamber, the flow did not enter the chamber uniformly. These experiments showed that with the ports on top of the culverts, some additional baffling is necessary to help distribute the flow into the chamber. The chamber water surface was rougher with this design. The average maximum hawser forces during filling are shown in Figure 43. The filling time required to maintain hawser forces of 5 tons or less was $15.7 \mathrm{~min}$. This compares to $12.2 \mathrm{~min}$ for the normal ILCS design.

The hawser forces determined from the experiments performed with modifications to the ports and culverts of the ILCS are compared with the normal ILCS design in Figure 44. The magnitude of the hawser forces with the ports on top and that of the normal ILCS design is similar for similar valve-opening operations. The filling time with the ports on top is slower, even though the portto-culvert area ratios are similar. This indicates there is more head loss in the manifold with the ports on top. This head loss could be reduced by rounding the edges of the ports. The experiments with no inner ports indicated that the transverse hawser forces were the forces controlling acceptable chamber performance. The high transverse forces indicate a poor distribution of flow into the chamber.

\section{Single culvert}

Experiments were performed with a single-culvert design to evaluate chamber performance. The initial single-culvert design is shown in Figure 45. The center of the longitudinal culvert was located in the center of the chamber, and the port design was the same as the original design. For the first experiments, no upstream port extensions or upstream and downstream wall baffles were used. This design was designated the Type 1 single culvert.

Time-histories of the hawser forces and filling curves are shown in Figure 46 for a 35-ft lift and 12-min valve operation. These results show that, even with this slow valve speed, large upstream longitudinal hawser forces occurred. Large transverse hawser forces were also measured with this design. The high transverse forces on the same side of the chamber, both upstream and downstream, indicate a strong side-to-side movement. A plot of the average maximum hawser forces versus filling time for the 8- and 12-min valve operations is shown in Figure 47 for the Type 1 single culvert. The Types 2-4 single-culvert designs that will be discussed in the following paragraphs are also included in Figure 47. These tests indicated that additional baffling was needed with the Type 1 single culvert to help distribute the flow more evenly in the chamber during filling.

Type 2 single culvert. The upstream port extensions and the upstream wall 

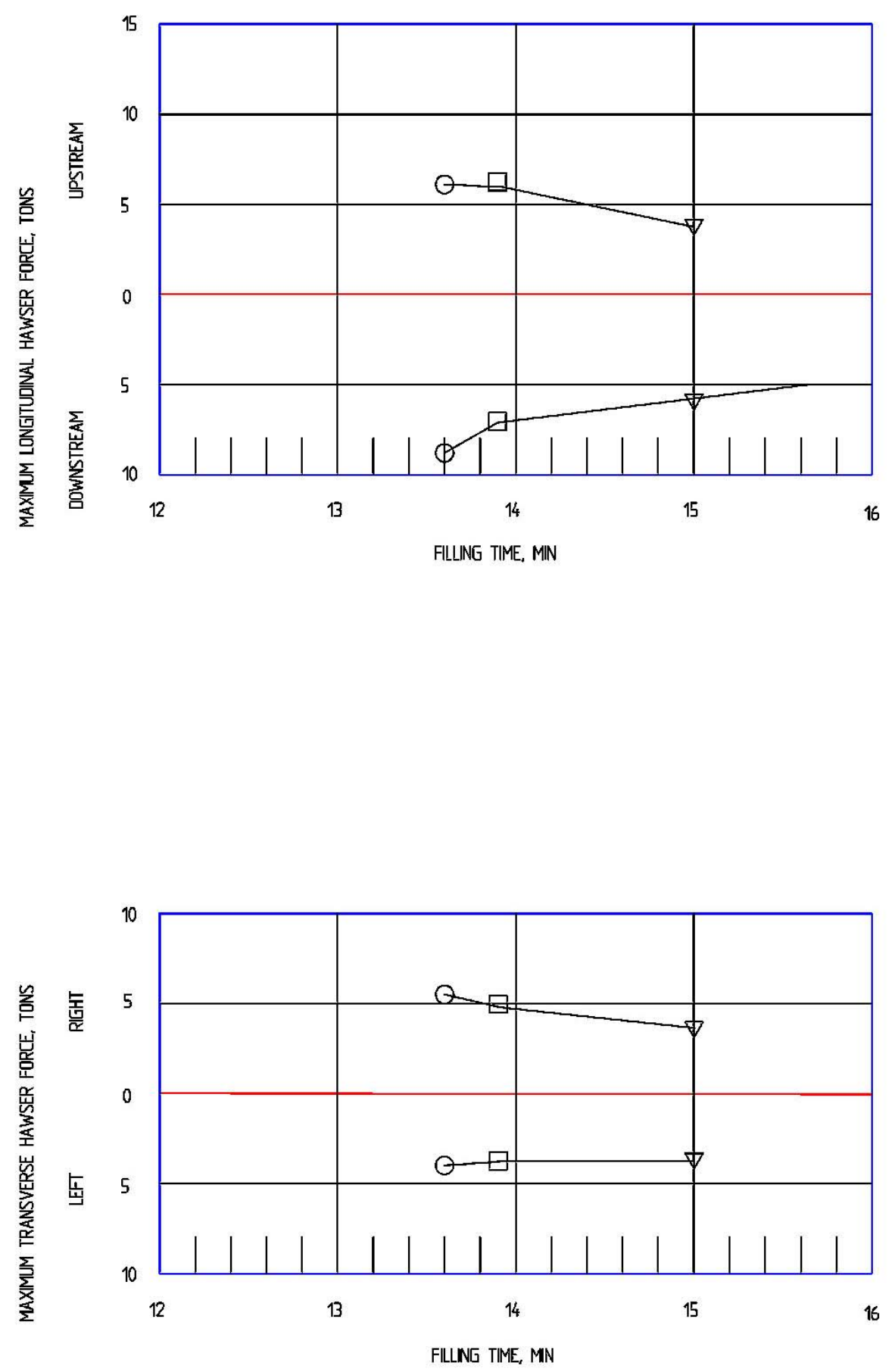

\begin{tabular}{|c|c|}
\hline \multicolumn{2}{|c|}{ LEGEND } \\
\hline SYMBOL & VALVE SCHEDULE, MN \\
\hline$O$ & 4.0 \\
\hline$\square$ & 5.0 \\
\hline$\nabla$ & 8.0 \\
\hline
\end{tabular}

ILCS MODEL, PORTS ON TOP 37-FT LIFT, 19-FT SUBMERGENCE

Figure 43. Hawser forces determined with ports on top of culvert 


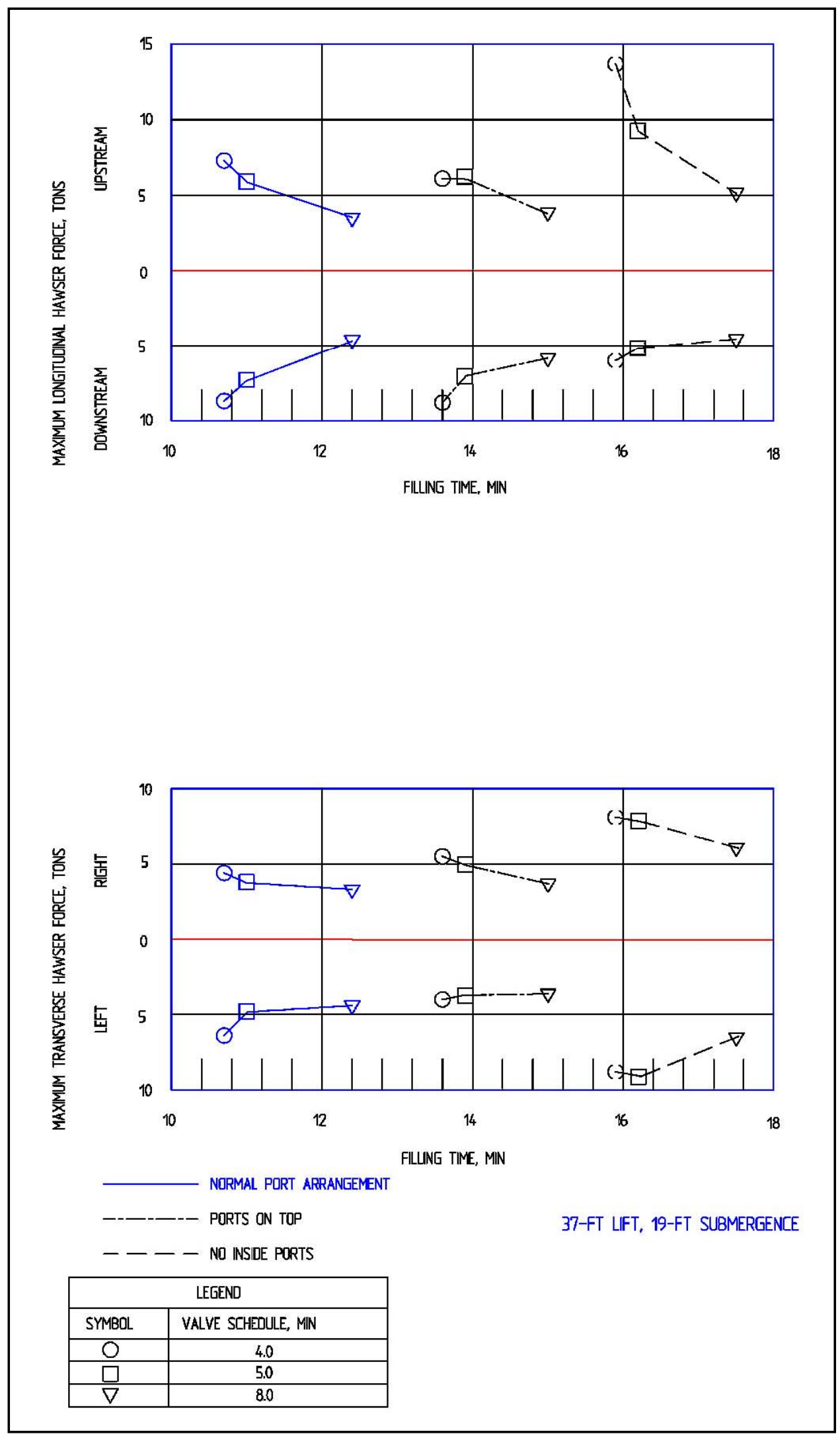

Figure 44. Comparison of hawser forces with different port configurations 


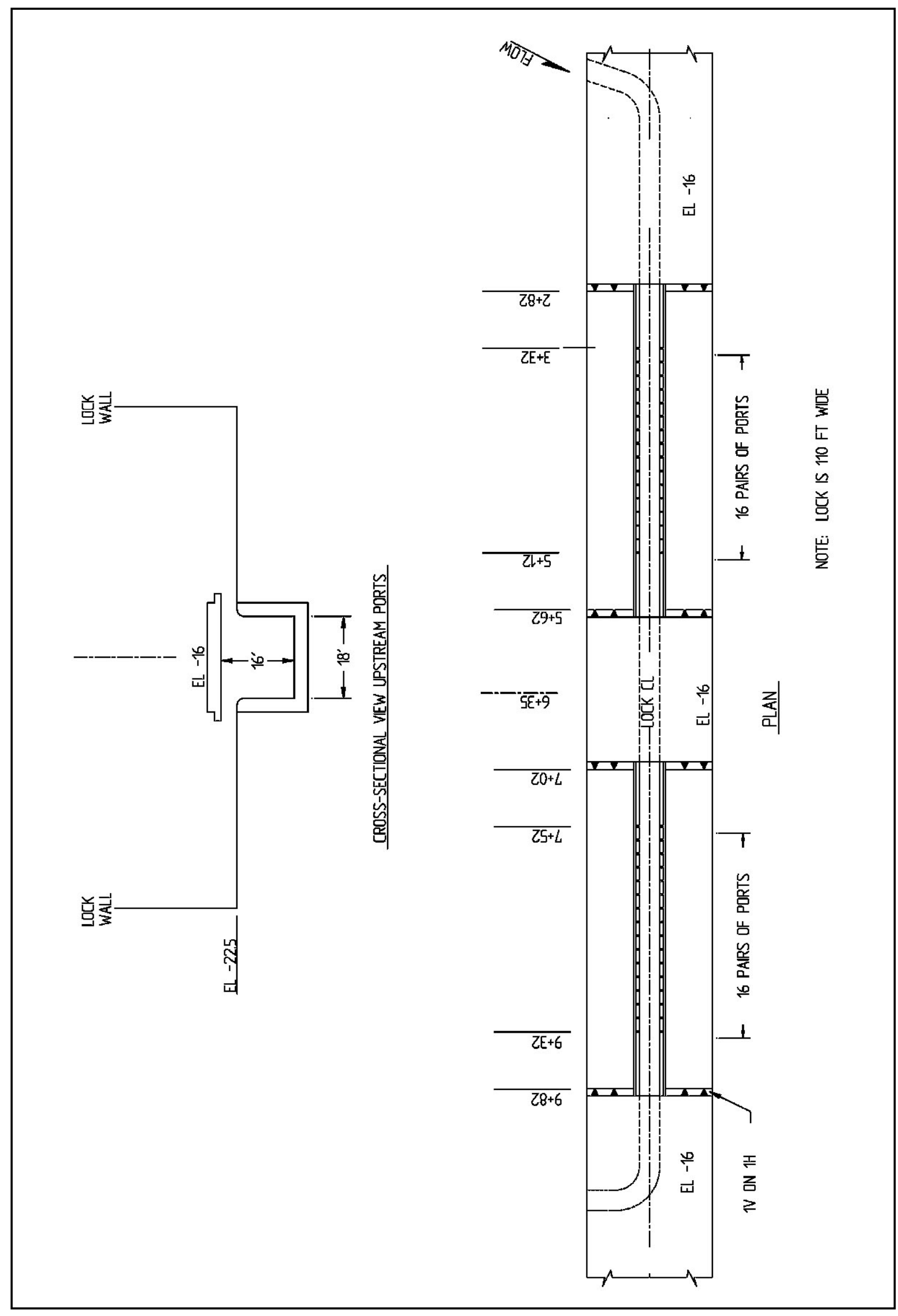

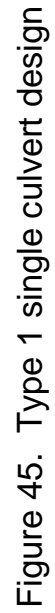




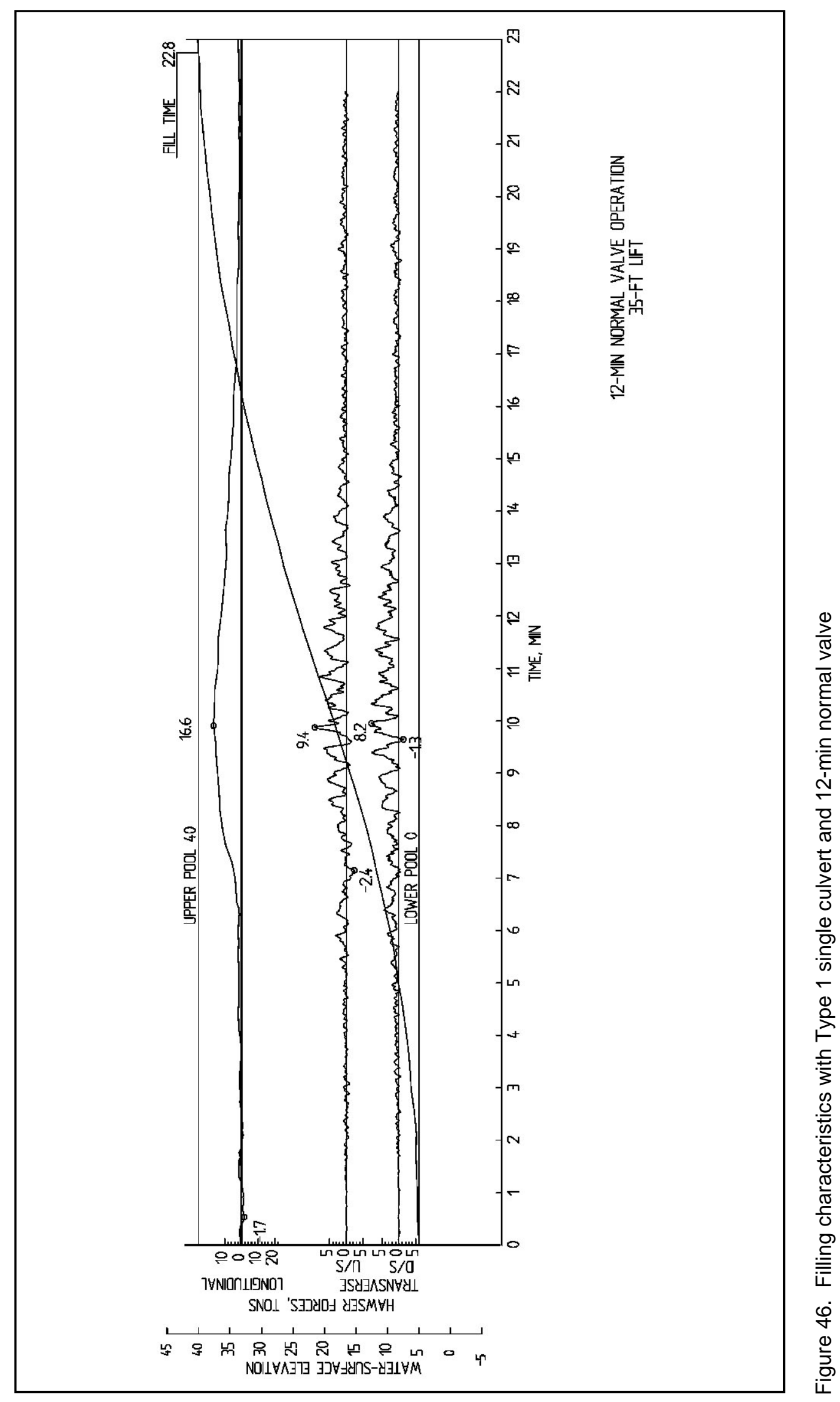



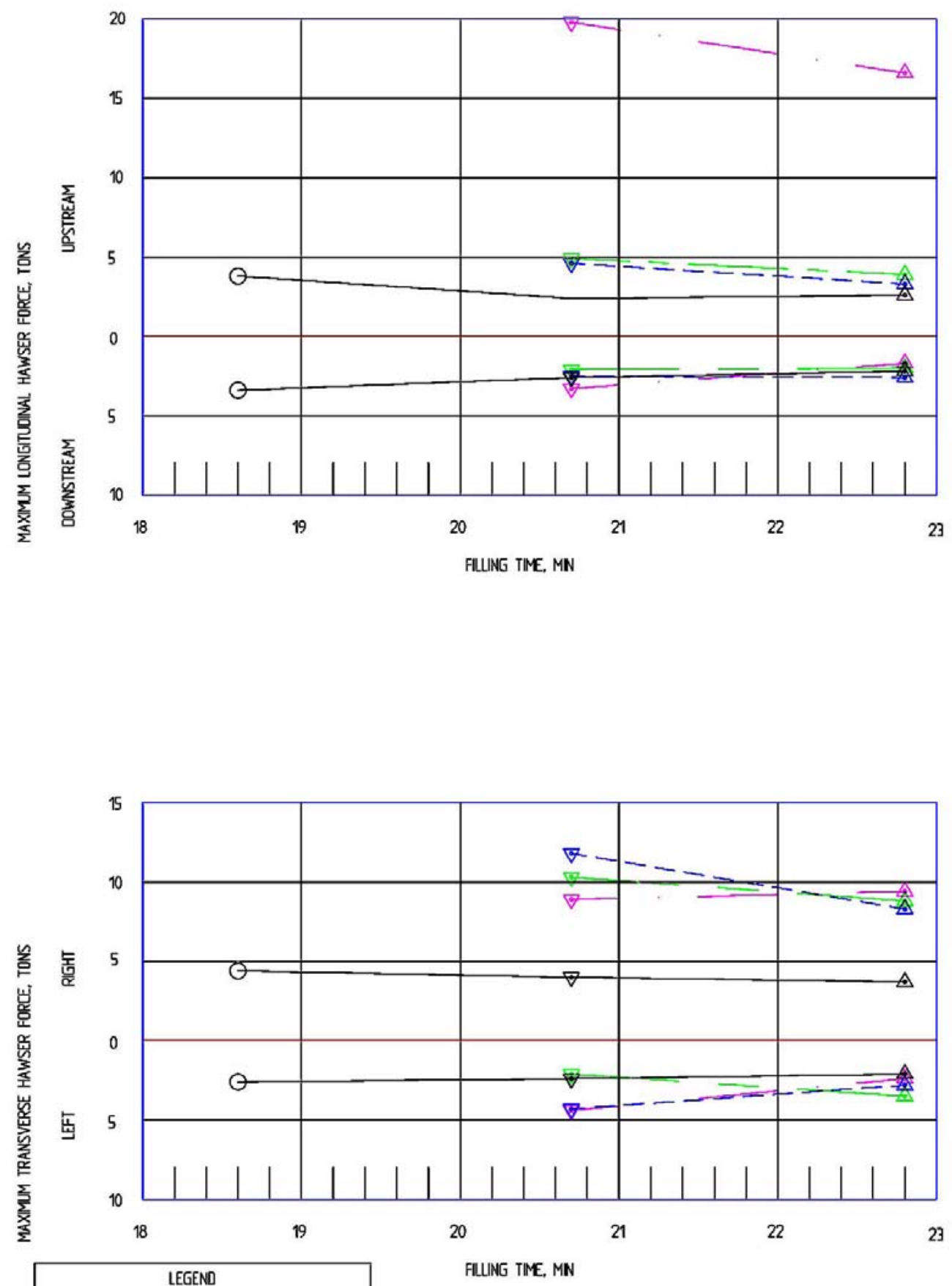

Figure 47. Comparison of hawser forces with different single culvert designs and 35-ft lift 


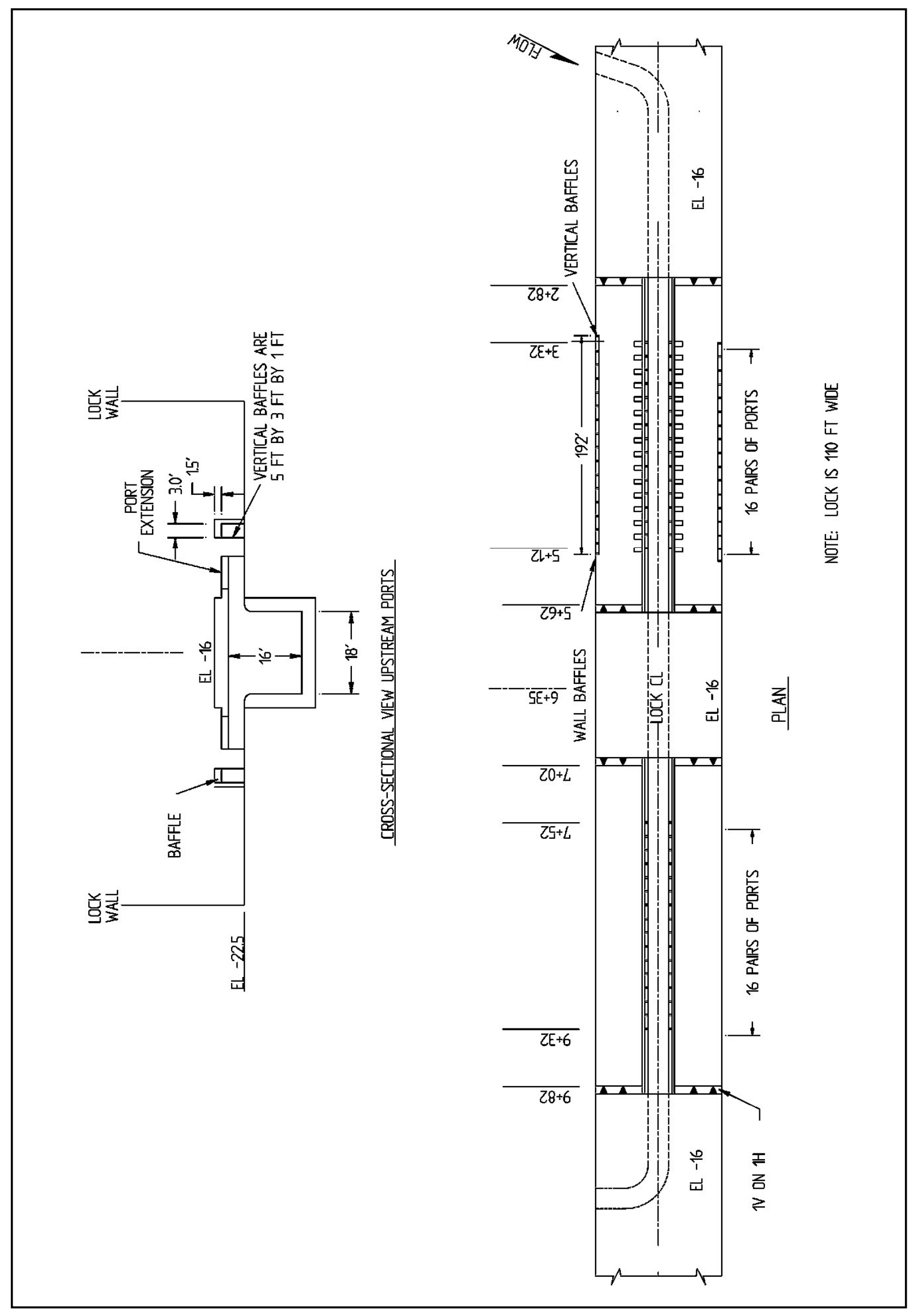

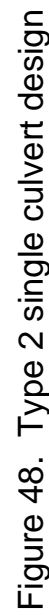


Type 2 single culvert. The average maximum hawser forces obtained with this design are shown in Figure 47. The large upstream longitudinal hawser forces were reduced to below 5 tons for the 8- and 12-min valve operations, indicating that the port extensions definitely help distribute the flow longitudinally in the chamber. The transverse forces were still much higher than desired.

Type 3 single culvert. The downstream wall baffles were added to the chamber, and this design was designated the Type 3 single culvert. The average maximum hawser forces obtained with this design are shown in Figure 47. Neither the longitudinal nor transverse hawser forces were changed significantly from the Type 2 design. These results indicated that the wall baffles were not effective when located on the lock walls with the single-culvert design.

Type 4 single culvert. The wall baffles located on the lock walls were placed in the chamber as shown in Figure 49. The distance between the port and the lock wall with the two-culvert normal ILCS (16.33 ft) was kept the same when the baffle was moved with the Type 4 single culvert. The average maximum hawser forces obtained with the Type 4 design and a 35- $\mathrm{ft}$ lift are shown in Figure 47. The transverse forces were less than 5 tons, even with a 4-min valve. The baffles spaced $16.33 \mathrm{ft}$ laterally from the ports were necessary with the single-culvert design to achieve desirable chamber performance. The strong sideto-side movement of the barges in the chamber observed with the Type 1 single culvert was significantly reduced.

Experiments were then conducted with the Type 4 single culvert and a $20-\mathrm{ft}$ lift. The average maximum hawser forces obtained with the Type 4 single culvert and a 20 -ft lift are shown in Figure 50. The filling time required to maintain hawser forces of 5 tons or less was $13.5 \mathrm{~min}$. This compares to $8.2 \mathrm{~min}$ with the original two-culvert design ILCS, indicating that, with this lift, the operation with a single culvert was approximately 65 percent slower.

\section{Summary of experimental results with modified ILCS}

The experiments conducted to study the effects of selected modifications to the ILCS original design were performed to simulate changes that might be required due to maintenance, site conditions, or construction costs. The singlevalve experiments showed what to expect if one of the culvert valves was out of operation for a two-culvert, two-valve filling system. The single valve must be operated at a speed of about one half the normal valve to maintain acceptable hydraulic conditions in the chamber. The transverse hawser forces were the controlling hawser forces for acceptable chamber performance with a single-valve operation. The transverse hawser forces were highest on the side of the operating valve.

The experiments to determine the effects of different intake locations revealed that the intake type, transitions from the intake to the filling culverts, valve wells, length of culvert upstream from the manifold, and the type valve selected for the filling operations had more influence on chamber performance than the intake location. The through-the-sill intake performed just as well as the conventional 


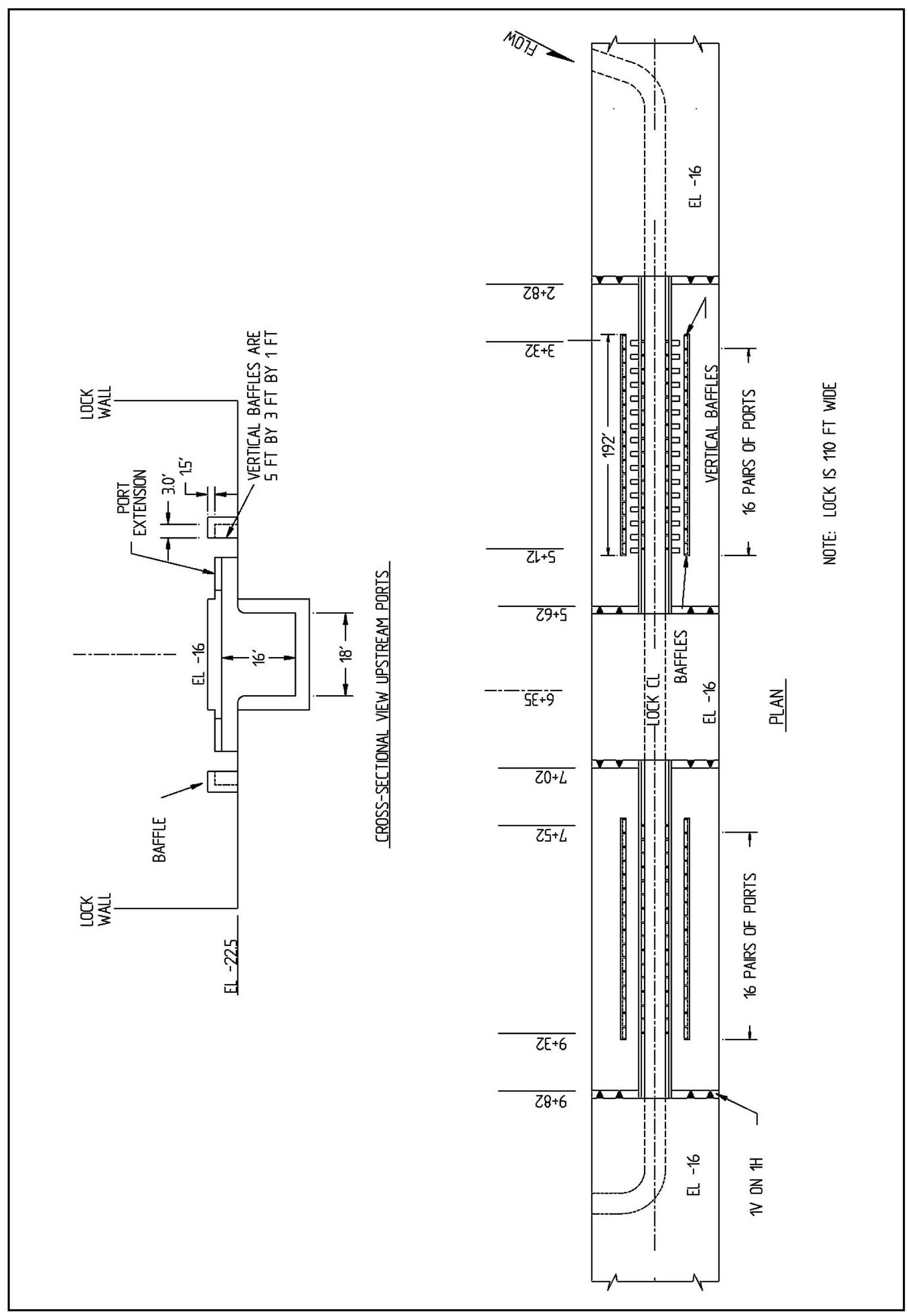

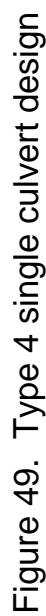



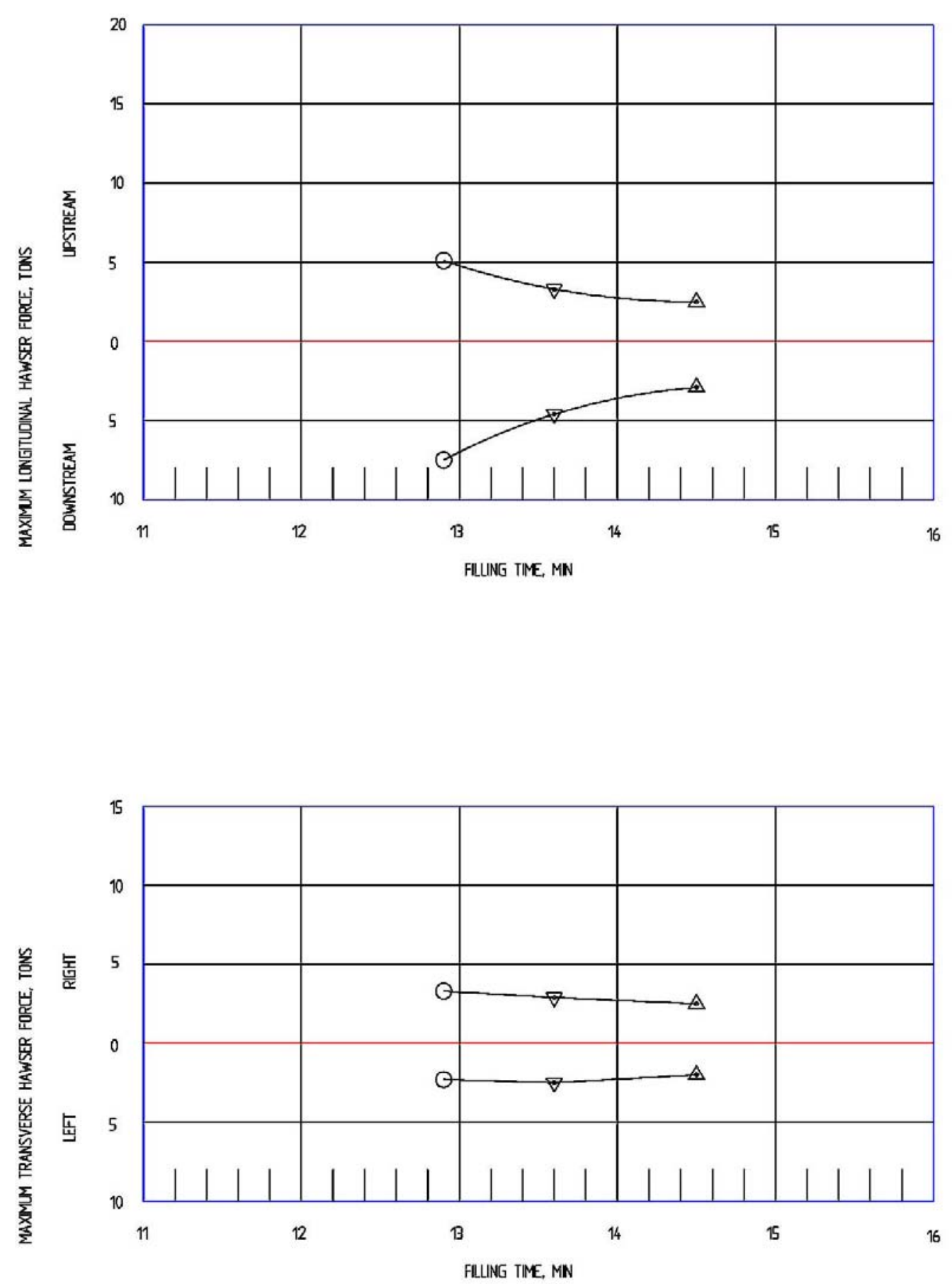

\begin{tabular}{|c|c|}
\hline \multicolumn{2}{|c|}{ LEGEND } \\
\hline SYMBOL & VALVE SCHEDULE, MN \\
\hline$O$ & 1.0 \\
\hline$\nabla$ & 2.0 \\
\hline$\triangle$ & 4.0 \\
\hline
\end{tabular}

TYPE 4 SINGLE CULVERT

20-FT LIFT

Figure 50. Hawser forces determined with Type 4 single culvert and 20-ft lift 
intakes located in the upper approach walls. In a two-culvert design, the chamber performance is more balanced when the energy level is similar at the first port in each culvert. The head losses between the intake and the first port need to be the same.

The experiments with no inner ports were performed to simulate port discharges from one side of the culvert. The results indicated that high hawser forces both longitudinal and transverse were measured with the 4- and 5-min valve operations and even with an 8-min valve operation the longitudinal and transverse hawser forces exceed 5 tons. These experimental results show that the flow in the chamber needs to be introduced as uniformly as possible.

The experiments with the ports on top showed that the filling time that produced acceptable chamber performance was about 30 percent slower with the ports on top of the culvert. The longitudinal hawser forces were predominantly in the downstream direction, indicating a need for some type of baffling near the upstream ports. Baffling placed on top of the culverts may require additional excavation, which is not desirable.

The single-culvert experiments showed that the baffling placed along the walls of the lock chamber with the original design ILCS was also required with the single culvert to achieve better chamber performance. The spacing between the ports and the baffling should be the same as the original two-culvert design. With a 35-ft lift, the filling time required to achieve acceptable chamber performance with normal valve operations $(18.5 \mathrm{~min})$ was 61 percent slower than the original design ILCS. With a 20 -ft lift, the filling time required to achieve acceptable chamber performance with normal valve operations (13.5 min) was 65 percent slower than the original design ILCS. 


\section{$6 \quad$ Numerical Model Results}

The numerical model LOCKSIM (Schohl 1999) was used to compute filling characteristics for the ILCS design. LOCKSIM is a numerical model developed at the Tennessee Valley Authority's (TVA's) Engineering Laboratory for simulation of one-dimensional transient filling and emptying flow in navigation locks.

The ILCS was modeled by using diverging manifolds to represent the ports. Eight diverging manifolds were placed in each culvert-four in the upper half of the chamber and four in the lower half of the chamber. A schematic representation of the model used to compare the filling characteristics is shown as Figure 51. Some of the loss coefficients were measured in the laboratory model while others, such as the diverging manifold components, were obtained from recommended values shown in the user's manual.

A comparison of the filling characteristics with an 8-min normal valve is shown in Figure 52. The filling curve from the model was determined by averaging the water-surface depths at nodes CHU, CHM, and CHL during the filling operation. These nodes represent the locations where the pressure measurements were obtained in the ILCS model. The comparison indicates that the filling curves are very similar. The longitudinal hawser forces were estimated from the model by determining the water-surface slope between CHU and CHL. If the forces due to drag and inertia are neglected and assuming barges in the lock chamber act as a single rigid vessel and the vessel blockage area has no effect on the hawser forces, the force required to hold a vessel in place is a function of water-surface slope only. The weight of the barges multiplied by the water slope gives an approximation of the longitudinal hawser force. These are the forces shown in Figure 52 that are compared to the longitudinal hawser forces measured in the laboratory model. The approximations of the longitudinal hawser forces from the water-surface slope are slightly higher than the magnitude of the forces measured in the laboratory model, and the forces tend to dampen quicker in the laboratory model. Since LOCKSIM is a one-dimensional flow model and the computation of the hawser forces from the model results in an approximation, the results should be viewed cautiously. The comparison does indicate the model is useful as a screening tool for eliminating some of the design alternatives. Additional research to take into account the hydrodynamics and the vessel effects during filling is needed to improve the computations. 


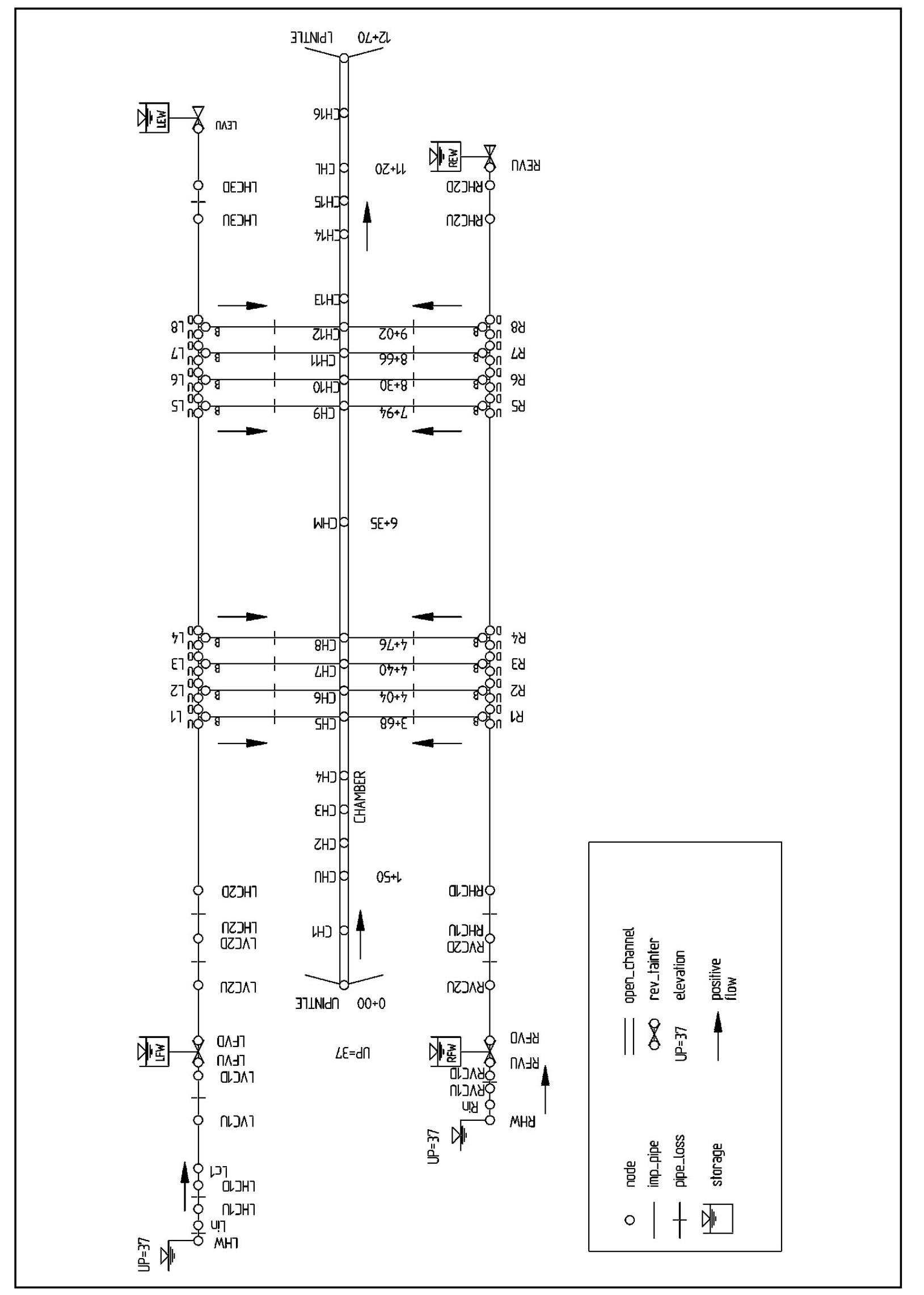

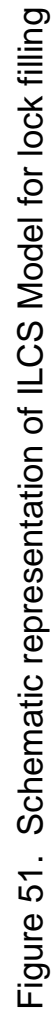




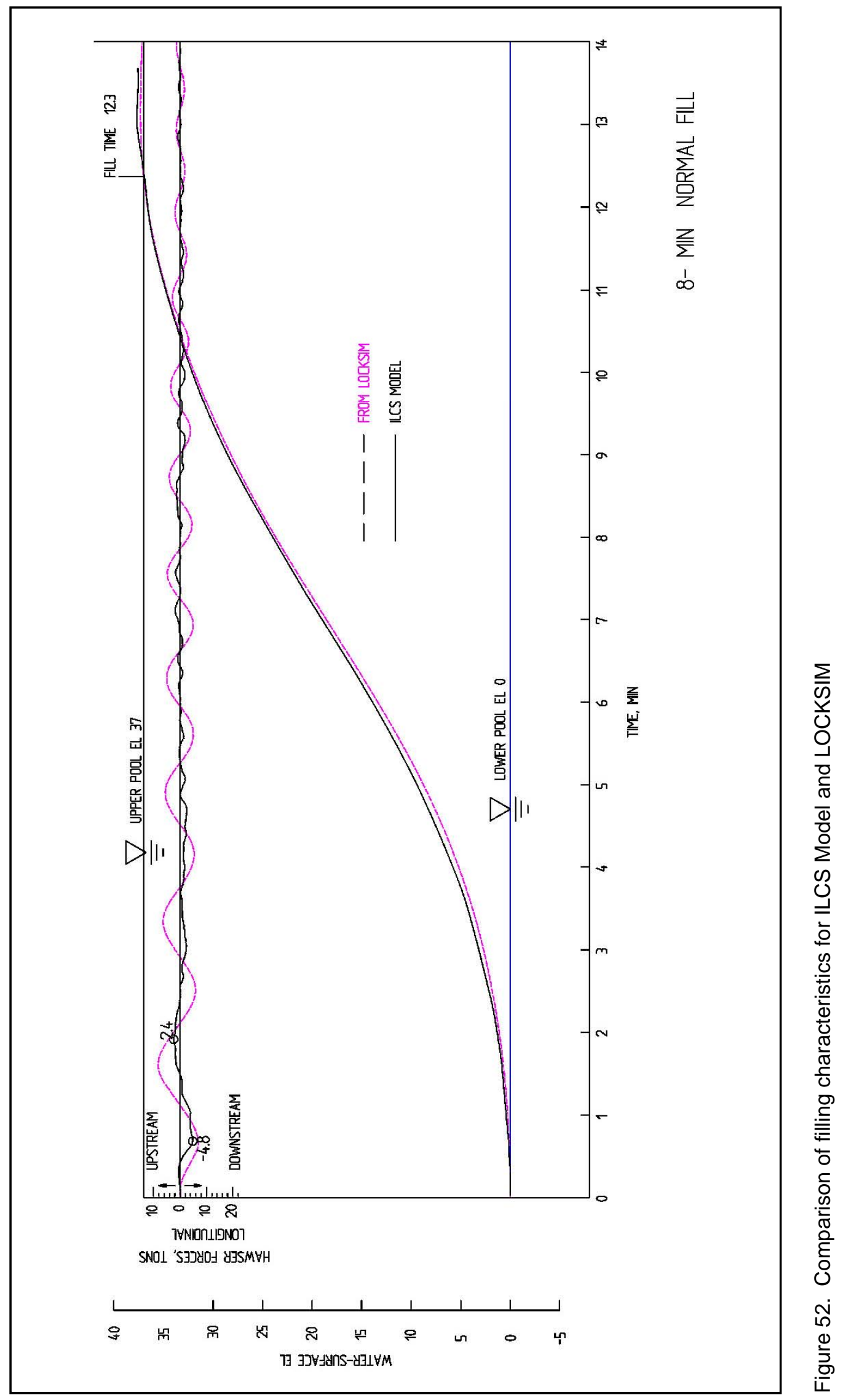




\section{Design Procedure for the ILCS Lock}

\section{Design Guidance}

Based on the results determined from the ILCS research, the following guidance is offered for the initial design of an ILCS lock.

\section{Operation times}

Filling and emptying times should be established based on an economic analysis for the navigation project. Once these times are known, the culvert sizes can be determined.

\section{Initial culvert size}

A simple method to estimate the initial culvert size is to first determine an acceptable maximum velocity for the culverts. For the low-head projects (less than $40 \mathrm{ft}$ ), this velocity is usually between 20 and $25 \mathrm{fps}$. A culvert size is selected, and the maximum discharge during the filling or emptying operation is computed. Typically, the average discharge during the filling operation is one half of the maximum discharge. Using the average discharge, the filling time can be determined knowing the volume of the lock chamber to be filled. The culvert size that produces an acceptable filling time is determined from this process.

\section{Ports}

The port size, location, and spacing should be determined next. This information can be determined from the guidance provided in Chapter 5 of this report.

\section{LOCKSIM}

The numerical model can then be developed to determine a better estimate of the filling and emptying times. Guidance for developing the model is provided in Chapter 6 and in Schohl (1999). If the results are unacceptable, the culvert size 
may need to be modified and another LOCKSIM model developed until acceptable results are obtained.

If unusual structural components, valving, or culvert geometry is required, a laboratory model is recommended to determine the chamber performance and verify the final design.

\section{Example ILCS Lock Design}

The following example problem (based on the Upper Mississippi River Project) is provided to illustrate the design steps summarized above.

Given—lock dimensions:

Pintle-to-pintle length $=1,270 \mathrm{ft}$

Lock width $=110 \mathrm{ft}$ wide

Design lift $=15 \mathrm{ft}$

Target filling time $=9 \mathrm{~min}$

Maximum culvert velocity $=20 \mathrm{fps}$

Initial culvert size $=\mathrm{A}\left(\mathrm{ft}^{2}\right)$

Maximum culvert discharge $=20 * \mathrm{~A}(\mathrm{cfs})$

Average culvert discharge $=10 * \mathrm{~A}(\mathrm{cfs})$

Area of lock chamber $=140,240 \mathrm{ft}^{2}$ (approximately)

Volume of chamber to be filled $=2,103,600 \mathrm{ft}^{3}$

Culvert size A to produce 9-min filling time with two culverts $=2,103,600 \mathrm{ft}^{3} /(540 \mathrm{sec} * 20 \mathrm{fps})=194.8 \mathrm{ft}^{2}$, or $14 \mathrm{ft}$ by $14 \mathrm{ft}$

Using a culvert size of $14 \mathrm{ft}$ by $14 \mathrm{ft}$, the port area for the culvert will be $196 \mathrm{ft}^{2} * 0.97=190 \mathrm{ft}^{2}$

Number of ports should be $190 \mathrm{ft}^{2} / 4.4 \mathrm{ft}^{2}=43$ (say 44 ports)

This will give a port-to-culvert area ratio of $\left(44 * 4.4 \mathrm{ft}^{2}\right) / 196 \mathrm{ft}^{2}=0.99$; should be okay.

Each culvert should contain 44 ports (22 in each half of the chamber, with 11 on each side of the culvert). 
Based on the guidance given in Figure 25, the port spacing should be about $17.78 \mathrm{ft}$ from center to center. A plan layout of the culverts and ports is shown in Figure 53.

A LOCKSIM model could now be developed (from this information and that provided in Chapter 6) to verify the filling time. 


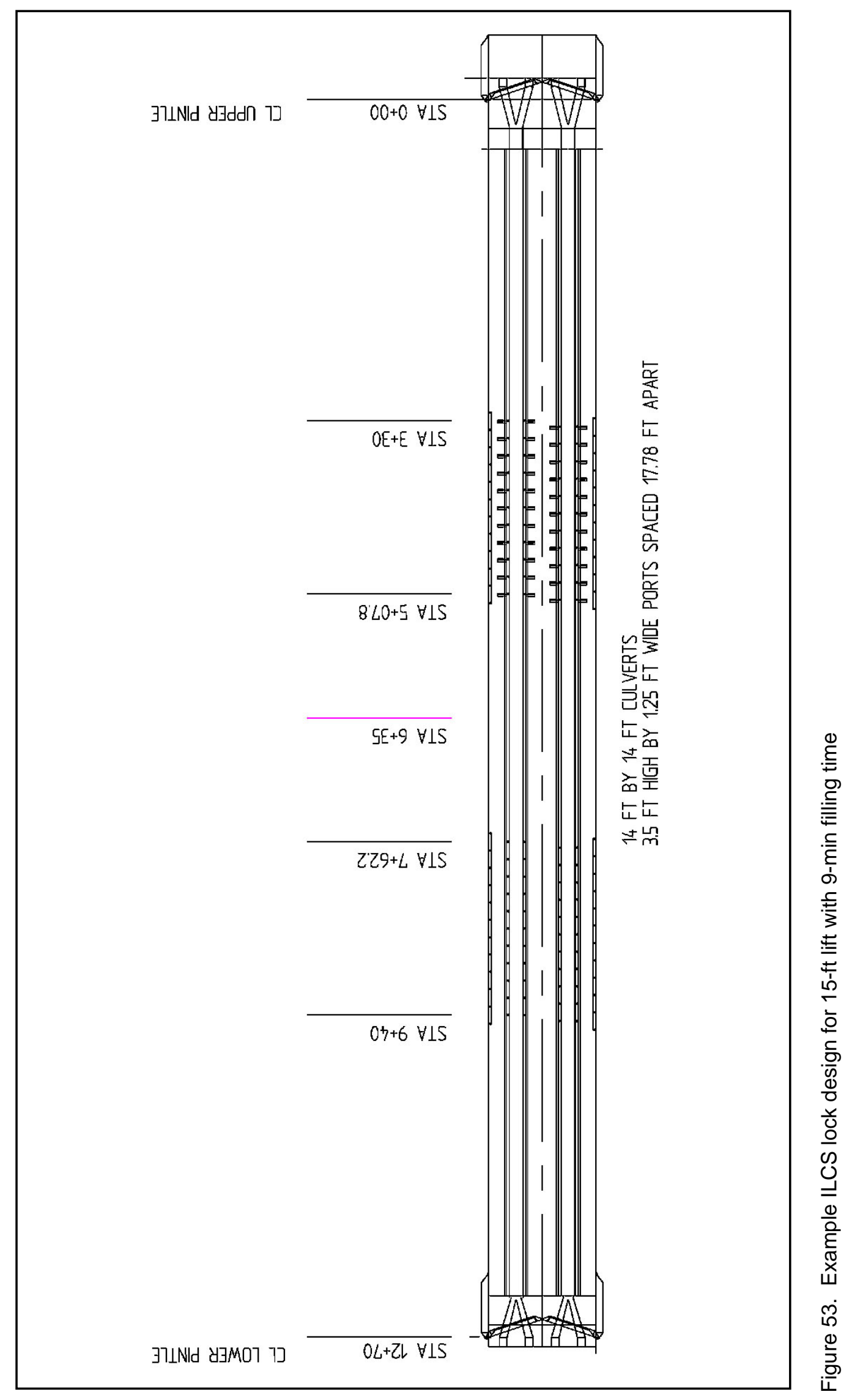




\section{Summary and Conclusions}

The investigation of the In-chamber Longitudinal Culvert System showed that this type of filling and emptying system was feasible from a hydraulic performance point of view. The system is adaptable to the innovative float-in and in-the-wet construction techniques. The system was not quite as efficient as the side-port filling and emptying system. However, the reduction in construction costs makes the system favorable over the project life. The system requires slightly deeper excavation where the culverts are located in the chamber and is probably better suited for rock foundations. Geotechnical evaluation is important to determine uplift pressures on the culverts for the various site conditions.

Guidance for designing the ILCS components is provided in Chapter 5, and a procedure for evaluating the initial design numerically is provided in Chapter 6 . Chapter 7 suggests a method to develop the initial design and provides a design example. The unique hydraulic components of the ILCS design are the port extensions and the wall baffles. These were necessary to provide a uniform distribution of flow into the chamber during filling and to assist in the energy dissipation.

A two-culvert system performed better than the single-culvert system, since it provided a better distribution of flow into the chamber and allowed faster operation times. The tests with single-valve operations and unusual port configurations and locations revealed that the lateral flow distribution during filling was undesirable and resulted in high transverse hawser forces on barges moored in the chamber. The filling and emptying times for acceptable chamber performance for lifts between 10 and $40 \mathrm{ft}$ and submergences between 19 and $29 \mathrm{ft}$ are shown in Figures 22 and 23, respectively. The recommended submergence is $19 \mathrm{ft}$. Less submergence will not allow the desired energy dissipation. Increased submergence allows for slightly faster operation times.

The following conclusions were determined from this study of the ILCS:

a. A two-culvert system is preferable.

$b$. The center of the culverts should be on the width-wise quarter points.

c. Conventional intakes as well as through-the-sill intakes perform well with the ILCS.

d. Valve-operating characteristics are important to the chamber performance. 
e. Acceptable chamber performance was achieved with normal valve operations between 4 and 8 min for the lift and submergence conditions evaluated.

$f$. Ports located on the sides of the longitudinal culvert are preferable to those on the top.

g. A culvert roof overhang is beneficial for ports located at the top on the sides of the culvert. It helps redirect the jet for ports without port extensions.

h. Port extensions are beneficial on the upstream ports. Port extensions also train the jets issuing from these ports in a direction normal to the longitudinal culvert and improve the longitudinal distribution of flow along the length of the chamber.

i. The port-to-culvert area ratio should be about 0.97 to help with flow control.

j. The port spacing in each manifold should be staggered.

$k$. Two groups of ports should be centered about the one-third points of the lock length.

l. The ports should be located so that the distance from the most upstream port to the most downstream port is about half of the pintle-to-pintle length of the lock.

$m$. Wall baffles are beneficial because they diffuse the port jets at the lock chamber floor. 


\section{References}

Ables, J. H., and Boyd, M. B. (1966a). "Filling and emptying system, Cannelton Main Lock, Ohio River, and generalized tests of sidewall port systems for 110- by 1,200-ft Locks; Hydraulic model investigation,” Technical Report 2-713, U.S. Army Engineer Waterways Experiments Station, Vicksburg, MS.

. (1966b). "Filling and emptying systems, low-lift locks, Arkansas River Project; Hydraulic model investigation,” Technical Report 2-743, U.S. Army Engineer Waterways Experiments Station, Vicksburg, MS.

Albertson, M. L., Dai, Y. B., Jensen, R. A., and Rouse, H. (1950). "Diffusion of submerged jets," Transactions, ASCE 115, 639-64.

Davis, J. P. (1989). "Hydraulic design of navigation locks,” Miscellaneous Paper HL-89-5, U.S. Army Engineer Waterways Experiment Station, Vicksburg, MS.

Headquarters, Department of the Army. (1995a). "Hydraulic design of navigation locks,” Engineer Manual 1110-2-1604, Washington, DC.

. (1995b). "Planning and design of navigation locks,” Engineer Manual 1110-2-2602, Washington, DC.

Hite, J. E., Jr. (1999). "Model study of Marmet Lock filling and emptying system, Kanawha River, West Virginia,” Technical Report CHL-99-8, U.S. Army Engineer Waterways Engineer Station, Vicksburg, MS.

. (2000). "New McAlpine Lock filling and emptying system, Ohio River, Kentucky,” Technical Report ERDC/CHL TR-00-24, U.S. Army Engineer Research and Development Center, Vicksburg, MS.

Pickett, E. B., and Neilson, F. M. (1988). "Lock hydraulic system model and prototype study data,” Miscellaneous Paper HL-88-1, U.S. Army Engineer Waterways Experiment Station, Vicksburg, MS.

Schohl, G. A. (1999). "User's manual for LOCKSIM: Hydraulic simulation of navigation lock filling and emptying systems," Contract Report CHL-99-1, U.S. Army Engineer Waterways Experiment Station, Vicksburg, MS. 
Stockstill, R. L. (1998). "Innovative lock design; Report 1, Case study, New McAlpine Lock filling and emptying system, Ohio River, Kentucky,” Technical Report INP-CHL-1, U.S. Army Engineer Waterways Experiment Station, Vicksburg, MS.

Vennard, J. K., and Street, R. L. (1982). Elementary fluid mechanics, 6th ed. John Wiley and Sons, New York. 


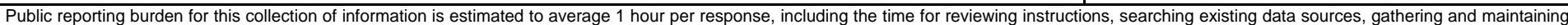

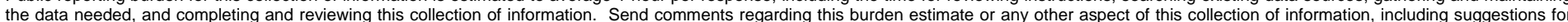

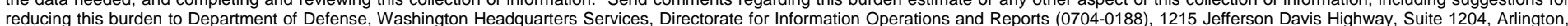

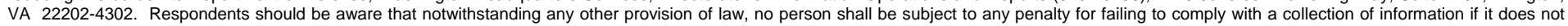
display a currently valid OMB control number. PLEASE DO NOT RETURN YOUR FORM TO THE ABOVE ADDRESS.
1. REPORT DATE (DD-MM-YYYY)
August 2003

\section{TITLE AND SUBTITLE}

In-Chamber Longitudinal Culvert Design for Lock Filling and Emptying System
3. DATES COVERED (From - To)

Oct 1998-Sep 2002

5a. CONTRACT NUMBER

5b. GRANT NUMBER

5c. PROGRAM ELEMENT NUMBER

5d. PROJECT NUMBER

5e. TASK NUMBER

5f. WORK UNIT NUMBER

33140

8. PERFORMING ORGANIZATION REPORT NUMBER

ERDC/CHL TR-03-8

U.S. Army Engineer Research and Development Center

Coastal and Hydraulics Laboratory

3909 Halls Ferry Road

Vicksburg, MS 39180-6199

\section{SPONSORING I MONITORING AGENCY NAME(S) AND ADDRESS(ES)}

U.S. Army Corps of Engineers

Washington, DC 20314-1000

10. SPONSOR/MONITOR'S ACRONYM(S)

11. SPONSOR/MONITOR'S REPORT NUMBER(S)

\section{DISTRIBUTION / AVAILABILITY STATEMENT}

Approved for public release; distribution in unlimited.

\section{SUPPLEMENTARY NOTES}

\section{ABSTRACT}

The U.S. Army Corps of Engineers is planning navigation improvements for many projects to meet predicted increases in tow traffic. Some of these improvements include the addition or replacement of the navigation lock. Innovative design and construction techniques are being investigated for reducing construction costs, as well as operation and maintenance costs. The Corps identified that a savings in lock construction could be achieved if the conventional concrete gravity lock walls with culverts inside them could be replaced with thin walls and longitudinal culverts located inside the chamber. This culvert design was designated the In-chamber Longitudinal Culvert System (ILCS).

This report provides the results of research conducted under Work Unit 33140, "In-Chamber Longitudinal Culvert Design for Lock Filling and Emptying Systems,” of the Innovations for Navigation Projects Research Program. Design guidance for the ILCS is provided for low- to medium-lift locks. The guidance includes culvert location; port size, location, and spacing; port extensions; roof overhang; and wall baffles. Guidance is also provided for modified ILCS designs and single-culvert designs. Lock chamber performance guidance, based on acceptable filling and emptying operations, is also included. The results show that the ILCS is a feasible design based on the hydraulic performance determined from the investigation.

\section{SUBJECT TERMS}

Filling and emptying system

Hawser forces

16. SECURITY CLASSIFICATION OF:

\begin{tabular}{|l|l|}
\hline a. REPORT & b. ABSTRACT \\
UNCLASSIFIED & UNCLASSIFIED
\end{tabular}

Innovative lock design

Lock chamber performance

Lock design guidance

\begin{tabular}{l|l} 
17. LIMITATION \\
OF ABSTRACT
\end{tabular}

Longitudinal culvert

Valve operations

\section{NUMBER 19 19. NAME OF RESPONSIBLE} OF PAGES

97

\section{PERSON}

19b. TELEPHONE NUMBER (include area code) 